\title{
Visualization of synaptic vesicle protein recycling during exo-endocytosis at individual hippocampal boutons
}

\author{
PhD Thesis \\ in partial fulfilment of the requirements \\ for the degree "Doctor of Philosophy $(\mathrm{PhD}) /$ Dr. rer. nat." \\ in the Neuroscience Program \\ at the Georg August University Göttingen, \\ Faculty of Biology \\ submitted by \\ Martin Wienisch \\ born in \\ Oberhausen, Germany
}


Herewith I declare, that I prepared the PhD Thesis

'Function of plasma membrane stranded synaptic vesicle proteins'

on my own and with no other sources and aids than quoted.

Göttingen, Dec. $15^{\text {th }} 2005$

\section{(Martin Wienisch)}




\section{LIST OF CONTENTS}

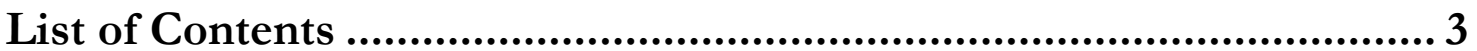

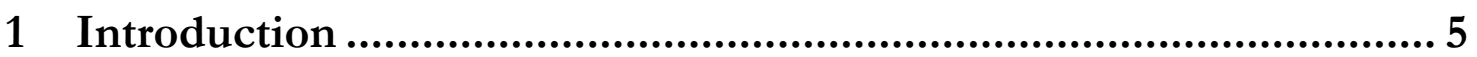

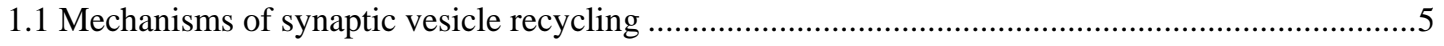

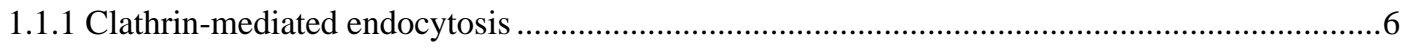

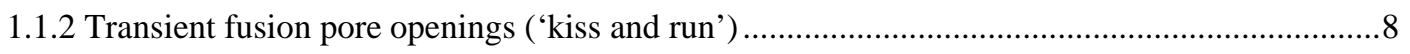

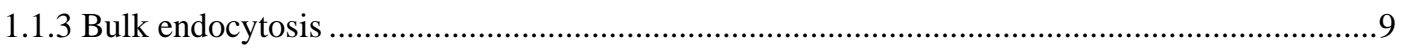

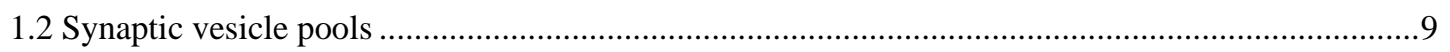

1.3 Kinetics of stimulated endocytosis ...........................................................................................

1.4 Synaptic vesicle cargo protein recognition...................................................................................

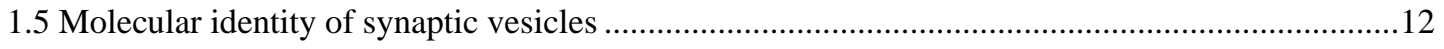

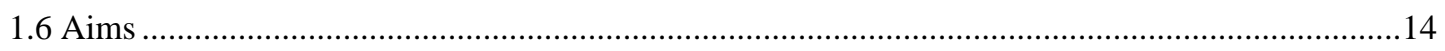

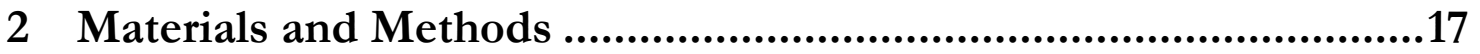

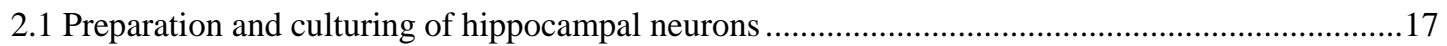

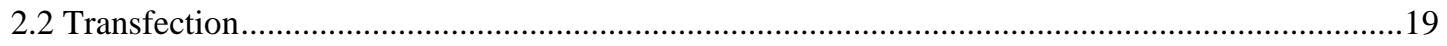

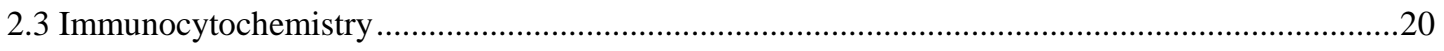

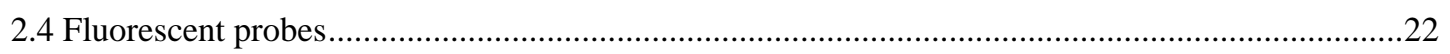

2.4.1 pHluorins for optical measurements of overall presynaptic activity ......................................22

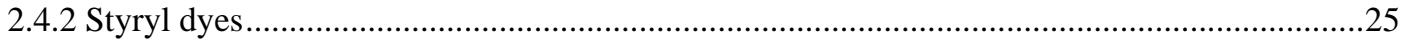

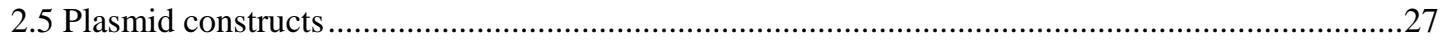

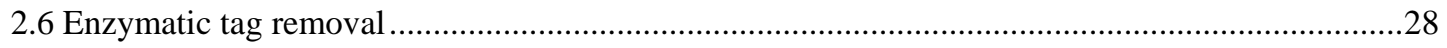

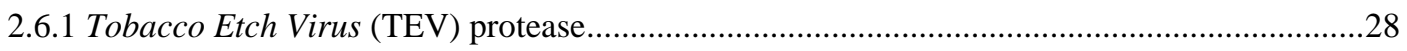

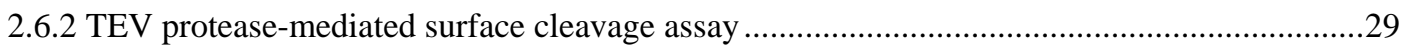

2.7 Epifluorescence and confocal microscopy of living neurons ..........................................................29

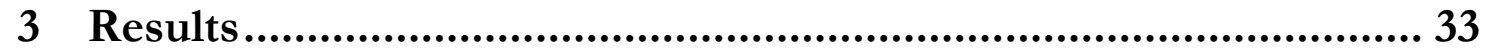

3.1 Vesicular proteins exocytosed and subsequently retrieved by compensatory endocytosis are non-

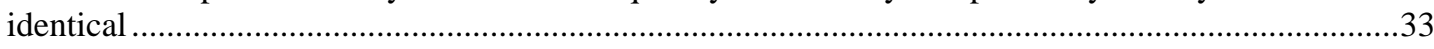

3.1.1 GFP-tagged synaptobrevin/VAMP is found on the plasma membrane of resting neurons ......33

3.1.2 Synaptobrevin-TEV-pHluorin (spH-TEV): a tool for tracking the post fusion fate of vesicular

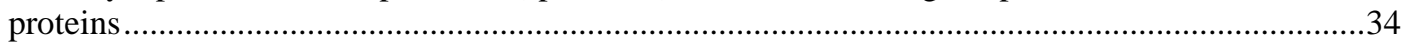

3.1.3 Vesicular proteins are lost post fusion...................................................................................... 
3.1.4 Vesicular proteins exo- and endocytosed during stimulation are not identical. 39

3.1.5 Degree of non-identity depends on stimulus duration, but is independent of method of fluorescent tag removal

3.1.6 Non-identity is also observed for synaptotagmin-I-TEV-pHluorin ...... 48

3.1.7 Stranded pool size is under modulatory control and comprises $~ 10 \%$ under native conditions .

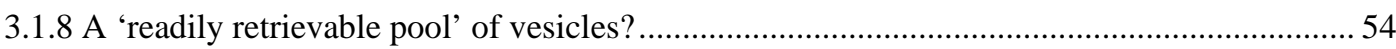

3.2 Stonin 2 acts as an endocytic sorting adaptor which targets synaptotagmin to presynaptic recycling vesicles 58

3.2.1 Stonin 2 facilitates endocytosis of plasma membrane stranded syt 1 in synaptic boutons. ..... 58

3.2.2 In stonin 2 knock-out mice the function of stonin 2 as specific adaptor for syt 1 is better seen

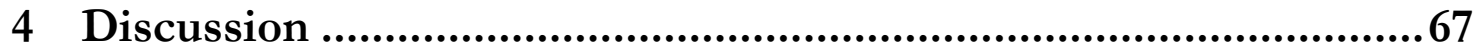

4.1 Vesicular proteins exocytosed and subsequently retrieved by compensatory endocytosis are nonidentical 67

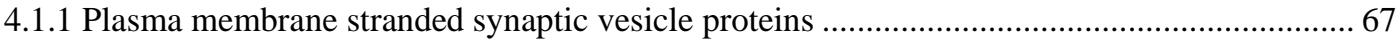

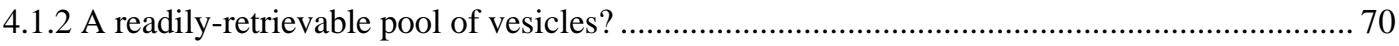

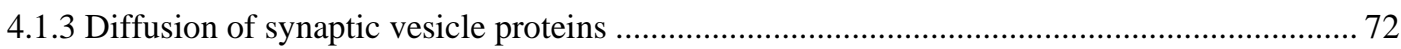

4.2 Role of stonin 2 in synaptotagmin 1 retrieval ......................................................................... 75

5 Summary .............................................................................. 77

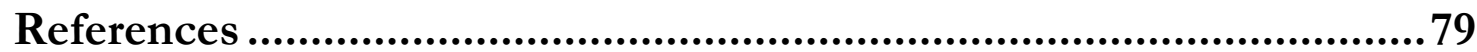

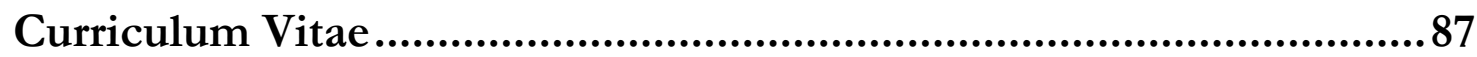

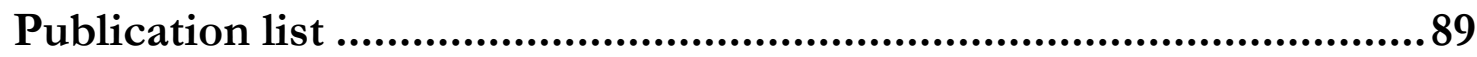

Acknowledgements .................................................................... 91 


\section{INTRODUCTION}

At the synapse, neurotransmitter is rapidly released from small vesicles which are triggered to fuse with the plasma membrane by the entry of $\mathrm{Ca}^{2+}$ ions (Katz and Miledi, 1967). The maintenance of normal communication requires that these vesicles are retrieved by a reverse process, i.e. endocytosis. Consequently, synaptic transmission rapidly fails if vesicle recycling by endocytosis is blocked (Koenig and Ikeda, 1989). Although synaptic vesicle endocytosis and cycling has been described in molecular detail by the fundamental electron-microscopic work of Heuser \& Reese and Cecarelli et al. in 1973, one key controversy surrounding synaptic vesicle endocytosis still remains to be settled: is it analogous to the well described clathrin-mediated endocytosis (CME) of membrane receptors in all cell types or do other, perhaps more direct mechanisms of retrieval, where vesicles open transiently without collapsing into the plasma membrane called "kiss-andrun" (Fesce et al., 1994) operate in parallel? Furthermore, functional synaptic vesicles are regenerated well within a minute after exocytosis, at an endocytic rate which exceeds that observed in non-neuronal cells by at least tenfold. Hence, a major challenge of this research is to understand the mechanisms by which rapid membrane recycling is executed with enough precision to faithfully regenerate small synaptic vesicles and to sort into the vesicles essential proteins while excluding plasma membrane proteins.

\subsection{Mechanisms of synaptic vesicle recycling}

Various modes of vesicle recycling have been proposed for synapses of the central nervous system (figure 1.1). In the classical endocytotic pathway (Heuser and Reese, 1973; Pearse, 1976; Shupliakov et al., 1997) vesicles collapse completely into the surface membrane, internalize slowly ( $>20 \mathrm{~s}$ ) in a clathrin-dependent manner, and then recycle through the endosome. In a faster, local endocytotic pathway, vesicles are rapidly retrieved after short-lived fusion pore openings ('kiss and run') (Aravanis et al., 2003; Ceccarelli et al., 1973; Fesce et al., 1994; Gandhi and Stevens, 2003; Koenig et al., 1998), maybe without even leaving the plasma membrane ('kiss and stay'), or may reform directly by uncoating from clathrin-coated vesicles without equilibration with endosomes (Takei et al., 1996). 
Another, much slower pathway that delivers vesicles via large infoldings and cisternae selectively to a reserve pool has been shown in frog motor nerve terminals (Miller and Heuser, 1984; Richards et al., 2000) and endocrine cells (Neher and Marty, 1982; Rosenboom and Lindau, 1994; Thomas et al., 1994) and might also be present in central nervous synapses. Here membranes from multiple vesicles are taken up piece-meal by non-clathrin-mediated 'bulk' endocytosis after extensive exocytosis. The molecular events involved in these kinetically distinct modes, however, remain unclear.
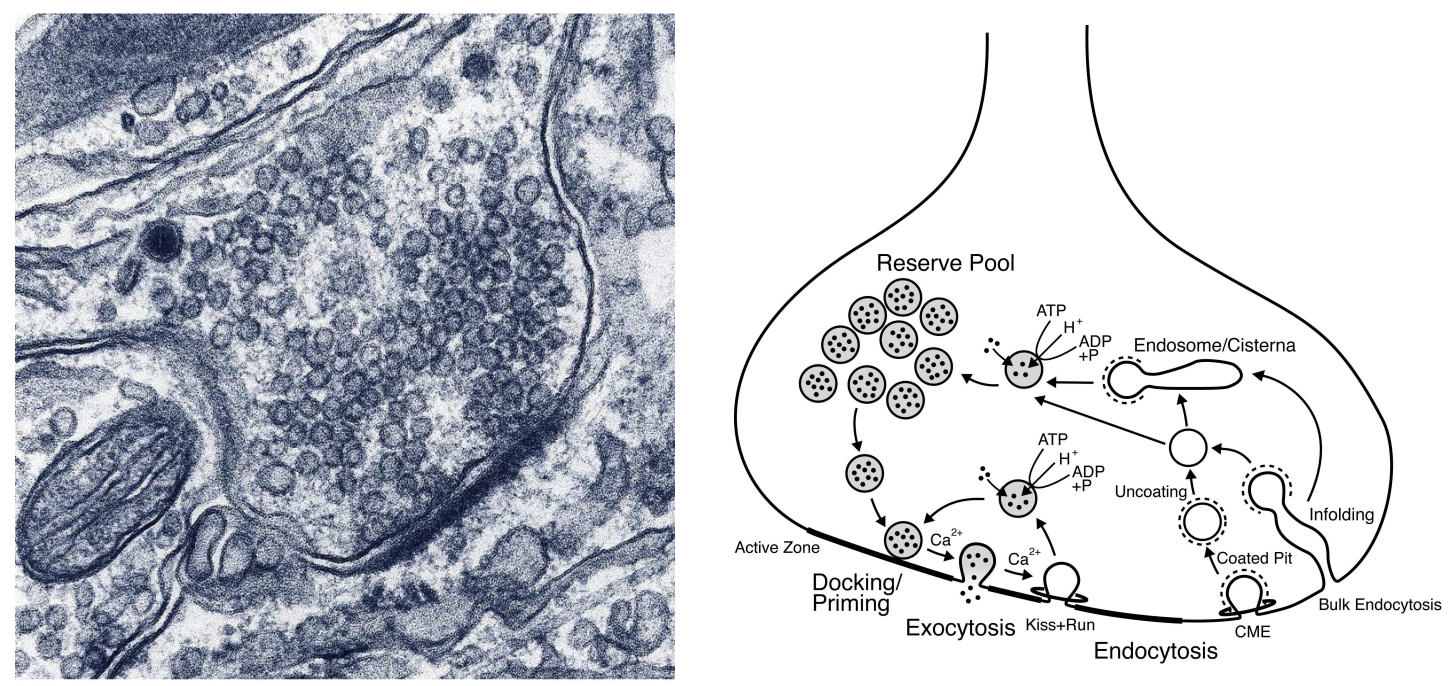

Figure 1.1 Synaptic vesicle retrieval.

left: Single synaptic hippocampal bouton (Courtesy of J. Klingauf).

right: Possible pathways in the synaptic vesicle cycle.

\subsubsection{Clathrin-mediated endocytosis}

Following neurotransmitter release, clathrin-mediated endocytosis is thought to be the major pathway for synaptic vesicle recycling (Brodin et al., 2000; Brodsky et al., 2001; Heuser and Reese, 1973). It can be separated into several spatially distinct steps (figure 1.2). The recruitment of clathrin from the cytosol, binding to the plasma membrane, subsequent invagination and fission of clathrin-coated vesicles from the membrane and finally disassembly of the coat in the cytosol (Cremona and De Camilli, 1997; 
Gundelfinger et al., 2003). The molecular mechanism of clathrin-mediated endocytosis is understood in some detail. Two sets of proteins are involved: those forming the clathrin coat and a number of accessory proteins. The basic module of the coat is the three-legged clathrin triskelion, which forms a lattice attaching to the plasma membrane via the tetrameric adaptor protein complex AP-2. Among the accessory proteins that associate with the coat are AP-180 (which promotes clathrin assembly and regulates vesicle size), dynamin (a GTPase that has a prime function in the fission reaction of clathrin-coated vesicles) and ampiphysin (which targets dynamin and other proteins to the coat) (Slepnev and De Camilli, 2000).

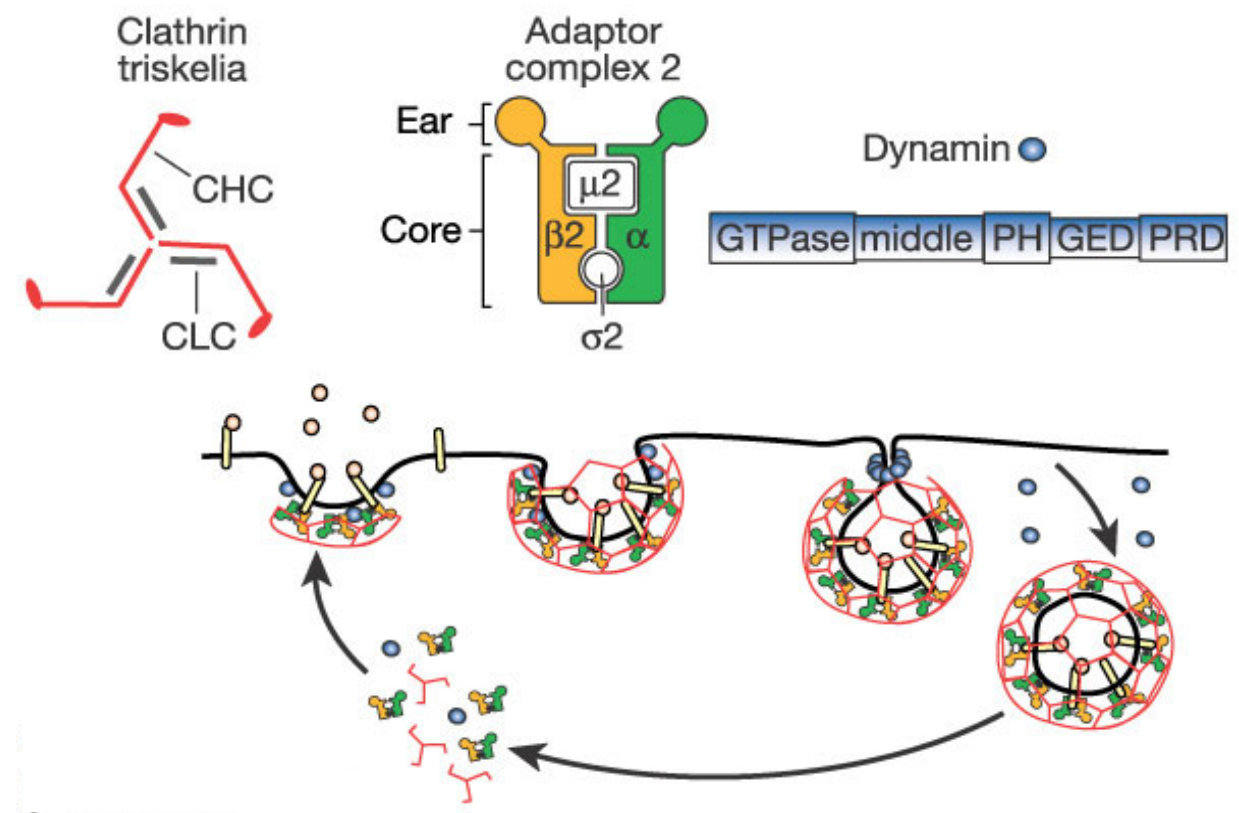

Figure 1.2 Sequential steps and molecular players of clathrin-mediated endocytosis.

The first reconstruction of the time course of clathrin-mediated endocytosis was obtained from electron micrographs (Miller and Heuser, 1984) by quick-freezing frog nerve-muscle preparations at various times after a stimulus and visualizing them by electron microscopy (figure 1.3). 

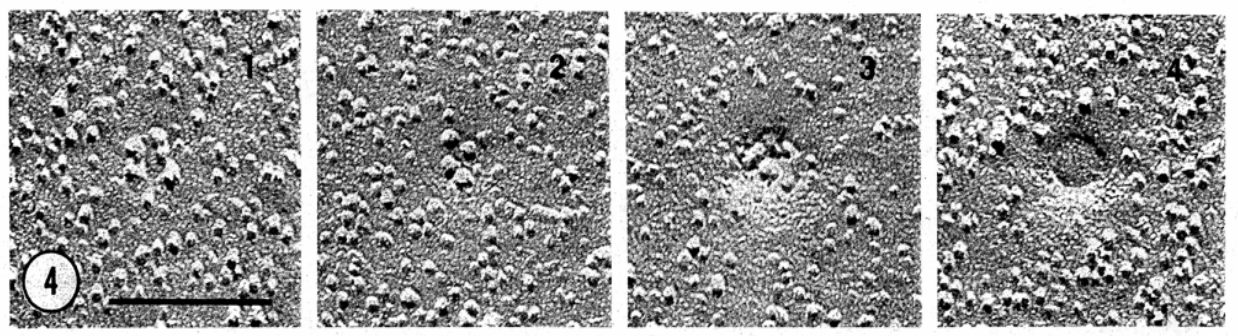

Figure 1.3 Freeze-fracture views of various stages in coated vesicle formation, arranged (from left to right) in a temporal sequence (from Miller and Heuser, 1984).

Using a genetically encoded fluorescent probe consisting of enhanced green fluorescent protein (EGFP) and either clathrin light chain (LCa-EGFP) (Gaidarov et al., 1999) or clathrin heavy chain (Damer and O'Halloran, 2000) the clathrin dynamics of constitutive endocytosis have been visualized. In addition, evanescent field fluorescence microscopy has allowed the study of the formation, fission as well as the movement of single clathrincoated vesicles away from the membrane (Merrifield et al., 2002).

\subsubsection{Transient fusion pore openings ('kiss and run')}

After the finding that coated vesicles are rarely observed on electron micrographs after weak stimulation of the synapse, when vesicles are released at a lower rate, a faster (clathrin-independent) mechanism was proposed (Ceccarelli et al., 1973). One form of the 'kiss-and-run' model suggests that the connection between the vesicle and synaptic cleft is an aqueous pore that opens to release the neurotransmitter, but rapidly closes before the vesicle is retrieved (Fesce et al., 1994). In hippocampal terminals a rapid 'kiss-and-run' type of endocytosis has been proposed based on the observation of partial release of the slowly ( 3 s) departitioning styryl dye FM 1-43 (Aravanis et al., 2003; Klingauf et al., 1998a; Pyle et al., 2000) as well as the quantal and transient nature of fluorescence signals from single synaptic vesicles labeled with synaptopHluorin (Gandhi and Stevens, 2003), a fusion construct of synaptobrevin and a pH-sensitive variant of GFP (Miesenbock et al., 1998). Additionally,(Stevens and Williams, 2000) found, by comparing fluorescence data and simultaneously recorded postsynaptic currents, that styryl dyes are only partially released 
during a hypertonic challenge in hippocampal boutons. However, the contribution of this mechanism to pool recycling remains debated.

\subsubsection{Bulk endocytosis}

Another, much slower pathway of vesicle endocytosis has been uncovered at motor nerve terminals of frog (Miller and Heuser, 1984; Richards et al., 2000) and snake (Teng and Wilkinson, 2000), endocrine cells (Neher and Marty, 1982; Rosenboom and Lindau, 1994; Thomas et al., 1994) and might also be present in central-nervous synapses (de Lange et al., 2003; Gad et al., 1998; Holt et al., 2003; Paillart et al., 2003). It is thought that after strong tetanic stimulation, large infoldings form which are pinched off from the plasma membrane after minutes. This process retrieves 'piece-meal' all membrane material from many exocytosed vesicles and is thus called 'bulk endocytosis'. Once internalized new reserve pool vesicles are slowly regenerated from these cisternae by the help of clathrin or eventually some other coat proteins.

\subsection{Synaptic vesicle pools}

Three pools of synaptic vesicles can be functionally distinguished in synapses of cultured hippocampal neurons (figure 1.4). One such group, the readily releasable pool (RRP), constitutes those vesicles that are immediately available for release and can be defined as the whole number of vesicles that are either docked at the active zone or primed for release. In a single synaptic bouton the RRP comprises five to ten vesicles. After extensive stimulation, the RRP is depleted and additional vesicles are recruited for exocytosis from the so-called 'reserve pool' containing about 20 vesicles. The RRP and the reserve pool together constitute the recycling pool. The remaining majority of 'inactive' vesicles is defined as the resting pool. There is little intermixing with the recycling pool under regular conditions, but vesicles out of this resting pool are recruited upon extensive stimulation (Rizzoli and Betz, 2005; Sudhof, 2000). 

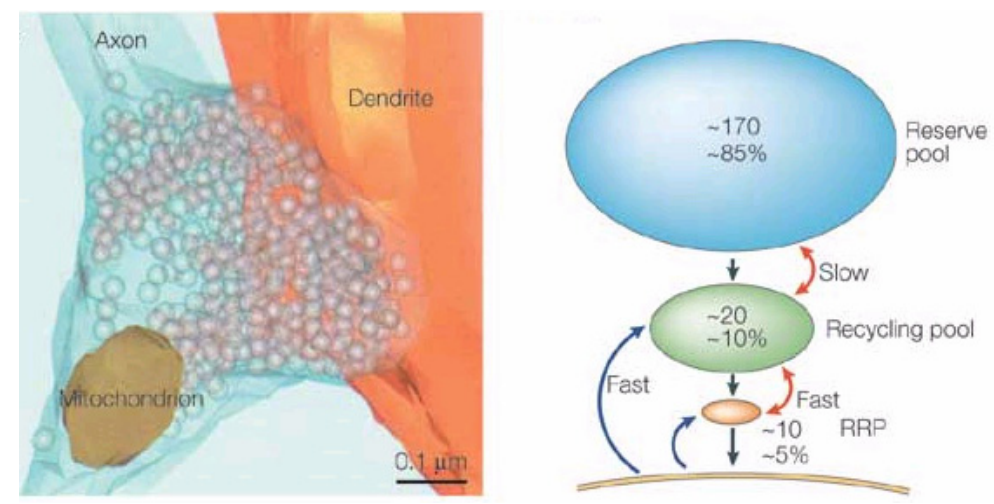

Figure 1.4 Synaptic vesicle pools of a typical hippocampal bouton (from Rizzoli and Betz, 2005).

\subsection{Kinetics of stimulated endocytosis}

Synaptic vesicles can be retrieved with a time constant of $1 \mathrm{~s}$, while clathrin-mediated endocytosis of transferrin receptors occurs on the time scale of minutes. Even if the fast mode of endocytosis in synapses is mediated by clathrin, it must be a specialized form capable of proceeding with very high speed. Most of our knowledge of the kinetics of stimulated endocytosis in hippocampal boutons comes from experiments using the fluorescent vesicle marker FM 1-43 (Aravanis et al., 2003; Klingauf et al., 1998b; Ryan et al., 1993; Ryan et al., 1996; Wu and Betz, 1996) and synaptopHluorin, a fusion construct of the vesicle protein synaptobrevin/VAMP-2 with a highly $\mathrm{pH}$-sensitive GFP variant (Gandhi and Stevens, 2003; Miesenbock et al., 1998; Sankaranarayanan and Ryan, 2000). However, neither technique allows distinguishing between different molecular mechanisms of membrane retrieval.

Mueller et al. recently visualized LCa-EGFP redistribution in hippocampal boutons (Mueller et al. 2004) and found stimulation to lead to a transient increase of fluorescence in synapses, but a slight and transient decrease in adjacent axonal segments. They showed that the rise and fall of the signal in boutons, with decay kinetics remarkably similar to previous estimates of the endocytic time course, reflected coat assembly and disassembly. Fluorescent transients, however, were preceded by a surprisingly long-lasting delay showing that endocytosis during the first few seconds of continuing stimulation cannot be 
mediated by the slow ( 10 s) formation of clathrin-coated pits (Loerke et al., 2005; Merrifield et al., 2002), although the rate of endocytosis measured with FM dyes is at its peak. One likely interpretation is that the early phase of endocytosis does not depend on clathrin, but is of the 'kiss and run' type and thus not seen with the LCa-EGFP probe.

An alternative explanation, however, could be a pool of preassembled 'ready-to-go' coats at the periphery of the active zone, which might support a first wave of endocytosis. Interestingly, such a first wave of endocytosis via coated vesicles lasting only $10 \mathrm{~s}$ has been observed by Miller and Heuser (1984) in their electron microscopic reconstruction of the time course of endocytosis at the frog neuromuscular junction.

\subsection{Synaptic vesicle cargo protein recognition}

Although multiple lines of evidence suggest that clathrin/ AP-2-mediated endocytosis is a major pathway for the activity-dependent recycling of synaptic vesicles at the nerve terminal (Brodin et al., 2000; Murthy and De Camilli, 2003; Sudhof, 2004) the precise molecular mechanisms of synaptic vesicle cargo protein recognition have remained elusive. Synaptotagmin 1, an important modulator of calcium-dependent neuroscretion within the synaptic vesicle membrane (Sudhof, 2004; Tucker and Chapman, 2002), has been proposed to regulate both the exo- and endocytic limbs of the vesicle cycle (Geppert et al., 1994; Nicholson-Tomishima and Ryan, 2004). Deletion of synaptotagmin 1 in mice, worms (Jorgensen et al., 1995), and flies results in pleiotropic defects in neuroexocytosis and impaired retrieval of synaptic vesicle membranes. Moreover, interfering with synaptotagmin function by mutation (Littleton et al., 2001), acute chemical inactivation (Poskanzer et al., 2003), or injection of antibodies (Llinas et al., 2004) leads to a partial depletion of the synaptic vesicle pool. How precisely synaptotagmin regulates synaptic vesicle endocytosis is unclear but direct interactions with the $\mu 2$ subunit of the heterotetrameric clathrin adaptor complex AP-2 (Grass et al., 2004; Haucke et al., 2000; Zhang et al., 1994), the $\mu$-homology domain of stonin 2 (Martina et al., 2001; Walther et al., 2001), and/ or phosphoinositides (Tucker and Chapman, 2002) may contribute to this.

Surprisingly, synaptotagmin 1 itself undergoes efficient endocytic internalization in neurons and neuroendocrine cells but remains at the plasmalemma in transfected 
fibroblasts (Jarousse and Kelly, 2001). The molecular mechanisms for synaptotagmin 1 internalization have thus remained obscure. In Drosophila synaptotagmin 1 function is tightly linked to the expression of the stoned B gene product, a putative endocytic accessory protein expressed in the nervous system and enriched at presynaptic nerve terminals (Fergestad and Broadie, 2001; Stimson et al., 2001). Stonin 1 and 2 are the only orthologs of stoned B in mammals (Martina et al., 2001). Stonin 2 has been linked to clathrin-mediated endocytosis by its interactions with AP-2 (Walther et al., 2004) and the endocytic accessory proteins eps15 and intersectin (Martina et al., 2001). Binding of stonin 2 to AP-2 is largely mediated by interactions between its $\mathrm{WVxF}$ motifs and the $\beta$-sandwich domain of the $\alpha$-adaptin appendage as well as indirect associations bridged by eps15 and perhaps other eps15-homology domain (EH) domain (Polo et al., 2003) containing factors. Determining the function role of stoned B mammalian orthologs may assist in understanding the relationship between clathrin-dependent endocytosis and protein internalization.

\subsection{Molecular identity of synaptic vesicles}

Synaptic vesicles have been estimated to contain about 200 protein molecules (Jahn and Sudhof, 1993) that can be classified according to their specialized functions in neurotransmitter uptake, trafficking and fusion (Sudhof, 2000). However, no shared characteristics exist that would make these proteins identifiable as synaptic vesicle proteins and little is known about how these proteins are specifically sorted into synaptic vesicles. The lipid composition of the vesicular membrane is similar to the one of neuronal plasma membranes but is enriched with cholesterol and depleted of glycolipids (Benfenati et al., 1989). This special protein and lipid composition has to be restored when a new synaptic vesicle is formed during endocytosis. This, however, does not necessarily imply that synaptic proteins remain clustered during exo- and endocytosis, i.e. synaptic vesicle proteins exo- and endocytosed need not to be identical. What distinguishes the above mentioned scenarios of rapid endocytosis fundamentally is, whether the molecules exoand endocytosed during the same stimulus are the same, i.e. identical. Maintaining molecular identity is the hallmark of a kiss-and-run-type endocytic mechanism, while non- 
identity would be the essential feature and kinetic advantage of a preassembled pool of 'ready-to-go' pit structures at the periphery of the active zone.

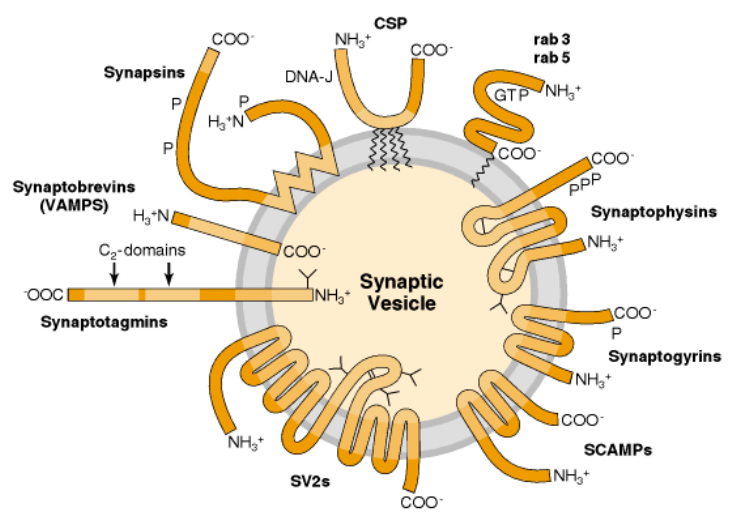

Figure 1.5 Structure of the major proteins of synaptic vesicles with putative functions in synaptic vesicle trafficking (from Südhof, 1995).

Some information addressing the question of molecular identity during exo-endocytic cycling comes from studies using the exo-endoytic activity marker synaptopHluorin $(\mathrm{spH})$, a fusion construct of the vesicle protein VAMP 2 / synaptobrevin 2 and a $\mathrm{pH}$-sensitive form of GFP (Miesenbock et al., 1998). Unexpectedly, a fraction of synaptopHluorin was found to appear on the external membrane of transfected hippocampal neurons and vesicular spH disperses quickly onto the plasma membrane during vesicle recycling ( $\mathrm{Li}$ and Murthy, 2001; Sankaranarayanan and Ryan, 2000). In addition, VAMP 2 /synaptobrevin 2 has also been shown to be present on the plasma membrane of nerve endings of the Torpedo electric organ (Taubenblatt et al., 1999). The reason for the existence of a surface population of VAMP 2 /synaptobrevin 2 is not clear. It might come from small inefficiencies during synaptic vesicle recycling or result from an alternate membrane trafficking pathway. It is also not known whether the apparent mislocalization of VAMP 2 /synaptobrevin 2 at the surface is a common feature of all synaptic vesicle membrane proteins but, the synaptic plasma membrane-associated proteins syntaxin-1 and SNAP-25 have been observed on synaptic vesicles (Walch-Solimena et al., 1995). 


\subsection{Aims}

The aim of this study was to visualize and track the fate of newly exocytosed synaptic vesicle proteins in individual hippocampal boutons of primary neuronal cultures in real time. Specifically it was asked whether the same molecules are retrieved during stimulusevoked exo-endocytosis, i.e. whether endocytosed synaptic vesicle components are the same as the exocytosed ones triggered by the same stimulus.

a. Retaining molecular identity

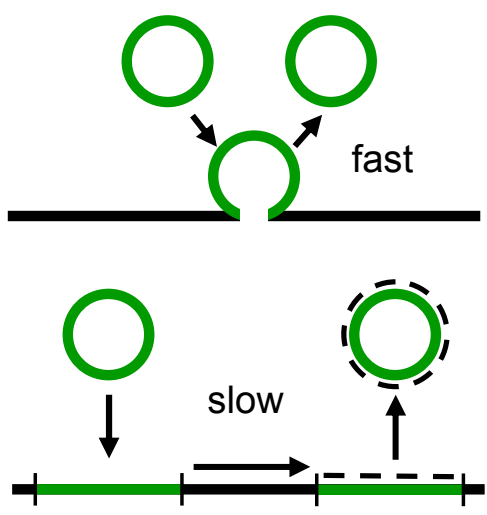

b. Loosing molecular identity

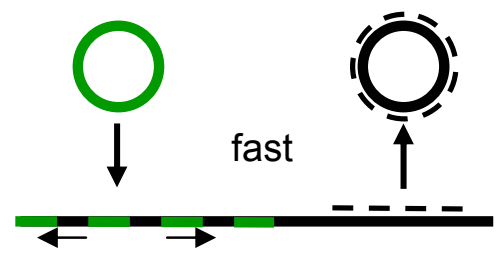

Figure 1.6 Do synaptic vesicles retain their molecular identity during exo-endocytic cycling?

a. Synaptic vesicle proteins and lipids inserted into the plasma membrane upon exocytosis might not diffuse apart either due to interaction (raft-like patch) or a diffusion barrier provided by a fusion pore (kiss-and-run). During subsequent compensatory endocytosis the same set of proteins would be taken up again.

b. Alternatively the vesicular membrane fully mixes with the plasma membrane and synaptic vesicle proteins are spreading by diffusion. A different set of proteins is endocytosed.

The finding that a significant fraction of synaptopHluorin $(\mathrm{spH})$ molecules resides in the plasma membrane of a synapse prompted the question, whether this stranded plasma membrane pool of $\mathrm{spH}$ has a physiological function. Perhaps it constitutes a pool which serves to form new synaptic vesicles by endocytosis. However, this would suggest that 
vesicles retrieved during compensatory endocytosis are different from those that fused and triggered endocytosis. Posed differently, synaptic vesicles would loose their identity during cycling. On the other hand recycling via kiss-and-run implies that the molecular integrity of a vesicle is maintained and would have the physiological benefit that an endocytosed vesicle is readily equipped with the needed protein content (figure 1.6).

It is unclear whether the molecular identity of synaptic vesicles is preserved in between exo-and endocytosis. Furthermore, this project intended to investigate whether the stranded pool size is under modulatory control and to which extent plasma membrane located synaptic vesicle proteins might play a role under physiological conditions. To this end a TEV-protease cleavage site was introduced between the synaptobrevin and GFP moieties accessible only by external enzyme if spH-TEV is in the plasma membrane. spHTEV behaved identical to the original fusion protein. It could be found that mostly digested molecules are recycled during compensatory endocytosis, i.e. VAMP 2 /synaptobrevin 2 molecules deposited on the plasma membrane prior to digestion. The same results were obtained via selectively bleaching the membrane $\mathrm{spH}$ pool by repeated laser scanning instead of digestive removal of the fluorophore, showing that neither the protease treatment nor the presence of the large GFP moiety affect synaptobrevin recycling or rates of endocytosis. Identical results were obtained with a synaptotagmin 1TEV-pHluorin construct, concluding that under these stimulus conditions most recycling synaptic vesicles loose their protein complement during exocytosis. By coexpressing synaptophysin, that was found to minimize the $\mathrm{spH}$ stranded pool size, and by using an antibody against the eternal luminal domain of synaptotagmin 1 it was possible to estimate that under physiological conditions a few percent of vesicular proteins are located near the active zone, constituting a pool of preferentially and swiftly recycled molecules. By successively decreasing the number of action potentials the size of this 'readily retrievable pool' of vesicles was titrated and it was found to correspond to 30-40 APs, remarkably close to the estimated size of the readily releasable or docked pool of vesicles.

In collaboration with the lab of Prof. Volker Haucke (Institut für Chemie und Biochemie, Freie-Universität-Berlin) the aim of the second part of this thesis was to explore the relationship between stonin 2 function in clathrin-dependent endocytosis and 
synaptotagmin 1 stranded pool size and internalization. Together we could show that stonin 2 is an AP-2-dependent sorting adaptor for endocytic internalization and recycling of synaptotagmin 1 in neurons. 


\section{MATERIALS AND METHODS}

\subsection{Preparation and culturing of hippocampal neurons}

CA1 and CA3 hippocampal neurons (figure 2.1) of 1-3 day old Wistar rats were prepared in sparse culture according to previously described protocols with minor modifications (Liu and Tsien, 1995; Malgaroli and Tsien, 1992). Hippocampi of typically three animals (postnatal day P1 or P2) were dissected under sterile conditions and placed into ice-cooled Hanks solution (Sigma H2387) supplemented with 20\% FBS. Surrounding tissue was removed carefully. Then, beginning at the joint between the CA1 region and the dentate gyrus the hippocampi were unfolded and most of the dentate gyrus was cut away, leaving just CA1 and CA3 regions. The hippocampi were sliced into thin sections and transferred to a centrifuge tube. The supernatant was aspirated and tissue was rinsed 2 times with Hank's solution $+20 \%$ FBS, and 2-3 times with Hank's solution alone. Tissue pieces were then digested for $10 \mathrm{~min}$ at $37^{\circ} \mathrm{C}$ with $2 \mathrm{ml}$ digestion solution containing $10 \mathrm{mg}$ trypsin (Sigma T1005) and $1 \mathrm{mg}$ DNase (Sigma D5025). After that, tissue pieces were rinsed 2 times with Hank's solution $+20 \%$ FBS to neutralize trypsin and then 3 times with plain Hank's solution. Cells were dissociated mechanically in $2 \mathrm{ml}$ dissociation solution containing $1 \mathrm{mg}$ DNase by gentle trituration with siliconized pasteur pipettes of decreasing diameters. $3 \mathrm{ml}$ of Hank's solution $+20 \%$ FBS were added, and cells were centrifuged for $10 \mathrm{~min}$ at $112 \mathrm{~g}$ at $4{ }^{\circ} \mathrm{C}$. Pelleted cells were resuspended in $\sim 2 \mathrm{ml}$ of Plating Medium and plated onto $18 \mathrm{~mm}$ coverslips. Coverslips were coated with $50 \mu \mathrm{l}$ Matrigel (BecktonDickinson; diluted 1:50 in Hank's solution $+10 \%$ FBS) before preparation, and incubated at $37{ }^{\circ} \mathrm{C}$ for at least one hour before use to allow polymerization. The Matrigel was aspirated off shortly before plating. About $50 \mu \mathrm{l}$ of the cell suspension was pipetted onto each of Matrigel-coated coverslips, and was incubated for 45 to 90 minutes at $37{ }^{\circ} \mathrm{C}$ to allow cells to settle and attach. Finally, the wells were filled with $1 \mathrm{ml}$ Plating Medium containing $2 \mathrm{mM}$ L-glutamine to promote proliferation of glial cells. After one day cells were fed by removing about half of the solution from the well and replacing it with fresh pre-warmed growth medium containing either $2 \mu \mathrm{M}$ or $4 \mu \mathrm{M}$ of the mitosis blocker cytosine arabinoside (Sigma C6645), depending on the density of glial cells. Cultures were 
maintained at $37{ }^{\circ} \mathrm{C}$ in a $95 \%$ air/ $5 \% \mathrm{CO}_{2}$ humidified incubator. The cells were fed every 3 days and then less frequently after 7 days. Cultures were used after 14-16 days in vitro.

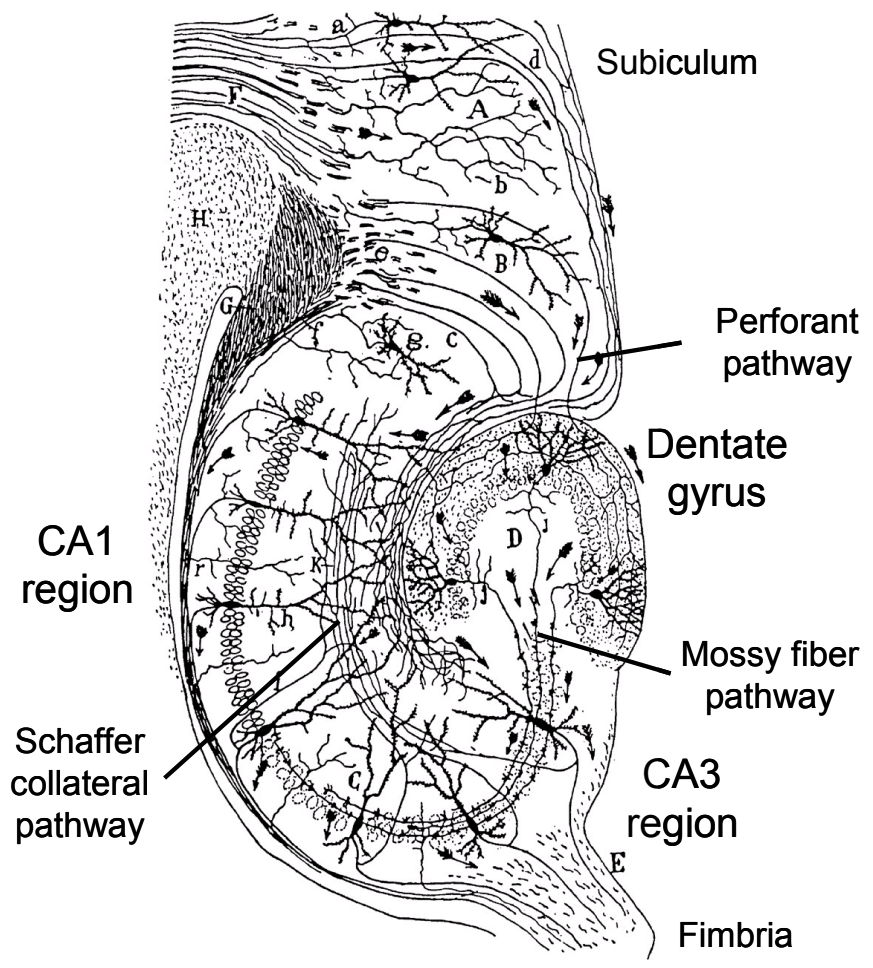

Figure 2.1 Drawing of the neural circuitry of the rodent hippocampus. Modified after Santiago Ramón y Cajal. Histologie du Systeme Nerveux de l'Homme et des Vertébrés, Vols. 1 and 2. A. Maloine. Paris. 1911. CA1 and CA3 regions were used for culturing.

Solutions used for cell culture preparation:

Medium: Minimal essential medium (MEM 51200-020 without phenol red, Gibco) with the following supplements per $500 \mathrm{ml}: 2.5 \mathrm{~g}$ glucose, $100 \mathrm{mg} \mathrm{NaHCO}$, $50 \mathrm{mg}$ transferrin (616420, Calbiochem).

Plating Medium: $100 \mathrm{ml}$ Medium contained $10 \% \mathrm{FCS}$, heat inactivated at $57^{\circ} \mathrm{C}$ for $30 \mathrm{~min}$, $1 \mathrm{ml} 0.2 \mathrm{M}$ L-glutamine solution, $2.5 \mathrm{mg}$ insulin 
Growth Medium: $100 \mathrm{ml}$ Medium contained $5 \% \mathrm{FCS}$, heat inactivated at $57{ }^{\circ} \mathrm{C}$ for $30 \mathrm{~min}$, $0.25 \mathrm{ml} \mathrm{0.2} \mathrm{M} \mathrm{L-glutamine} \mathrm{solution,} 2 \mathrm{ml} \mathrm{B}-27-S u p p l e m e n t$ (17504-010, Gibco), $4 \mu \mathrm{M}$ or 2 $\mu \mathrm{M}$ cytosine arabinoside (C6645, Sigma).

Hank's Solution: Hank's balanced salt solution without calcium or magnesium (H2387, Sigma) plus $50 \mathrm{mg} / 1 \mathrm{NaHCO}_{3}, 1 \mathrm{mM}$ HEPES, pH adjusted to 7.3-7.4 with $\mathrm{NaOH}$

Hank's Solution with $20 \%$ FBS

Dissociation Solution: Hank's solution plus $12 \mathrm{mM} \mathrm{MgSO} \cdot 7 \mathrm{H}_{2} \mathrm{O}$

Digestion Solution: $137 \mathrm{mM} \mathrm{NaCl}, 5 \mathrm{mM} \mathrm{KCl}, 7 \mathrm{mM} \mathrm{Na}_{2} \mathrm{HPO}_{4}, 25 \mathrm{mM}$ HEPES, adjusted with $\mathrm{NaOH}$ to $\mathrm{pH}$ 7.3-7.4

FBS: Fetal bovine serum (Biochrom KG)

Trypsin: type XI (T1005 Sigma)

DNase: type IV (D5025, Sigma)

Matrigel (Beckton-Dickinson): diluted 1:50 in Medium (MEM)

Unless otherwise noted, all chemicals were purchased from Sigma, Steinheim, Germany.

\subsection{Transfection}

Neurons were transfected by a modified calcium phosphate transfection procedure, based on protocols developed by Threadgill, Dudek and collaborators (Threadgill et al., 1997; Xia et al., 1996) and optimized according to our cell culture conditions. After 4-6 days in vitro the growth medium was removed, saved and replaced with serum-free Neurobasal A Medium (NBA, Invitrogen, Carlsbad, California, USA) 30 min prior to transfection. A calcium phosphate/DNA precipitate was formed at room temperature and in darkness for 15-20 $\mathrm{min}$ in the solution comprising of $50 \mu \mathrm{l} 2 \mathrm{xBES}$ buffered saline ( $\mathrm{pH} 7.00 \pm 0.05$ ), 5$30 \mu \mathrm{g} / \mathrm{ml}$ plasmid DNA and $5 \mu \mathrm{l}$ of $2.5 \mathrm{M} \mathrm{CaCl}_{2}$ stock solution, filled up with sterile $\mathrm{ddH}_{2} \mathrm{O}$ up to $100 \mu \mathrm{l}$. The precipitate was added drop-wise to $900 \mu \mathrm{l} \mathrm{NBA}$ while gently vortexing. The conditioned medium above the cells in each well was stored and replaced by $500 \mu \mathrm{l}$ of the diluted calcium phosphate/DNA precipitate solution. Following a 5-30 
min incubation at $37^{\circ} \mathrm{C}$ and $5 \% \mathrm{CO}_{2}$, during which the appearance of a fine sandy precipitate covering the cells was observed, the cultures were washed in Hank's Balanced Salt Solution (HBSS) and returned to the original conditioned culture media. The efficiency was typically between $5 \%$ and $20 \%$, and there was no apparent toxicity to the cells. The product of a transfected gene coding for green fluorescence protein (EGFP) could be detected by epi-fluorescent microscopy as early as 6 hours post-transfection and expression was stable for at least two weeks. In the co-transfection experiments, the total DNA concentration was kept at $5 \mu \mathrm{g}$ per well with equal amounts of the plasmid DNA coding for different fluorescent probes. In all cases, the DNA was prepared with Qiagen (Hilden, Germany) endotoxin-free maxi-prep plasmid DNA purification kits.

Solutions used for transfection:

\section{2x BES-buffered saline (BBS):}

$50 \mathrm{mM}$ BES (N,N-bis[2-hydroxyethyl]-2-aminoethanesulfonic acid) $280 \mathrm{mM} \mathrm{NaCl}$

$1.5 \mathrm{mM} \mathrm{Na}_{2} \mathrm{HPO}_{4} \cdot 2 \mathrm{H}_{2} \mathrm{O}$

adjusted to $\mathrm{pH} 7.00 \pm 0.05$ with $\mathrm{NaOH}$ and sterilized by filtering $(0.2 \mu \mathrm{m}$ filter $)$.

Hank's Balanced Salt Solution (HBSS):

without phenol red, Invitrogen, Carlsbad, California, USA

Neurobasal A Medium: (NBA):

Invitrogen, Carlsbad, California, USA

$\mathrm{CaCl}_{2}$ :

2.5M stock solution made from dihydrate salt; sterilized by filtering $(0.2 \mu \mathrm{m}$ filter $)$.

Unless otherwise noted, all chemicals were purchased from Sigma, Steinheim, Germany.

\subsection{Immunocytochemistry}

Immunostainings of primary hippocampal cultures have been performed against synaptotagmin 1. Synaptotagmin 1 is an integral membrane glycoprotein of neuronal 
synaptic vesicles and secretory granules of neuroendocrine cells and is widely expressed in hippocampus. It has a variable N-terminal domain that is exposed to the lumen of the vesicle or the extracellular space and a conserved cytoplasmic tail that contains two $\mathrm{Ca}^{2+}$ binding C2-domains (figure 2.2). $\mathrm{Ca}^{2+}$-binding to synaptotagmin triggers exocytosis of synaptic vesicles, thus linking neurotransmitter release to $\mathrm{Ca}^{2+}$-influx during depolarization.

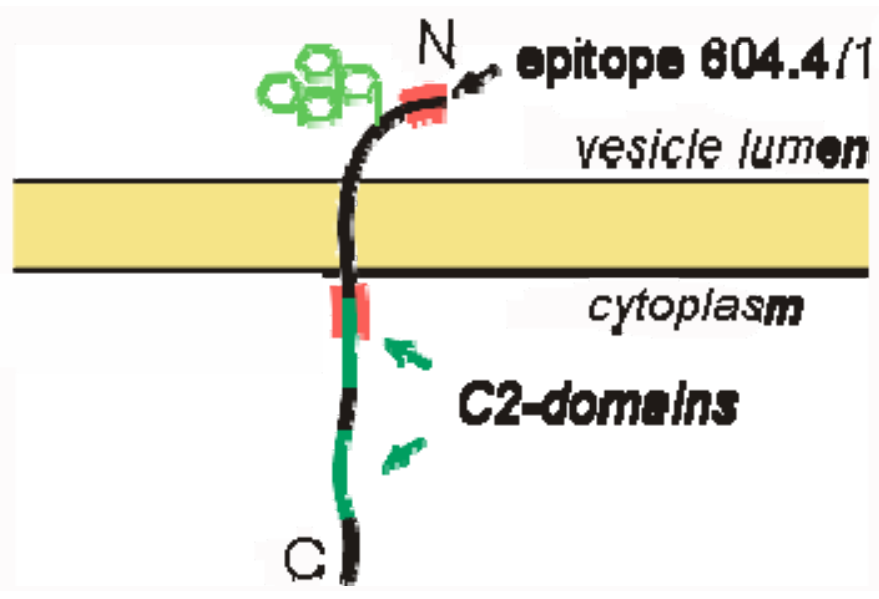

Figure 2.2 Schematic of synaptotagmin 1 showing the epitope used to label the plasma membrane stranded pool (source: website Synaptic Systems, Göttingen, Germany).

To assess the fraction of non-internalized surface-stranded synaptotagmin 1, live neurons were labeled with monoclonal syt1 lumenal domain antibody (mouse monoclonal, ascites, 604.4, used at 1:100 dilution; Synaptic Systems, Göttingen, Germany) at $4^{0} \mathrm{C}$ in $\mathrm{Ca}^{2+}$ - free PBS solution in the presence of TTX (Alomone labs, Jerusalem, Israel) and 4\% goat serum for 1 hour to allow for specific binding and to prevent antibody uptake by spontaneous synaptic activity. Cells were then rinsed with ice-cold PBS, fixed at $4^{0} \mathrm{C}$ for 30 min with 4\% formaldehyde in PBS, freshly prepared from paraformaldehyde, and stained with Alexa 488 secondary anti-mouse antibodies (used at 1:1000 dilution; Molecular Probes, USA).

For labeling the total pool of syt1 cells were fixed $4^{\circ} \mathrm{C}$ with $4 \%$ formaldehyde in PBS, permeabilized with $0.4 \%$ saponin (Sigma, Steinheim, Germany) and labeled with the primary and then secondary antibodies as indicated above. 
Images were acquired with identical imaging settings for both conditions.

\subsection{Fluorescent probes}

The studied hippocampal boutons, approximately $1 \mu \mathrm{m}$ in diameter, are only a few times larger than the optical resolution limit of conventional light microscopic techniques, limiting the resolvable details to the whole-synapse level. To nevertheless study presynaptic dynamics on a vesicular or even molecular level, specific fluorescence tracers of membrane trafficking have been developed that makes it possible to map local recycling of synaptic vesicles. One possible approach is to label recycling membranes with styryl dyes. Another strategy, and the technique principally employed in this study, is to use chimeric constructs made by fusing variants of the Aequoria Victoria green fluorescent protein (GFP) to the protein of interest.

\subsection{1 pHluorins for optical measurements of overall presynaptic activity}

Virtually any protein can be tagged with GFP - a compact, $23 \mathrm{kD}$ protein containing an amino-acid triplet (Ser-Try-Gly) that rearranges into a fluorophore (Chalfie et al., 1994). The resulting chimeras are easily expressed in cells, produce intense fluorescent signal, are relatively photostable and thus can be imaged repetitively and for long time without loss of fluorescence. Also, the GFP tag usually does not alter the targeted protein's transport or function, so the chimeras can be used to track proteins through intracellular pathways. With intentioned high illumination levels, GFP fluorescence of chimeras can be photobleached. This permits analysis of diffusional mobility and transport itinerary of tagged proteins under steady-state conditions - when the overall spatial or intercompartmental distribution of chimera may appear to be unchanging. It is possible to label different proteins with differently colored variants of GFP and visualize them simultaneously in the same cell. The ability to quantify dynamics of the GFP-tagged proteins by tracking and photobleaching permits analysis of central questions in membrane trafficking and secretory function. 
Using structure-directed combinatorial mutagenesis, Miesenböck and coworkers obtained new variants of GFP proteins by modifying $\mathrm{pH}$-dependency of GFP-fluorescence (Miesenbock et al., 1998). These new GFPs were termed $\mathrm{pH}$-sensitive green fluorescent protein-based sensors, or pHluorins.

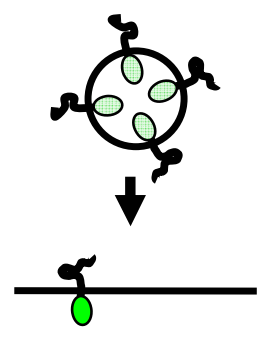

exocytosis

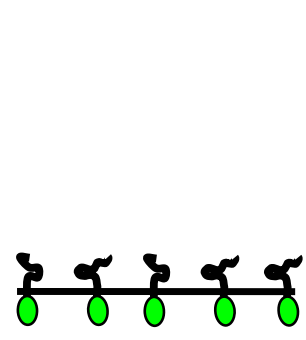

Figure 2.3 Exo-endocytic activity can be measured with synaptopHluorin.

The pHluorin molecule is attached to the luminal aspect of VAMP/synaptobrevin. At the resting $\mathrm{pH}$ of 5.6 within vesicles, the fluorescence signal from pHluorin is completely quenched. During firing of action potentials, the vesicles undergo fusion with the plasma membrane leading to the externalization of pHluorin to $\mathrm{pH}$ of 7.4. This relieves the proton-dependent quenching and causes an increase in fluorescence. The fluorescence signal then recovers following endocytosis by reacidification of vesicles. Unquenched molecules constantly present on the plasma membrane can contribute a significant background signal.

The lumen of synaptic vesicles has an acidic $\mathrm{pH}$ ( $\mathrm{pH}$ 5.6) resulting from the activity of a vacuolar $\mathrm{H}^{+}$-ATPase (Nelson, 1992). The generated $\mathrm{pH}$ gradient is necessary to drive neurotransmitter loading into the vesicle from the cytosol. However, following exocytosis, the vesicle lumen faces rapid switch to the neutral $\mathrm{pH}(\mathrm{pH}$ 7.4) of the extracellular environment. Since the pK value of pHluorins is about 7.1 (Sankaranarayanan et al., 2000) their fusion to the luminal part of a transmembrane synaptic vesicle protein can be used as a tool to monitor the $\mathrm{pH}$ shift upon exocytosis. Such a fusion construct of the synaptic vesicle protein VAMP2/synaptobrevin 2 and pHluorin is called synaptopHluorin $(\mathrm{spH}$, figure 2.3) (Miesenbock et al., 1998). The fluorescence of $\mathrm{spH}$ is quenched by proton excess in the vesicle lumen but is unquenched after fusion with the plasma membrane. This process yields an exocytosis-dependent fluorescent signal which diminishes after 
endocytosis and reacidification of vesicles. Since the reacidification is rapid, the fluorescence decay reflects the time course of endocytosis (Sankaranarayanan et al., 2000). Surprisingly, up to $30 \%$ of synaptopHluorin has been shown on the external membrane of the cell (Sankaranarayanan et al., 2000) and is therefore exposed to the extracellular solution with neutral $\mathrm{pH}$. This fraction of unquenched synaptopHluorin molecules adds a significant background to the fluorescent signal.

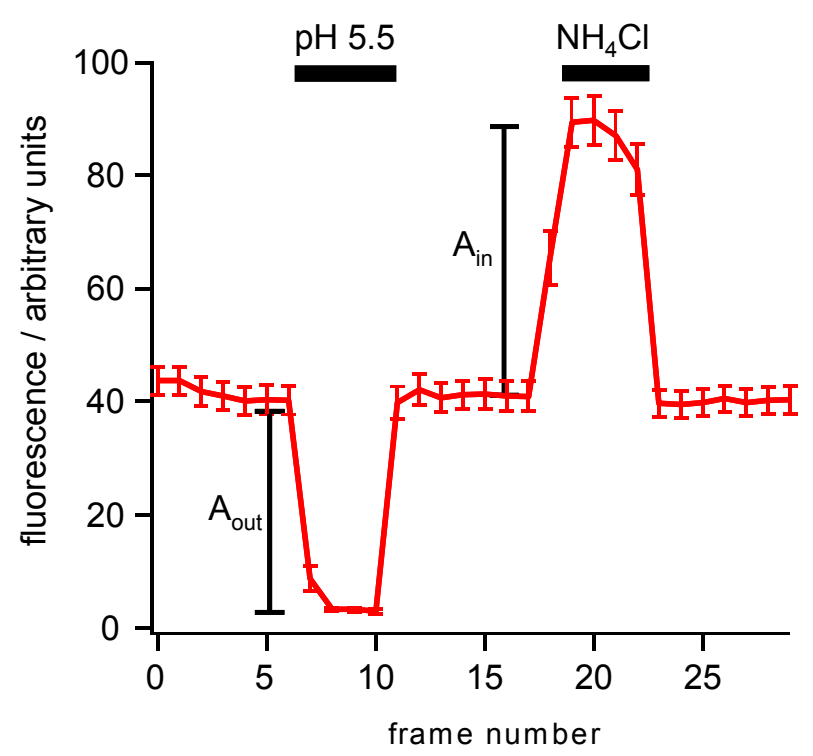

Figure 2.4 Example trace of the acid-base protocol used to determine the fraction of the plasma membrane stranded $\mathrm{spH}$ pool.

Figure 2.4 shows the acid-base protocol used in this study in order to determine the fraction of the surface-stranded synaptopHluorin pool. An acidic pulse quenches the fluorescence of plasma membrane located fluorophores, an ammonium pulse unquenches the fluorescence of the vesicular fluorophores. The fraction of the plasma membrane located synaptopHluorin was calculated as $A_{\text {out }} /\left(A_{\text {out }}+A_{\text {in }}\right)$.

In this study two modified versions of pHluorin-labeled synaptic vesicle proteins were used, serving as genetically encoded probes for measuring the fate of synaptic vesicle proteins during exo-endocytic cycling:

synaptopHluorin-TEV (spH-TEV) 
$\mathrm{spH}-\mathrm{TEV}$ is based on the original $\mathrm{spH}$ construct but I genetically introduced a highly specific Tobacco Etch Virus (TEV) protease recognition sequence flanked by flexible linker regions in between the synaptobrevin 2 and the pHluorin domain. This recognition site is only accessible to extracellularly added enzyme if spH-TEV resides in the plasma membrane. Thus it is feasible to selectively remove the unquenched fluorophores of the spH-TEV molecules in the plasma membrane by enzymatic digestion.

synaptotagmin 1-TEV-pHluorin (sytpH-TEV)

SytpH-TEV is a chimera of pHluorin and synaptotagmin 1. The lumenal portion of synaptotagmin 1 is formed by the $\mathrm{N}$-terminal part of the protein (figure 2.2). Therefore pHluorin had to be fused to the N-terminus of synaptotagmin 1 . However, since pHluorin (being a variant of GFP) is a cytosolic protein and, in contrast to $\mathrm{spH}$, is fused to the $\mathrm{N}$ terminus of synaptotagmin, a signal-sequence had to be added to enable the membrane insertion of syt-TEV-pHluorin during translation. To this end, the signal-sequence of neuropeptide precursor preprotachykinin ( $\mathrm{ppT}$ ) was fused to the N-terminus of the construct.

Analogous to spH-TEV, sytpH-TEV has a TEV protease recognition site between the pHluorin and the synaptotagmin 1 moiety.

Both constructs were cloned into expression plasmids that had a promoter of the gene for the presynaptic protein synapsin, which is neuron-specific. This strategy is advantageous because the possible background fluorescence arising from transfected glia cells below the examined neurons could be eliminated. Secondly, the neuron-specific promoter provided expression levels of the pHluorin probes close to physiological conditions.

\subsubsection{Styryl dyes}

Lichtman and colleagues first described the activity-dependent uptake and release of sulforhodamine and other fluorescent dyes in reptilian preparations (Lichtman et al., 1985). A further advance was made by Bill Betz and Fei Mao with the development of styryl dyes (most notably FM 1-43) that stain synaptic vesicles in an activity-dependent 
manner in a variety of preparations (Betz et al., 1996; Cochilla et al., 1999). Styryl dyes possess a hydrophilic head group with a double positively charged pyridinium residue and a lipophilic tail group with variable length that allows them to reversibly insert into the outer leaflet of exposed membranes (figure 2.5).

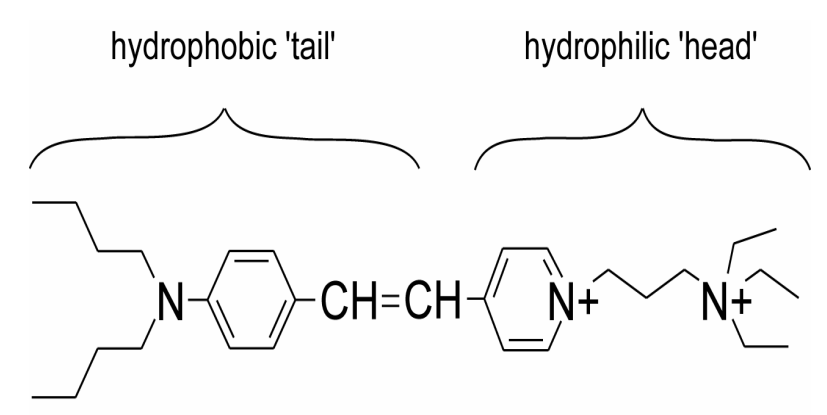

Figure 2.5 Structural formula of the amphiphilic styryl dye FM 1-43.

The permanently positively charged headgroup, however, prevents the dye from passively flipping over and crossing the lipid bilayer. Another important feature is the dramatic increase in quantum yield (about 350 times) when the dye partitions into a membrane. This characteristic which permits imaging of stained membranes while the dye is present in the external solution. In this study, the red-shifted styryl dye FM5-95 (Molecular Probes) was used to stain synaptic vesicles since its far-red emission does not interfere with the imaging of the green fluorescence of pHluorins. FM5-95 can be internalized by endocytosis and then, after washing off non-internalized dye, released by subsequent rounds of exocytosis. Uptake of the dye reflects endocytosis, while the extent of exocytosis is reflected by the loss of fluorescence from labeled vesicles during departitioning from the vesicle's luminal membrane into the extracellular solution (figure 2.6). 


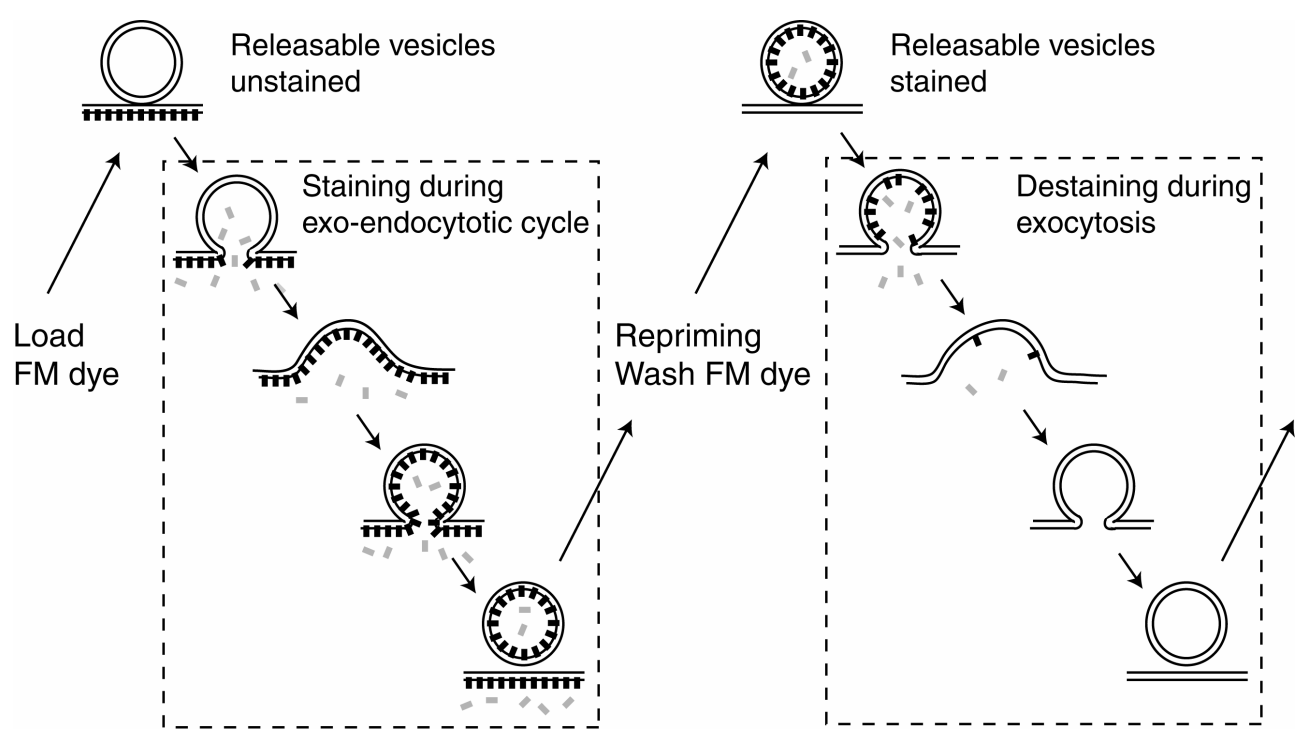

Figure 2.6 Experimental procedure to selectively stain and destain synaptic vesicles with FM dyes. [Courtesy of J. Klingauf.]

\subsection{Plasmid constructs}

Superecliptic pHluorin-synaptobrevin 2 (Miesenbock et al., 1998) was provided by G. Miesenböck (Yale University, CT, USA). A DNA fragment encoding the cleavage site for recombinant TEV protease (rTEV), flanked by spacer arms (amino acid sequence SGGSGGDYDIPT'TENLYFQGELKTVDAD), was introduced into the linker region between the synaptobrevin 2 and the pHluorin moiety by PCR.

The synaptotagmin-1-TEV-pHluorin (sytpHluorin) expression construct was made by fusing cDNAs encoding the signal sequence of rat preprotachykinin (amino acid sequence MKILVAVAVFFLVSTQLFAEEIGAN) to the amino-terminal domain of $\mathrm{pH}$-sensitive fluorescent protein (superecliptic pHluorin), in turn tagging the N-terminal end of rat synaptotagmin 1. pHluorin and synaptotagmin 1 were linked by the rTEV target site (amino acid sequence DYDIPTTENLYFQGELKTVDAD).

Monomeric red fluorescent protein (Campbell et al., 2002) was used to replace EGFP in a plasmid encoding for a GFP-tagged synaptophysin (Kaether et al., 2000); gift of A. Iliev, European Neuroscience Institute, Göttingen, Germany) to generate the synaptophysinmRFP construct. 
All generated constructs were cloned into a modified version of the pcDNA3 expression plasmid (Invitrogen, Carlsbad, California, USA) carrying a neuron-specific human synapsin 1 gene promoter (Kugler et al., 2001); obtained from S. Kügler, University of Göttingen, Germany, and were verified by dideoxynucleotide sequencing.

Expression plasmids of wild type stonin 2 and of the mutant form stonin $2^{\triangle \mathrm{WF} \triangle \mathrm{NPF}}$ lacking the ability to bind to AP-2, eps15 and intersectin were provided by the lab of Prof. Volker Haucke (Institut für Chemie und Biochemie, Freie-Universität-Berlin).

\subsection{Enzymatic tag removal}

\subsubsection{Tobacco Etch Virus (TEV) protease}

TEV protease is the common name for the $27 \mathrm{kDa}$ catalytic domain of the Nuclear Inclusion a (NIa) protein encoded by the tobacco etch virus (TEV). Because its sequence specificity is very stringent, far more than that of factor $\mathrm{Xa}$, thrombin, or enterokinase, TEV protease is a very useful reagent for cleaving fusion proteins. TEV protease recognizes a linear epitope of the general form E-Xaa-Xaa-Y-Xaa-Q-(G/S), with cleavage occurring between Q and G or Q and S (Parks et al., 1995). The most commonly used sequence is ENLYFQG. The structure of TEV protease is similar to those of serine proteases like chymotrypsin (Phan et al., 2002). Like the serine proteases, TEV protease utilizes a "catalytic triad" of residues to catalyze peptide hydrolysis.

Thus far, TEV proteases have been of importance for biochemical purifications, or were used to separate two fused variants of GFP from each other by cleavage in vitro (Kohl et al., 2002). A recent study used the protease thrombin to remove a short epitope tag attached to AMPA receptors on living neurons (Passafaro et al., 2001). However, a problem with many commercial thrombin sources is its secondary protease activity. In addition thrombin is an agonist of proteinase-activated receptors (PARs). Hippocampal neurons have been shown to express several types of PARs and their activation by thrombin was found to alter various physiological functions (Kiseleva et al., 2004; SmithSwintosky et al., 1997) that can lead to neurotoxicity or even apoptosis (Donovan et al., 1997). 
In this study AcTEV ${ }^{\mathrm{TM}}$ protease (Invitrogen, Carlsbad, California, USA) was used, a recombinant and enhanced form of TEV protease. Like its native form, AcTEVTM protease recognizes the seven-amino-acid sequence ENLYFQG and cleaves between Q and $\mathrm{G}$ with high specificity. The optimal temperature for cleavage is $30^{\circ} \mathrm{C}$; however, the enzyme is active over wide ranges of temperature and $\mathrm{pH}(\mathrm{pH}$ 6.0-8.5).

\subsubsection{TEV protease-mediated surface cleavage assay}

Proteolytic cleavage was performed at room temperature by adding 60U AcTEV protease and $1 \mathrm{mM}$ of the reducing agent dithiothreitol (DT'T) (Invitrogen, Carlsbad, California, USA) directly to the living neurons for $15 \mathrm{~min}$. The progress of cleavage was assayed by imaging the loss of fluorescence arising from the unquenched plasma membrane pool of the pHluorin-labelled constructs. After completion of the digest the protease was removed by perfusing the cells for 2 min with normal imaging solution.

To ensure that cleavage with TEV protease is specific, the protein sequences of several synaptic membrane proteins were checked. In no case was a random occurrence of the TEV protease recognition site found.

\subsection{Epifluorescence and confocal microscopy of living neurons}

A modified Tyrode solution (in mM: $150 \mathrm{NaCl}, 4 \mathrm{KCl}, 1 \mathrm{MgCl}_{2}, 2 \mathrm{CaCl}_{2}, 10$ glucose, 10 HEPES, pH 7.4) was used as an imaging buffer in all experiments unless otherwise indicated. Synaptic boutons were stimulated by electric field stimulation (platinum electrodes, $10 \mathrm{~mm}$ spacing, $1 \mathrm{~ms}$ pulses of $50 \mathrm{~mA}$ current of alternating polarity, $10 \mu \mathrm{M}$ CNQX and $50 \mu \mathrm{M}$ AP-5 to prevent recurrent action potentials) at room temperature. Fast solution exchanges were achieved by a piezo-controlled stepper device (SF77B, Warner Instruments) using a 3 barrel square glass tubing. Ammonium chloride solution ( $\mathrm{pH}$ 7.4) was prepared by substituting $50 \mathrm{mM} \mathrm{NaCl}$ in normal saline with $\mathrm{NH}_{4} \mathrm{Cl}$, while all other components remained unchanged. Acidic solution with a final $\mathrm{pH}$ of 5.5 was prepared by 
replacing HEPES with 2-[N-morpholino]ethane sulphonic acid ( $\mathrm{pK}=6.1$ ), all other components in the saline remained unchanged.

To label recycling synaptic vesicles, the cells were additionally exposed to $10 \mu \mathrm{M}$ FM 5-95 (Molecular Probes) during the electrical-field stimulation. This step was followed by an extra $60 \mathrm{~s}$ of dye exposure to ensure labeling of all recycling membrane during the course of endocytosis. After $10 \mathrm{~min}$ rinsing in dye-free solution, FM5-95 was unloaded by a prolonged train of action potentials.

Images were taken by a cooled slow-scan CCD camera (PCO SensiCam-QE, Kelheim, Germany) mounted on a Zeiss inverted microscope (Axiovert S100TV) with a Zeiss x 63, 1.2 NA water-immersion objective and an eGFP filter set (DCLP 505, BP 525/50; AHF Analysentechnik, Germany). Fluorophores were exited at $470 \mathrm{~nm}$ with Xe-arc lamp illumination (Polychrom II, Till Photonics, Germany) for $500 \mathrm{~ms}$ at $2 \mathrm{~s}$ interval. Imaging data were collected with TillVision Software (Till Photonics, Germany). For further analysis, the data were processed, normalized and averaged, using custom-written macros in Igor Pro (Wavemetrics, Lake Oswego, OR, USA).

FM5-95 was exited at $515 \mathrm{~nm}$ and imaged using a $565 \mathrm{~nm}$ dichroic mirror and a $590 \mathrm{~nm}$ long pass emission filter (AHF Analysentechnik, Germany).

Photobleaching was performed by repetitive laser scanning at $488 \mathrm{~nm}$ for 90 s with a Leica SP2 confocal microscope.

To avoid the bias introduced by manual selection of functional boutons, an automated detection algorithm was used. The image from the time series showing the maximal pHluorin response during stimulation was subjected to an à-trous wavelet transformation with the level $k=4$ and detection level $l_{d}=1.0$ (Olivo-Marin, 2002), resulting in a segmented mask image (figure 2.7). Spots on mask images, each representing putative functional boutons, were identified, and only masks with areas between 4 and 20 pixels were accepted for calculating single bouton fluorescence transients. All automatically identified masks and calculated time courses were visually inspected for correspondence to individual functional boutons. 

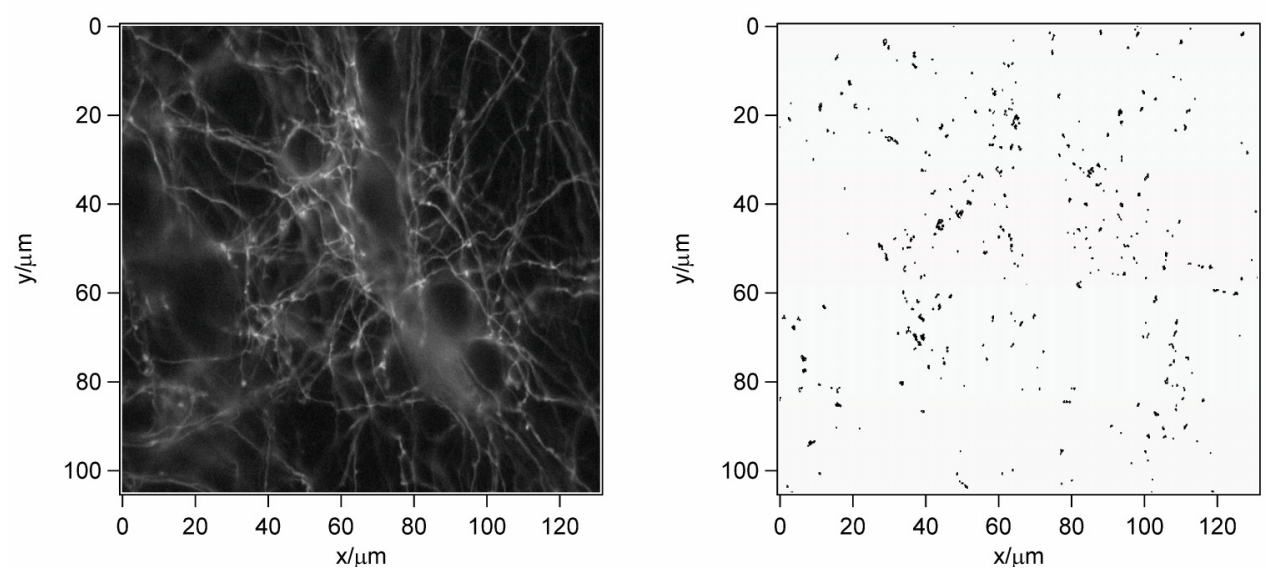

Figure 2.7: Automated detection of functional boutons by a wavelet-generated mask.

left: Image of axonal arborizations during electrical stimulation.

right: Corresponding wavelet mask identifying active synapses as black spots. 



\section{RESULTS}

\subsection{Vesicular proteins exocytosed and subsequently retrieved by compensatory endocytosis are non-identical}

\subsubsection{GFP-tagged synaptobrevin/VAMP is found on the plasma membrane of resting neurons}

Overall endocytic activity can be measured with synapto-pHluorin ( $\mathrm{spH}$ ), a fusion construct of the vesicle protein synaptobrevin 2 (or VAMP 2) and a $\mathrm{pH}$-sensitive form (pHluorin) of GFP (Miesenbock et al., 1998). The pHluorin/GFP-moiety resides in the acidic vesicle lumen, rendering it a good indicator for exo-endocytosis. The fluorophore is unquenched upon exocytosis and is quenched again upon reacidification of endocytosed vesicles, a process that is accomplished within seconds (see methods for details). However, a fraction of up to $30 \%$ of $\mathrm{spH}$ has been shown to be present on the external axonal membrane of transfected hippocampal neurons under resting conditions (Sankaranarayanan et al., 2000); cf. figures 3.1 and 3.3b). Since the fluorophores of this fraction are exposed to the neutral $\mathrm{pH}$ of the extracellular medium $(\mathrm{pH} 7.4)$ while the vesicular pool is quenched ( $\sim \mathrm{pH} 5.5)$, resting neurons typically display staining of external somatic and axonal membranes (figure 3.1). The origin of the surface population of synaptobrevin remains unclear, but its contribution seems to be independent of the absolute expression level. Even strong overexpression after viral gene transfer (Semliki Forest Virus) results in the same (about 25\%) fraction of plasma membrane stranded spH (data not shown).

This lack of correlation between the degree of surface expression and the total $\mathrm{spH}$ content suggests that the surface distribution of $\mathrm{spH}$ is not the result of overexpression and raises the question if the plasma membrane pool might be of physiological importance. In particular, it is unclear whether and to which extent these plasmamembrane stranded proteins participate in exo- endocytic cycling and, as a consequence of it, if the molecular identity of both vesicular and plasma membranes is preserved during synaptic activity. 

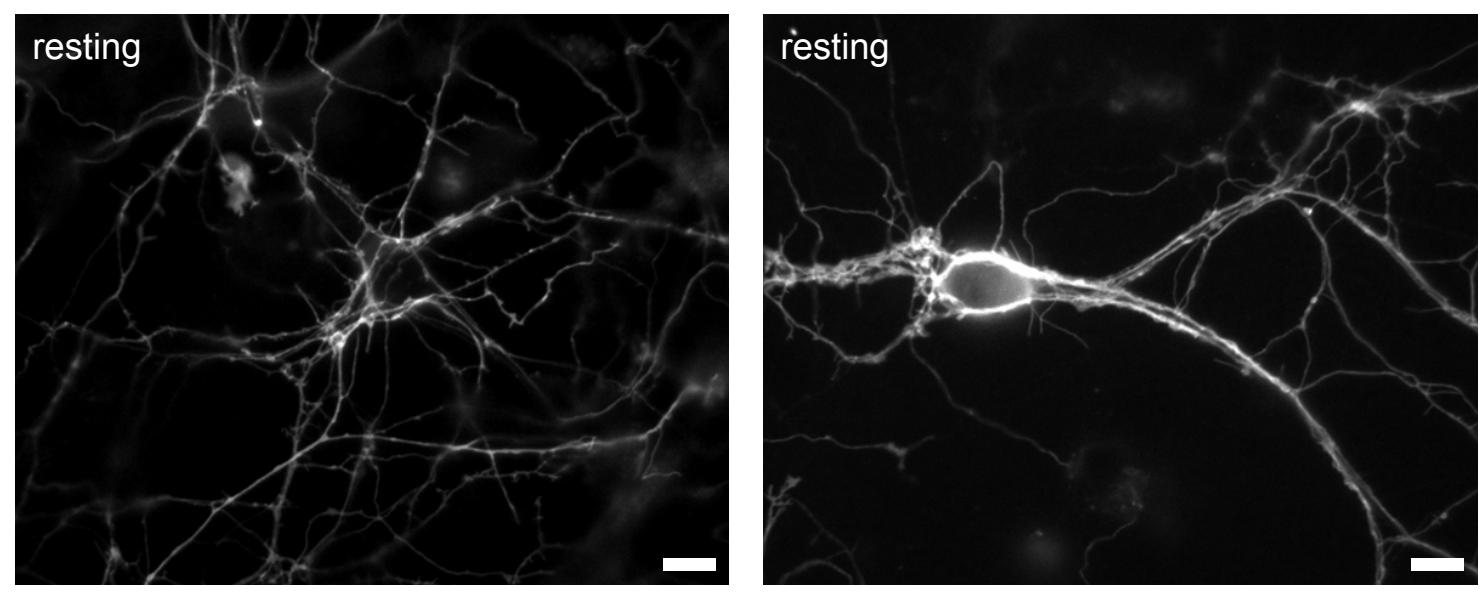

Figure 3.1 Two exemplar images of hippocampal neurons in culture, transfected with synaptopHluorin $(\mathrm{spH})$. Even during resting conditions, a sizable fraction of $\mathrm{spH}$ is found on the plasma membrane. Scale bars are $10 \mu \mathrm{m}$.

However, a crucial technical problem is that, once the vesicular membrane fuses with the plasma membrane, the newly added plasma membrane spH molecules become visually indistinguishable from those resided in the stranded pool.

\subsubsection{Synaptobrevin-TEV-pHluorin (spH-TEV): a tool for tracking the post fusion fate of vesicular proteins}

To test whether synaptic vesicles maintain their identity with respect to their protein composition during exo- endocytic cycling a TEV-protease cleavage site was introduced between the VAMP and GFP moieties that is only accessible to external enzyme if spHTEV is in the plasma membrane as illustrated in figures 3.2 and 3.4b. With this it is possible to irreversibly cut off the fluorescent GFP moiety at those spH molecules that are on the plasma membrane by adding the enzyme to the extracellular solution. To improve efficiency of cleavage a spacer arm has been inserted up- and downstream of the recognition site (curved lines in figure 3.2). Furthermore, to better match physiological conditions the expression of the construct is controlled by the neuron-specific promoter of the presynaptic protein synapsin (pSyn). 


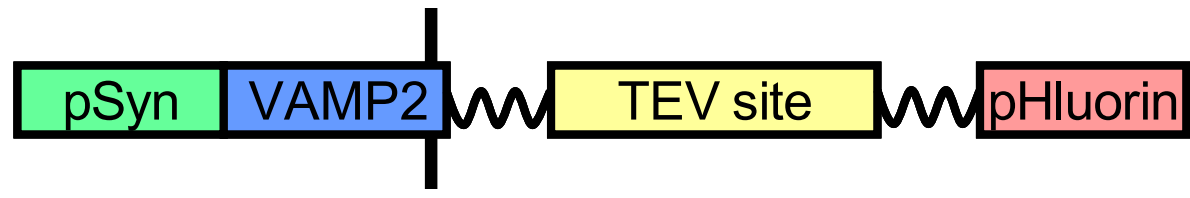

Figure 3.2 Schematic representation of the modified synaptopHluorin construct, bearing a cleavage site for TEV protease on the luminal/extracellular domain. The construct is under control of the neuron specific promoter for synapsin (green).

spH-TEV, like spH, is specifically targeted to synaptic boutons. The spH-TEV spots responding to the electrical stimulation colocalize with spots stained with the synaptic activity marker FM 5-95 (figure 3.3a), and fluorescence transients upon stimulation with 200 APs are indistinguishable from those obtained with $\mathrm{spH}$ (figure 3.3b). Like for $\mathrm{spH}$ (Sankaranarayanan et al., 2000), up to $30 \%$ of spH-TEV is found on the plasma membrane of boutons at rest, as revealed by surface fluorescence quenching by short superfusion with acidic solution of $\mathrm{pH} 5.5$ (figure 3.3b, right, and figure $3.4 \mathrm{a}$, first two images).

For investigating the fate of vesicular SNAREs post fusion the plasma membrane pool of spH-TEV, which normally will mask the spatiotemporal dynamics of vesicular SNAREs during stimulation, can be almost completely 'silenced' in terms of fluorescence intensity by exposure to TEV protease for $15 \mathrm{~min}$ (figure 3.4c). 

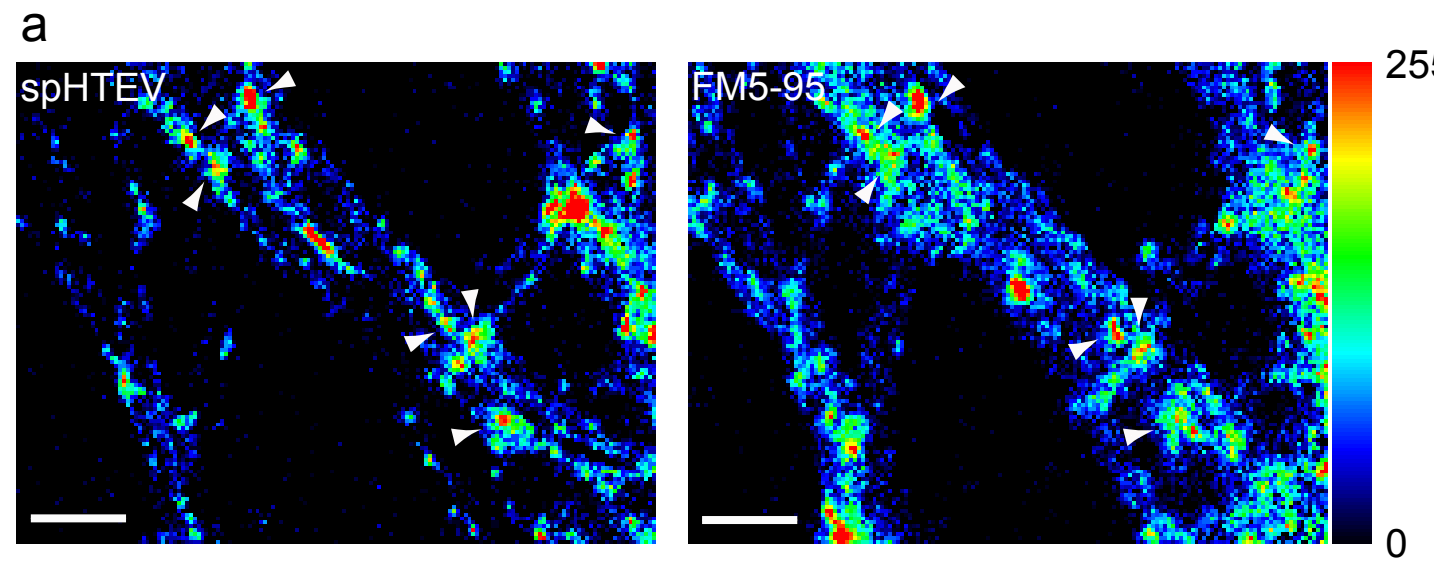

$\mathrm{b}$
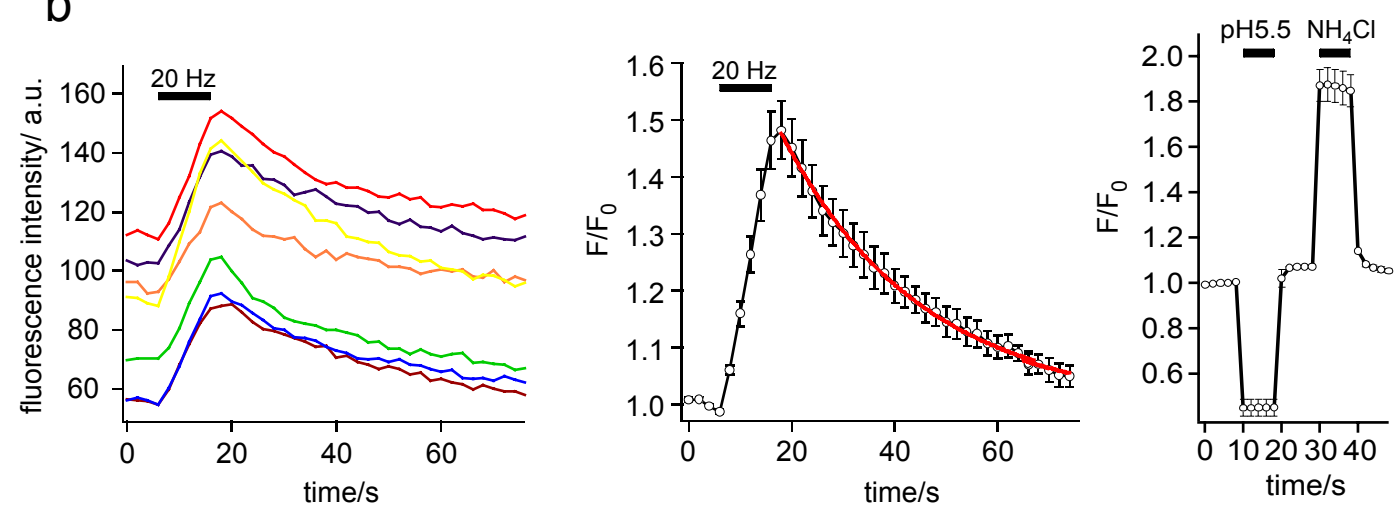

Figure 3.3 Synaptobrevin-TEV-pHluorin (spH-TEV) is targeted to functional boutons.

a. Axonal branches of hippocampal neurons in primary culture overexpressing spH-TEV. Difference image (left), obtained by subtraction of the image recorded before from the one recorded immediately after a stimulation train of $200 \mathrm{APs}$, indicates transient fluorescence increases at sites that can be stained and destained with the activity marker FM 5-95 (right), identifying them as functional presynaptic boutons. Scale bar is $5 \mu \mathrm{m}$.

b. Individual fluorescence transients of exemplar boutons marked by arrow heads in (a) (left), average fluorescence signal (middle, red line represents single exponential fit with $\tau=26.9 \mathrm{~s}$ ), and average fluorescence signal from boutons superfused with acidic ( $\mathrm{pH} \mathrm{5.5)}$ and high ammonium chloride $(50 \mathrm{mM})$ solution revealing $33.2 \% \pm 0.9 \%$ of PM stranded spH-TEV ( $n=3$ experiments, $>50$ boutons each, error as SEM). 
a
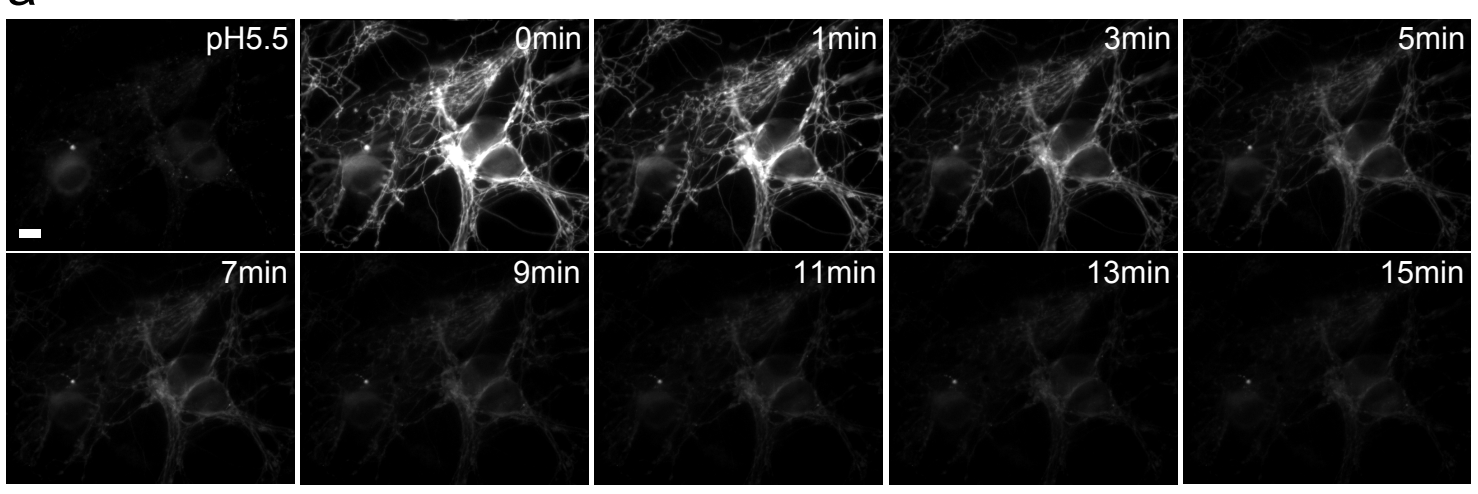

b

C
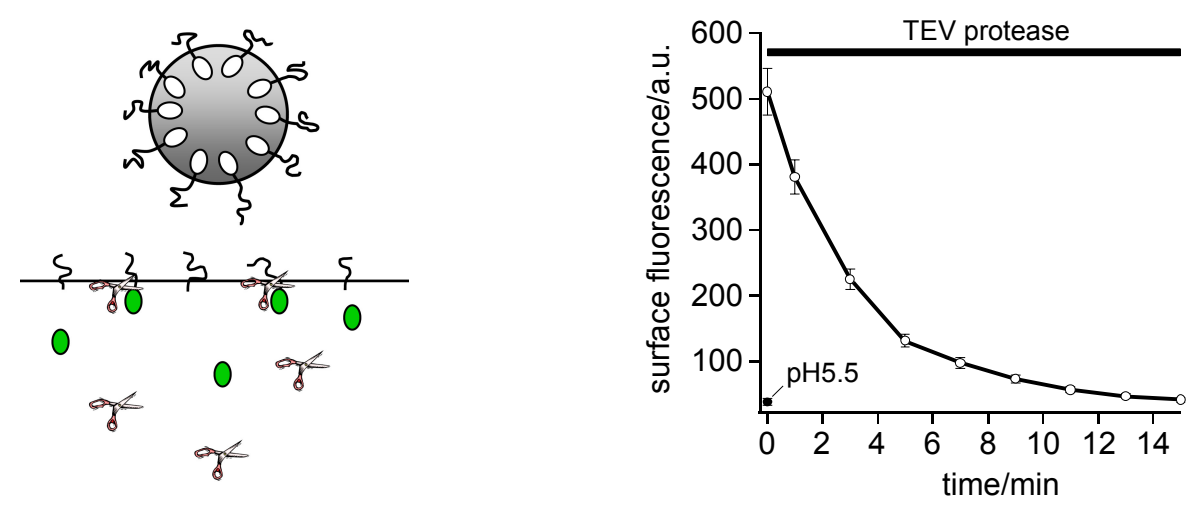

Figure 3.4 The plasma membrane-stranded fraction of synaptobrevin-TEV-pHluorin (spH-TEV) can be effectively cleaved.

a. Exposure of neurons expressing spH-TEV to $0.12 \mathrm{U} / \mu \mathrm{L}$ TEV protease at room temperature leads to effective cleavage of the pHluorin moiety from synaptobrevin molecules residing in the plasma membrane within 15 min.

b. Schematics of the selective cleavage of the plasma membrane stranded pool by TEV protease.

c. Cleavage decreases the plasma membrane spH-TEV fluorescence down to a level that is comparable with acidic quenching by perfusing cells with solution of pH 5.5. Scale bar in images is $10 \mu \mathrm{m}$.

\subsubsection{Vesicular proteins are lost post fusion}

If axons expressing spH-TEV are stimulated postdigest, the boutons light up as vesicular spH-TEV is dequenched upon vesicle fusion (figure 3.5, left). For analysis of the spatiotemporal dynamics of vesicular spH-TEV a line of interest (LOI, 3 pixels or $615 \mathrm{~nm}$ 
width) is drawn on a maximum projection image along an axonal stretch. For each image of the recorded stack (i.e. for each time point) the integrated fluorescence below each LOI point is plotted in a kymograph image (figure 3.5, right).
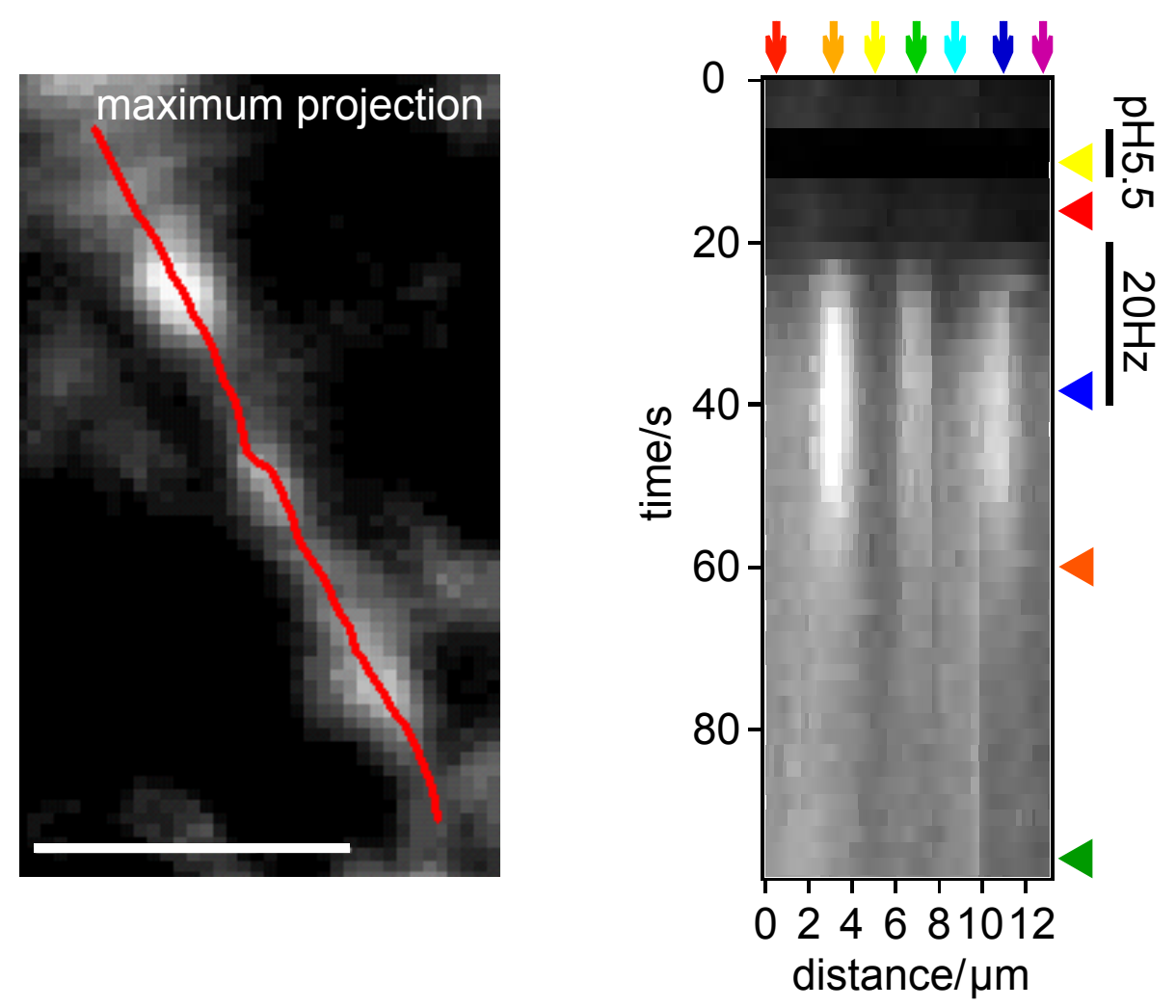

Figure 3.5 Vesicular proteins are lost post fusion.

Maximum projection image (left) of a recorded stack of an axonal segment with 3 functional spH-TEV expressing boutons stimulated with 400 APs. Scale bar is $5 \mu \mathrm{m}$. For further analysis a LOI (red solid line) was placed along the axon to create a waterfall plot, or kymograph (right). Fluorescence intensities at each distance of the LOI (origin is next to the upper left corner of maximum projection image) are integrated over a width (normal to the LOI) of three pixels. Times of acidic pulse and stimulation are indicated by bars, color-coded arrow heads indicate times and positions of spatial and temporal profiles displayed in figure 3.6 .

Superfusion with acidic $(\mathrm{pH}$ 5.5) solution postdigest reveals that most spH-TEV in the plasma membrane has been digested (only small drop in fluorescence intensity upon perfusion with acidic solution, figure 3.6b). Upon stimulation and exocytosis of vesicles spH-TEV dequenches and, surprisingly, spreads quickly in the axonal plasma membrane as can be seen by comparing spatial (horizontal) and temporal (vertical) profiles of the 
kymograph at different times (figure 3.6a) and distances (figure 3.6b), marked by the colored arrowheads in figure 3.5. Since the fluorescence increase in axonal segments is not significantly delayed compared to the bouton signals and smaller in maximal amplitude (figure 3.6b), vesicular SNAREs after fusion most likely diffuse laterally in the plasma membrane with a rather fast diffusion constant, typical for transmembrane proteins (Kenworthy et al., 2004). After stimulation vesicular SNAREs are retrieved and quenched by vesicle lumen reacidification only in the boutons, leading even to a slight reversal of the bouton/axon gradient at $\mathrm{t}=95 \mathrm{~s}$ (figure 3.6a, compare blue and green profile).

a

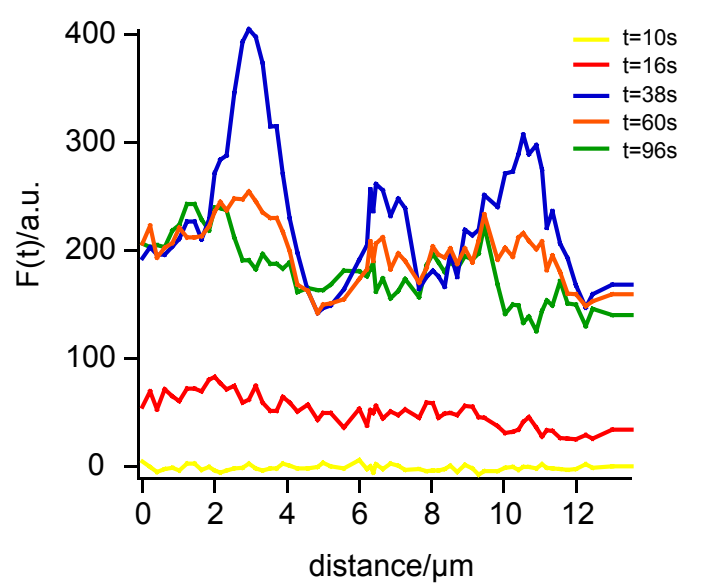

b

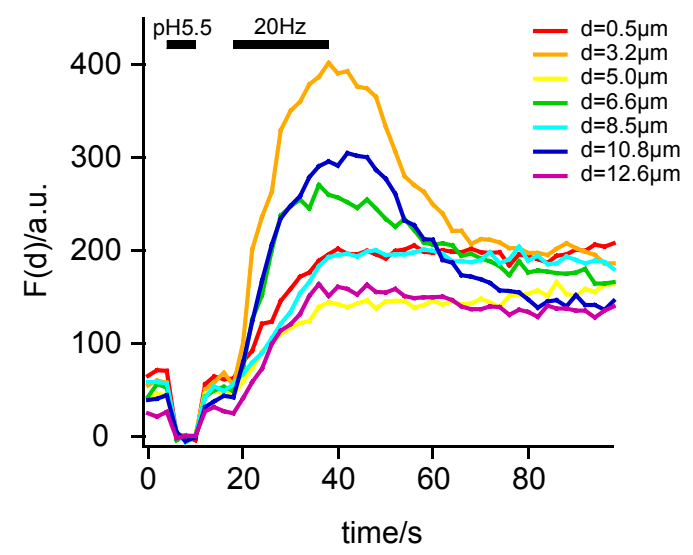

Figure 3.6 Analysis of the axonal spread of released spH-TEV molecules.

a. Exemplar spatial profiles along the LOI in figure 3.5a at different times indicated by color-coded arrow heads in figure $3.5 \mathrm{~b}$.

b. Exemplar time courses at different positions along the LOI in figure 3.5a, color-coded according to the colors of arrow heads in figure $3.5 \mathrm{~b}$.

\subsubsection{Vesicular proteins exo- and endocytosed during stimulation are not identical}

Interestingly, in contrast to fluorescence transients predigest (figure 3.3b), recovery of the $\mathrm{spH}-\mathrm{TEV}$ transients in the three depicted boutons appears to be incomplete postdigest (figures 3.5 and 3.6b). This finding suggests that a significant fraction of the exocytosed 
spH-TEV molecules remains after stimulation on the plasma membrane without being endocytosed and subsequently quenched again.
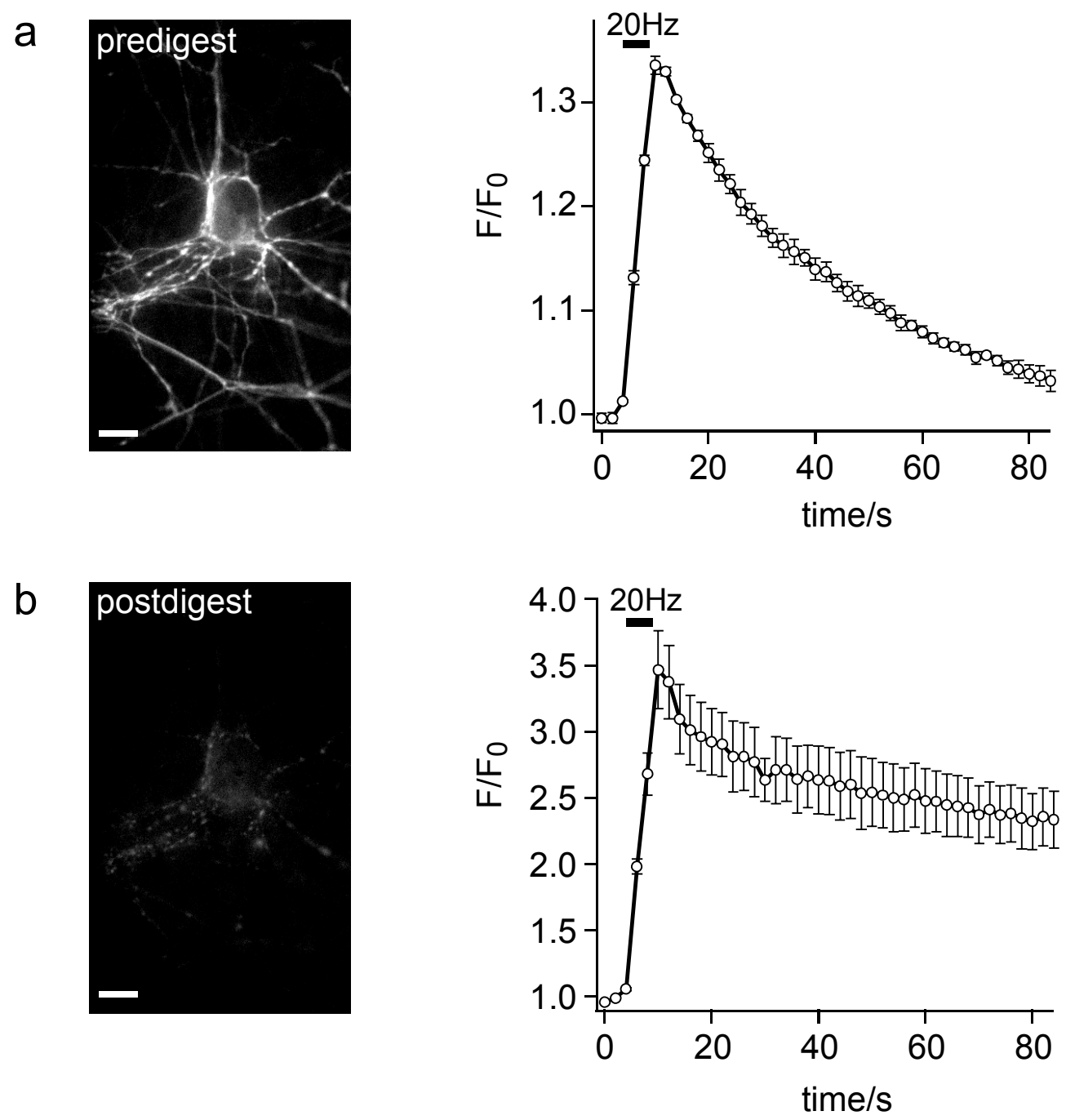

Figure 3.7 Vesicular proteins exo- and endocytosed during stimulation are not identical.

a. Image of neuronal processes expressing spH-TEV (left, Scale bar $10 \mu \mathrm{m}$ ). Prior to digest with TEV protease control fluorescence transients at boutons upon stimulation with $100 \mathrm{APs}$ at $20 \mathrm{~Hz}$ show complete recovery within $\mathrm{t}=80 \mathrm{~s}$ (right).

b. Image of neuronal processes, shown in (a), but after digest with TEV protease shows very little PM fluorescence (left, Scale bar $10 \mu \mathrm{m}$ ). Fluorescence transients of boutons upon stimulation with 100 APs at $20 \mathrm{~Hz}$ display increased relative amplitudes, as expected because of the smaller background surface fluorescence, but recovery is incomplete (right). 
Furthermore, this newly created fluorescent plasma membrane pool of spH-TEV molecules distributes homogeneously in the external axonal membrane (figures 3.5 and 3.6b).

To study this effect more carefully for a defined stimulus, the next step was to analyze the recovery of fluorescence transients in the same set of boutons pre- and postdigest upon stimulation with 100 APs (figure 3.7). Comparison of the fluorescent transients obtained pre- (figure 3.7a) and postdigest (figure 3.7b) reveals two main findings. First, digest with TEV protease increases the relative amplitude $\left(\Delta \mathrm{F} / \mathrm{F}_{0}\right)$. This is expected since in both preand postdigest cases the same number of vesicles should be released with 100 APs while the background signal $\mathrm{F}_{0}$ arising from the unquenched surface spH-TEV pool is strongly reduced after the digest. Second, the digest indeed leads to incomplete recovery $(40.1 \%$ at $58 \mathrm{~s}$ after stimulus end) of fluorescence transients, as observed before (cf. figure 3.6 and figure 3.7). Since vesicular proteins, once released, tend to diffuse away from the release sites (figure 3.5), a likely explanation is, that during compensatory endocytosis, at least in part, plasma membrane-stranded spH-TEV molecules have been retrieved instead of the spH-TEV released during stimulation. A model for this hypothesis is shown in figure 3.8.
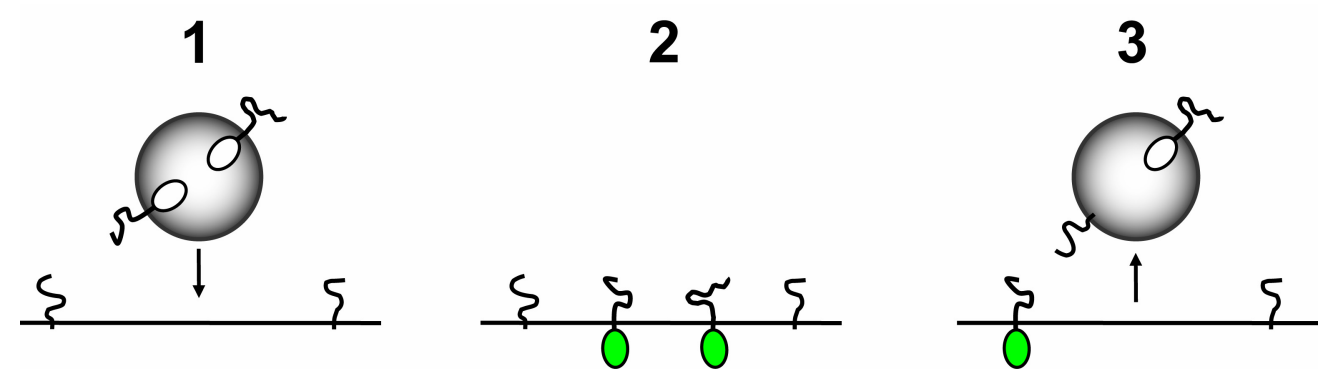

Figure 3.8 Possible model explaining the spH-TEV transients obtained postdigest (figure 3.7b).

After digest with TEV protease most molecules in the plasma membrane are void of pHluorin (1). With stimulation intact spH-TEV molecules are inserted into the plasma membrane and are dequenched (2). During compensatory endocytosis previously digested molecules are preferentially retrieved, leading to incomplete quenching of spH-TEV (3).

After TEV digest the spH-TEV molecules in the plasma membrane have lost their pHluorin moiety and are therefore non-fluorescent. The vesicular spH-TEV molecules 
still have their fluorophores but are invisible since they are quenched (1). Upon triggered fusion intact spH-TEV molecules are inserted into the plasma membrane, dequenched, and give rise to the increase in fluorescence intensity (2). These newly added molecules mix quickly with the previously digested pool so that during compensatory endocytosis a mixture of spH-TEV molecules with and without fluorophores is retrieved. However, only those molecules that are endocytosed and still have a GFP-moiety are dequenched again while a new pool of unquenched intact spH-TEV molecules is left in the plasma membrane resulting in incomplete recovery of the fluorescence transients (3).

Prior to digestion this process of mixing is not observed since intact plasma membranestranded and newly inserted by exocytosis spH-TEV molecules will equally contribute to the dequenching signal during reacidification of endocytosed vesicles, leading to complete recovery.

This means that incomplete recovery is always observed as long as there are relatively more digested spH-TEV molecules in the plasma membrane than in the vesicular pool. However, assuming partial mixing of both pools during every exo- and endocytic cycle progressively more digested spH-TEV will accumulate in the vesicular membrane and intact spH-TEV in the plasma membrane. Once the ratio of digested/intact spH-TEV molecules in both pools is equilibrated, the fluorescent transients after stimulation will again show full recovery. This scenario only differs from the one before digest by a reduced total number of intact spH-TEV molecules in both pools.

To test this hypothesis the relative stoichiometry of molecules in synaptic vesicle and the plasma membranes was first restored by turning over most synaptic vesicles with a prolonged train of action potentials (800 APs at $5 \mathrm{~Hz}$ ) in the same set of boutons and then a stimulus with 100 APs was applied again. Indeed the transient nature of the spH-TEV signals was fully recovered (figures 3.9 and 3.10b). The proposed model is also validated by the reappearance of fluorescently labeled axonal branches after the prolonged stimulation (figure 3.9, left) and reduced $\mathrm{F} / \mathrm{F}_{0}$ amplitude sizes (figure 3.9, right; figure 3.10a), comparable to those recorded predigest (figure 3.7a). Moreover the restored transient character of the spH-TEV signal after pool mixing excludes the possibility that the incomplete recovery postdigest is caused by a simple lack of endocytosis due to e.g. toxic effects of the protease treatment. 

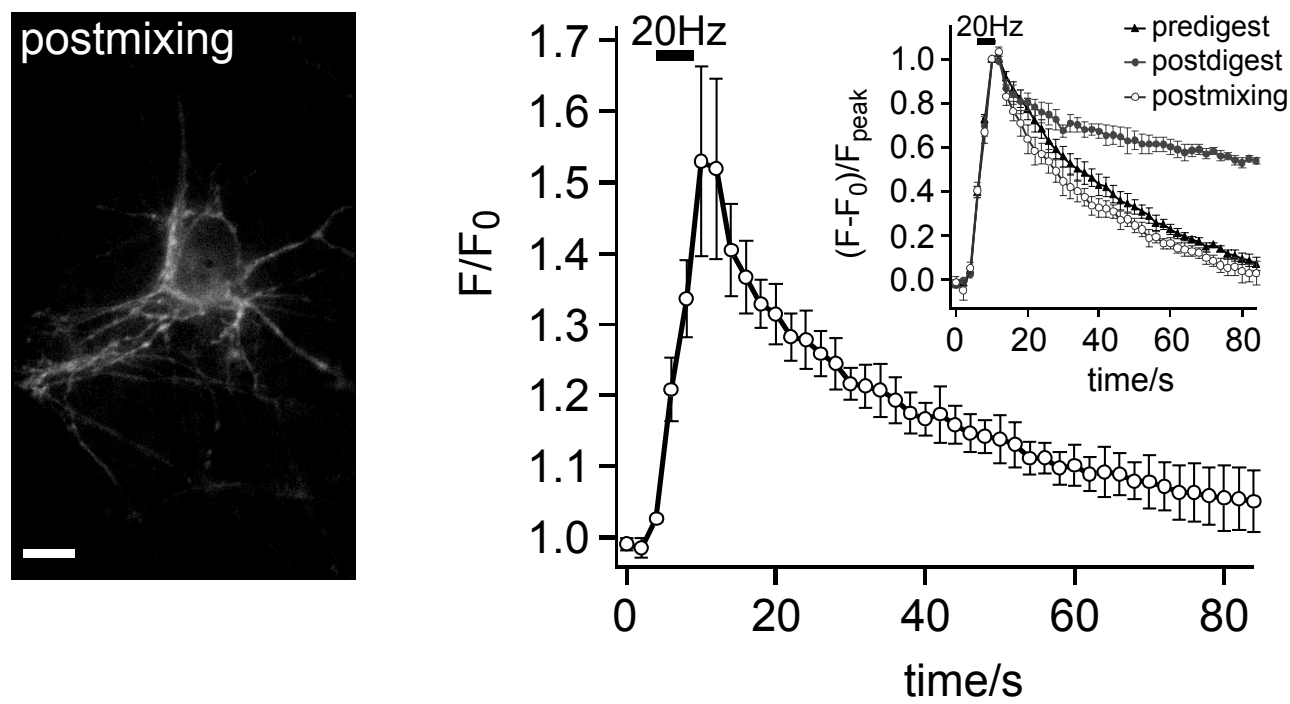

Figure 3.9 Image of neuronal processes postdigest but after mixing vesicle and plasma membrane pools of spH-TEV with a prolonged train of action potentials ( $800 \mathrm{APs}$ at $5 \mathrm{~Hz}$ ) shows again significant fluorescence of plasma membrane stranded spH-TEV (left, Scale bar $10 \mu \mathrm{m}$ ). Fluorescence transients of postmixing boutons upon stimulation with $100 \mathrm{APs}$ at $20 \mathrm{~Hz}$ display again complete recovery (right), demonstrating that endocytosis is not blocked by TEV protease digestion. The inset shows normalized responses for 100 APs at $20 \mathrm{~Hz}$ pre- (figure 3.7a), postdigest (figure $3.7 \mathrm{~b}$ ), and postmixing ( $\mathrm{n}=3$ experiments, $>50$ boutons each, error as SEM).

Thus, it seems that the majority of synaptic vesicles loose their molecular identity during exo-endocytic cycling by mixing of their molecular content with plasma membrane proteins. Alternatively, the results can be explained by assuming that synaptic vesicles indeed do maintain their molecular identity in raft-like structures that diffuse slowly to the periphery of the active zone, waiting to be internalized quickly during the next round of stimulation. Digestion would render these intact vesicle membrane patches 'fluorescently silent', thereby leading to incomplete fluorescence recovery, if those vesicle patches at endocytic sites are retrieved preferentially over those freshly inserted at the release sites. Since, however, earlier experiments showed fast diffusion (figures 3.5 and 3.6) after fusion, the movement of raft-like vesicle patches to the peri-active zone would have to be very fast. Otherwise, diffusion can become rate-limiting, and one would expect to see a pronounced delay in the partial recovery of the spH-TEV signals, i.e. a change in the time 
course of the remaining recovery, which was not observed (cf. figure 3.7a,b; inset in figure 3.9).

a

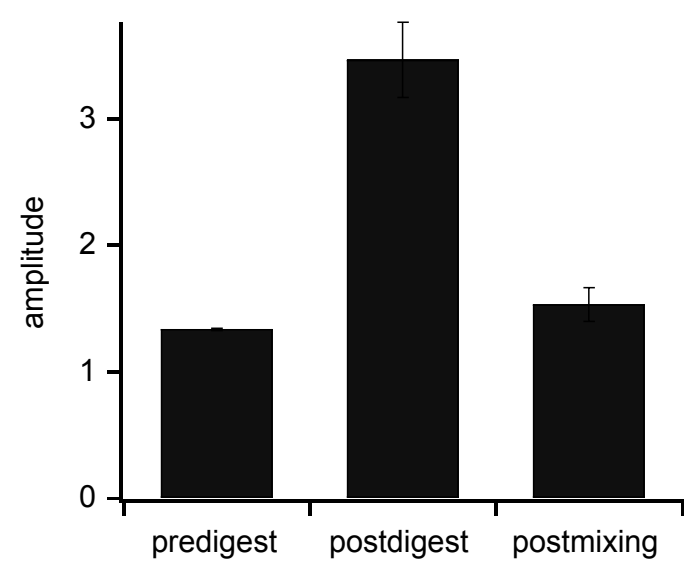

b

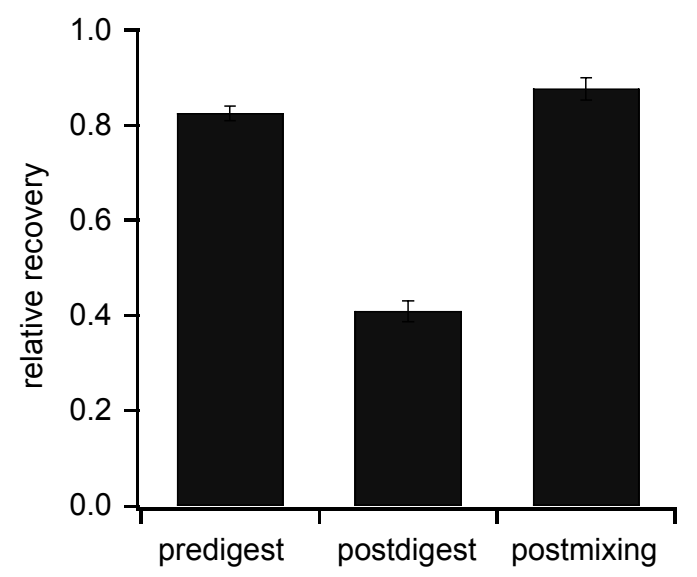

Figure 3.10 Summary showing the relative amplitudes $\left(F / F_{0}, a\right)$ and the relative recoveries of fluorescent transients (b) after stimulation with 100 APs pre-, postdigest and postmixing. Relative recovery is defined as $\left(1-\left[\left(F-F_{0}\right) / F_{\text {peak }}\right]\right)$ and calculated for $58 \mathrm{~s}$ after stimulus end. ( $n=3$ experiments, $>50$ boutons each, errors as SEM)

\subsubsection{Degree of non-identity depends on stimulus duration, but is independent of method of fluorescent tag removal}

If the degree of recovery reflects the amount of vesicular spH-TEV released relative to the amount of stranded spH-TEV, it should depend on the stimulus duration. The more vesicles are being released, the more intact spH-TEV molecules will be added and mix with the previously digested pool on the membrane so that retrieved vesicles would contain a larger fraction of quenchable molecules. Indeed a two times prolonged stimulus of 200 APs yielded significantly more recovery (50.0\% at $58 \mathrm{~s}$ after stimulus end) of the postdigest transients (figure 3.11).

However, different degrees of fluorescence recovery for differing ratios of vesicular and stranded spH-TEV may also be a consequence of a competition between cleaved and noncleaved forms of spH-TEV for binding at sites of endocytosis. In fact, the cleaved form lacking the $27 \mathrm{kD}$ pHluorin moiety may be preferentially retrieved for steric reasons. To 
test this, the fluorescence of the stranded pool was silenced by selective photobleaching (Gandhi and Stevens, 2003) instead of proteolytic cleavage (figure 3.12).

a

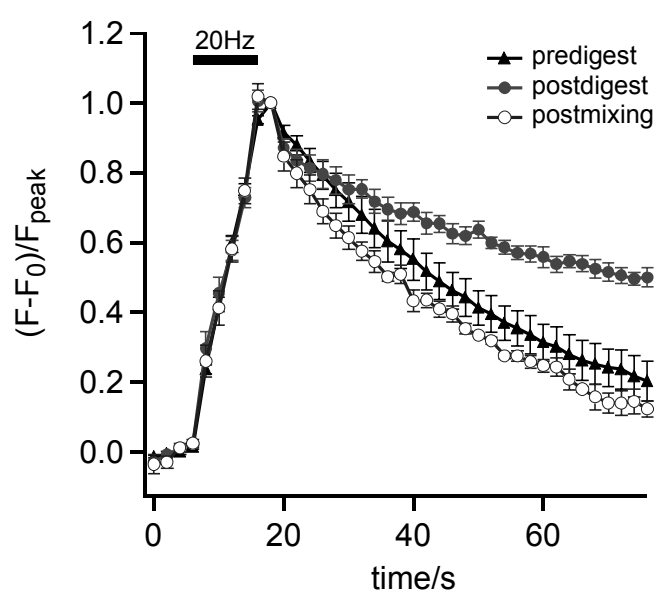

b

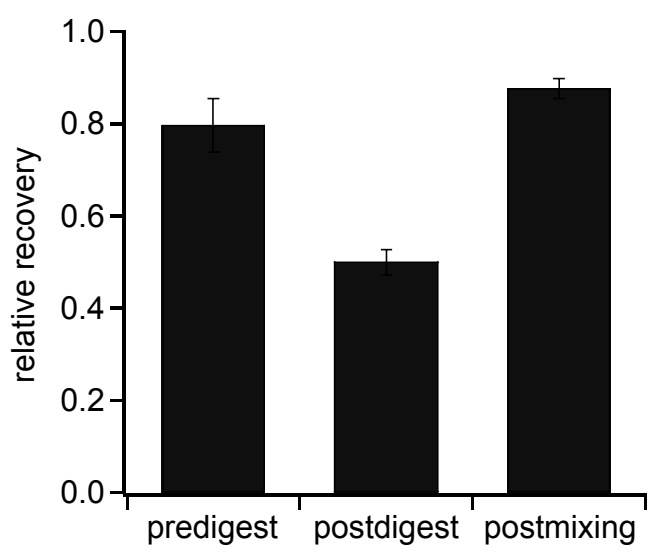

Figure 3.11 Time course and relative recoveries of fluorescent transients after stimulation with 200 APs.

a. Normalized responses for 200 APs at $20 \mathrm{~Hz}$ pre-, postdigest, and postmixing ( $\mathrm{n}=3$ experiments, $>50$ boutons each, error as SEM).

b. Relative recoveries calculated from (a) at $58 \mathrm{~s}$ after stimulus end.

Repeated laser scanning at high intensity was used for bleaching to minimize bleaching time and thereby any turnover by spontaneous release. However, even at pH 5.6 roughly $2.5 \%$ of pHluorin molecules exist in the deprotonated state (Sankaranarayanan et al., 2000) and will be susceptible to photobleaching. Additionally, protonated non-emitting GFP can absorb light and the photobleaching effect of other variants of GFP has been found to be even higher in an acidic environment (Greenbaum et al., 2000).

To check how much of the vesicular versus the plasma membrane spH-TEV pool is photobleached for the chosen experimental conditions pulses of acidic and high ammonium solution were applied before (figure 3.13a) and after (figure 3.13b) the bleaching protocol. These data show that bleaching of unquenched spH-TEV (reduction of fluorescence intensity during $\mathrm{pH} 5.5$ pulse) is about six-fold as effective as that of quenched vesicular spH-TEV (reduction of intensity during $\mathrm{NH}_{4} \mathrm{Cl}$ pulse) and is a good 
alternative method to selectively eliminate the fluorescence contribution of stranded $\mathrm{spH}$ TEV molecules.
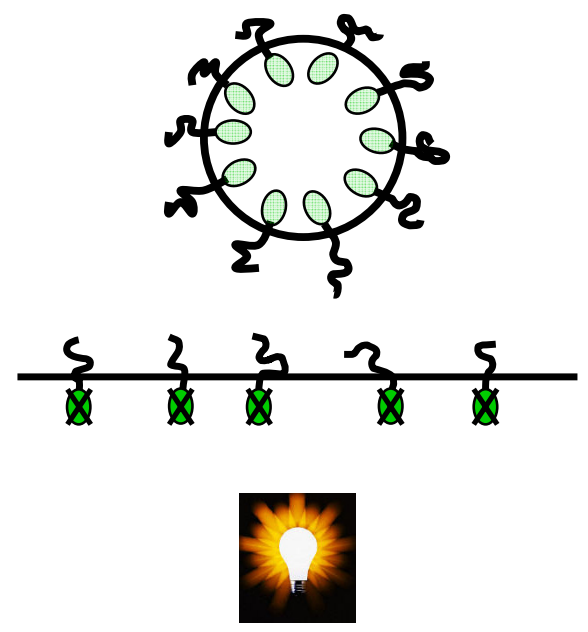

Figure 3.13 Selective photobleaching.

The fluorescence contribution of the spHTEV molecules in the plasma membrane is eliminated by photobleaching them. On the other hand, fluorophores inside the synaptic vesicles should be quenched by the acidic environment and thus protected from photobleaching.

a

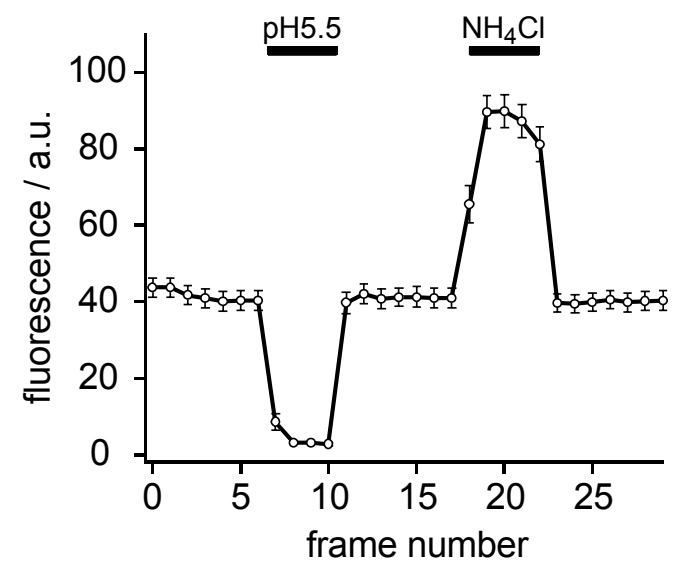

b

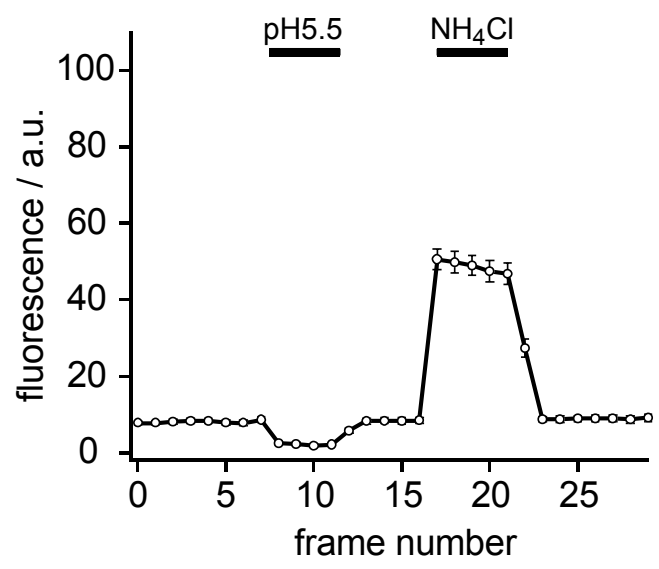

Figure 3.12 Plasma membrane stranded spH-TEV is photobleached 6-fold faster than the quenched vesicular spH-TEV.

Applying pulses of acidic and high ammonium solution before (a) and after (b) $90 \mathrm{~s}$ period of repeated laser scanning at high intensity shows that $82.8 \%$ of the unquenched plasma membrane spH-TEV pool but only $14.0 \%$ of the quenched vesicular spH-TEV pool are photobleached. Each frame is 2.9 s. Errors as SEM. 
a

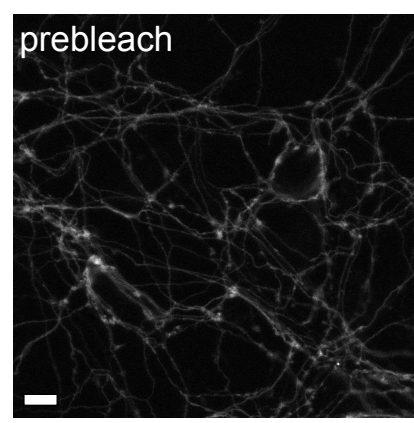

b

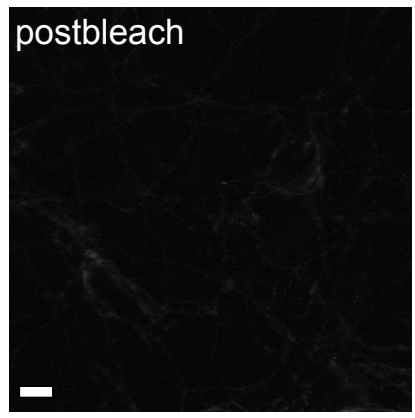

C
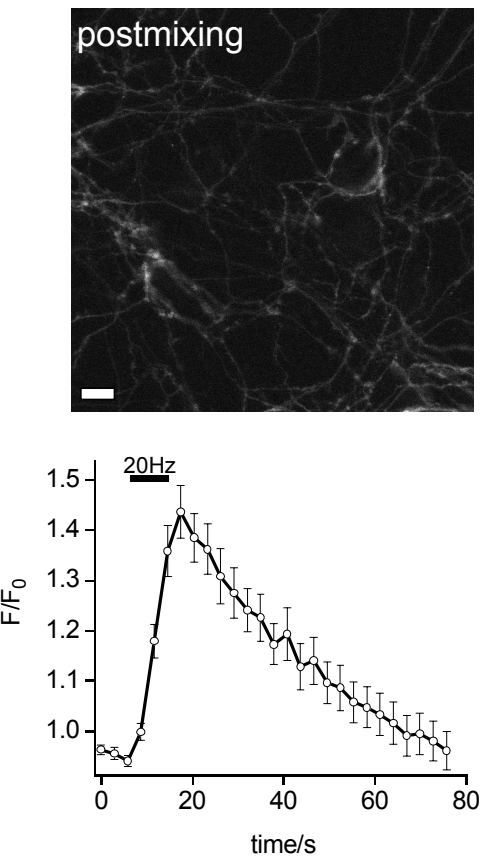

Figure 3.14 Non-identity is also observed post fast bleaching by repeated laser scanning.

a. Image of axonal arborizations expressing spH-TEV (top, Scale bar $10 \mu \mathrm{m}$ ). Prior to photobleaching fluorescence transients at boutons upon stimulation with 200 APs at $20 \mathrm{~Hz}$ show complete recovery (bottom).

b. Image of axonal arborizations shown in (a) but after selective photobleaching of the plasma membrane stranded spH-TEV pool by repetitive laser scanning at $488 \mathrm{~nm}$ for $90 \mathrm{~s}$ shows very little plasma membrane fluorescence (top, Scale bar $10 \mu \mathrm{m}$ ). Fluorescence transients of boutons upon stimulation with $200 \mathrm{APs}$ at $20 \mathrm{~Hz}$ display increased relative amplitudes, as expected, but recovery is incomplete (bottom).

c. Image of axonal arborizations of (b) after mixing vesicle and plasma membrane pools of spH-TEV with a prolonged train of action potentials $(800 \mathrm{APs}$ at $5 \mathrm{~Hz}$ ) shows again a significant fluorescence of PM stranded spH-TEV (top, Scale bar $10 \mu \mathrm{m}$ ). Fluorescence transients of boutons upon stimulation with 200 APs at $20 \mathrm{~Hz}$ display complete recovery again (bottom).

The results are the same as those obtained when cutting off the fluorophore by digestion, showing that neither the protease treatment nor the presence of the large pHluorin moiety affect synaptobrevin recycling or rates of endocytosis.

In a next step spH-TEV expressing boutons were stimulated with $200 \mathrm{APs}$ at $20 \mathrm{~Hz}$ preand postbleach as well as postmixing (with 800 APs at $5 \mathrm{~Hz}$ ). Qualitatively and quantitatively the same results were obtained as for digestion (cf. figure 3.14 and figure 
3.11). This demonstrates that neither the protease treatment nor the presence of the large pHluorin/GFP moiety affect synaptobrevin recycling or rates of endocytosis.

\subsubsection{Non-identity is also observed for synaptotagmin-I-TEV-pHluorin}

Is the observed non-identity of exo- and endocytosed vesicles with respect to synaptobrevin specific to this protein, or are other vesicle proteins also lost post fusion? To address this question, a chimera with pHluorin fused to the lumenal $\mathrm{N}$-terminus of synaptotagmin-1 (syt1) including a TEV-protease cleavage site (sytpH-TEV) was constructed (figure 3.15).

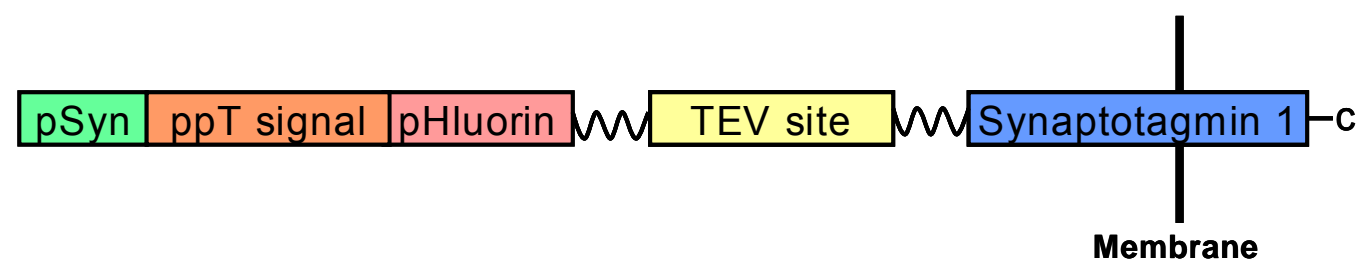

Figure 3.15 Schematic representation of the synaptotagmin 1-TEV-pHluorin construct, bearing a cleavage site for TEV protease on the luminal/extracellular domain. The construct is under control of the neuron specific promoter for synapsin (green) and has an $\mathrm{N}$-terminal signal sequence of preprotachykinin (ppT) for membrane insertion (see methods for details).

The sytpH-TEV chimera is properly targeted to presynaptic vesicles as electrical stimulation with $200 \mathrm{APs}$ at $20 \mathrm{~Hz}$ gave rise to stimulation-dependent fluorescence transients at synaptic boutons (figure 3.17) indistinguishable from spH-TEV responses (inset in figure 3.17d) and colocalized with other presynaptic vesicle proteins (figure 3.16). 

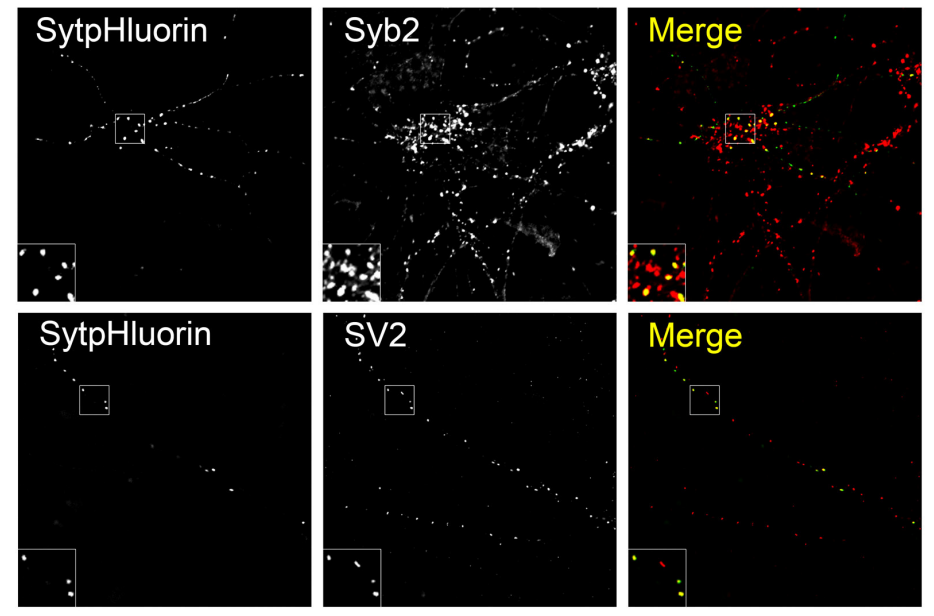

Figure 3.16 Syt-TEV-pHluorin is correctly targeted to presynaptic vesicle clusters.

Rat brain hippocampal neurons transfected with the sytpH-TEV construct were grown 14 days in vitro prior to fixation and immunostained against synaptic vesicle markers synaptobrevin 2 or SV2A (red). SytpHTEV colocalizes with the synaptic vesicle proteins synaptobrevin/VAMP2 and SV2A. Inset magnification $2 \mathrm{X}$. Image width is $50 \mu \mathrm{m}$.

Figure was kindly provided by Dr. Kasim Diril, Institut für Chemie und Biochemie, Freie-Universität-Berlin.

Like for spH-TEV, acid quenching and alkalinization of the vesicular lumen with ammonium revealed a stranded fraction of sytpH-TEV of about $25 \%$ (figure $3.17 \mathrm{~b}$ ). As shown in figure 3.17c the plasma membrane stranded sytpH-TEV can also be silenced by exposure to TEV protease. After 15 min of digestion stimulation with 200 APs at $20 \mathrm{~Hz}$ produced fluorescence transients that only partially recovered (figure 3.17d). After mixing stranded and vesicular pools with 800 APs at $5 \mathrm{~Hz}$, transients recovered again completely in the same set of boutons. For both spH-TEV and sytpH-TEV stranded pool sizes were similar and degrees of recovery postdigest were the same (figure $3.17 \mathrm{~d}$, see also figure 3.22) for a given stimulus paradigm (here $200 \mathrm{APs}$ at $20 \mathrm{~Hz}$ ). The observation that pHluorin labeled synaptobrevin 2 as well as synaptotagmin 1 get lost post fusion suggests that this effect might be a common feature of all vesicle protein species. 
a
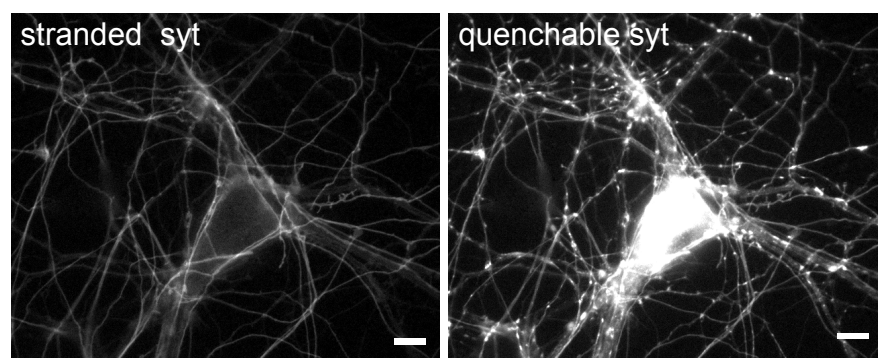

C

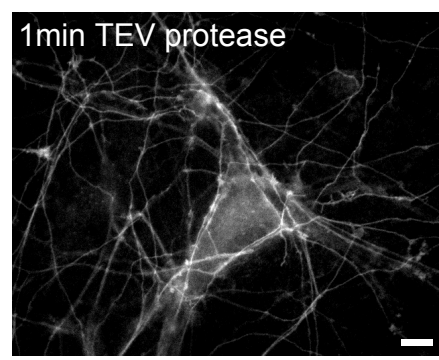

\section{5 min TEV protease}

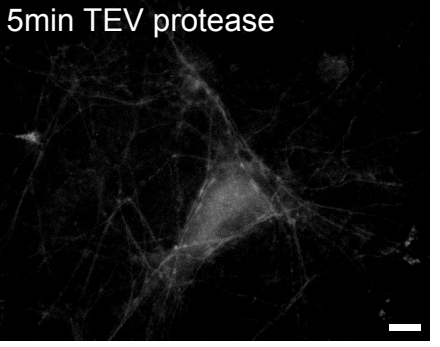

b
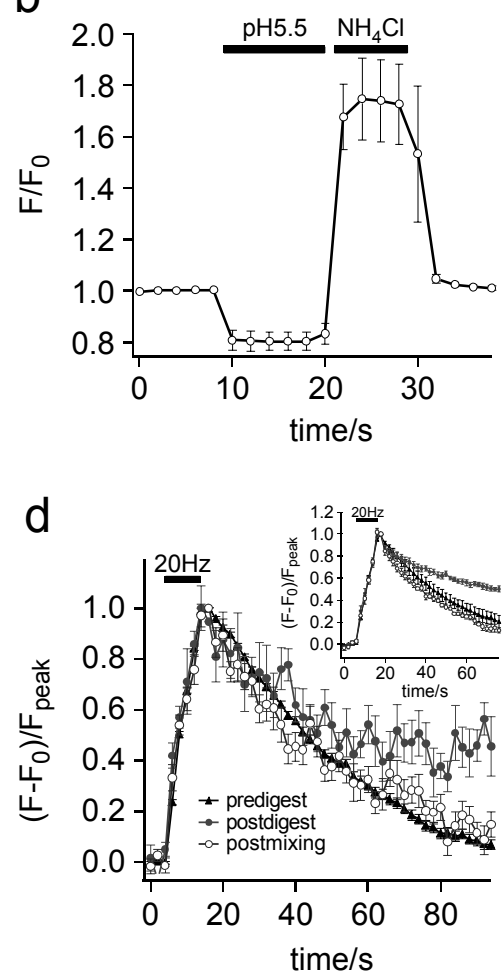

Figure 3.17 Loss of vesicle identity is also observed for synaptotagmin-I-TEV-pHluorin.

a. Images showing the plasma membrane stranded (left) and vesicular sytspH-TEV fluorescence distribution at axonal arborizations expressing sytpH-TEV. Images were computed by subtracting pictures before and during an acidic solution pulse and during and after a high ammonium solution pulse, respectively. Scale bars are $10 \mu \mathrm{m}$.

b. Fluorescence profiles of boutons during pulses of acidic $(\mathrm{pH} 5.5)$ and high ammonium solution. Similar to $\mathrm{spH}$-TEV chimera, $23.9 \% \pm 5.6 \%$ of molecules were sorted to the plasma membrane $(\mathrm{n}=3$ experiments, $>50$ boutons each, error as SEM).

c. Images of axonal arborizations shown in (a), after 1 and 5 min of TEV protease treatment at room temperature. Scale bars are $10 \mu \mathrm{m}$.

d. Normalized sytpH-TEV fluorescence transients of boutons (shown left) upon stimulation with 200 APs at $20 \mathrm{~Hz}$ pre-, postdigest, and postmixing reveal the same degree of incomplete recovery postdigest as $\mathrm{spH}-\mathrm{TEV}$ responses under the same conditions (inset). 


\subsubsection{Stranded pool size is under modulatory control and comprises $\sim 10 \%$ under native conditions}

Interactions between pairs of synaptic vesicle proteins can play a role in synaptic vesicle biogenesis (Thiele et al., 2000). Synaptobrevin/VAMP 2 is known to form a complex on the synaptic vesicle membrane with synaptophysin 1 (Calakos and Scheller, 1994). Therefore the change in stoichiometry of vesicular proteins by synaptobrevin (or $\mathrm{spH}$ ) overexpression might artificially introduce a membrane pool of 'missorted' synaptobrevins/spH (Pennuto et al., 2003). Thus, to control for a potential overexpression artifact, synaptopHluorin (spH-TEV) was cotransfected along with a fusion construct of synaptophysin 1 and monomeric red fluorescent protein, synaptophysin-mRFP (figure 3.18a). Synaptophysin-eGFP has successfully been used as a synaptic vesicle marker before (Kaether et al., 2000), so regions with overlapping green (spH-TEV) and red (synaptophysin-mRFP) fluorescence indicate the locations of presynaptic boutons. Cooverexpressing synaptophysin-mRFP did not abolish targeting of a significant fraction of spH-TEV to the plasma membrane, in fact it still displayed a diffuse component of distribution along the axonal plasma membrane (figure 3.18a, left). However, the increased level of synaptophysin resulted in an about three-fold change of the vesicular to plasma membrane distribution ratio (figure 3.18b) of spH-TEV, as assayed by application of pulses of acidic ( $\mathrm{pH}$ 5.5) and high ammonium solution.

Accordingly, relative amplitudes of fluorescence transients upon stimulation $\left(\mathrm{F} / \mathrm{F}_{0}\right)$ are increased (also about threefold), when coexpressing synaptophysin-mRFP (figure 3.18c, left). Both the absolute fluorescence intensity of synapses during $\mathrm{NH}_{4}$-application, a measure for the total expression level of spH-TEV, and the size of the absolute amplitudes after stimulation with 200 APs were not significantly changed when synaptophysin-mRFP was co-overexpressed (total expression level in a.u. \pm SEM; control: $1006 \pm 177$, plus synaptophysin: $905 \pm 156$; absolute amplitudes in a.u. \pm SEM; control: $127 \pm 32$, plus synaptophysin: $88 \pm 23 ; n=3$ experiments for control and 5 for synaptophysin coexpression with $>50$ boutons each). This suggests that the number of spH-TEV copies per vesicle is similar for both conditions. Normalized signals, however, reveal that the degree of recovery is slightly larger in the presence of synaptophysin-mRFP (figure 3.18c, right). 
a
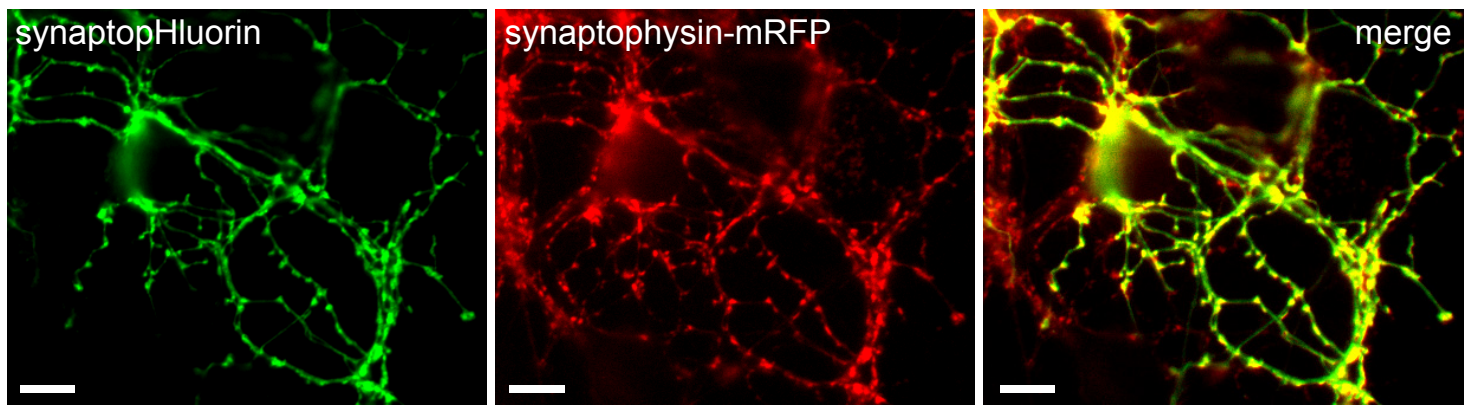

b

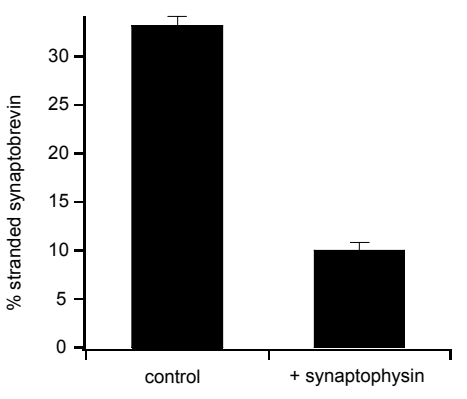

C
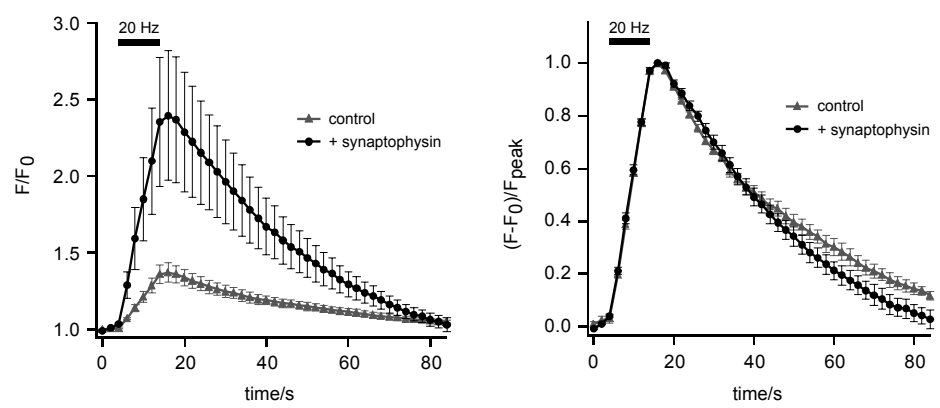

Figure 3.18 Stranded pool size is under modulatory control.

a. Images of axonal arborizations of living hippocampal neurons under resting conditions expressing spHTEV (left) along with synaptophysin-mRFP (middle) showing colocalization at presynaptic boutons (right). Scale bars are $10 \mu \mathrm{m}$.

b. Relative fluorescence intensities of $\mathrm{PM}$ stranded SpH-TEV at control boutons and those cooverexpressing synaptophysin-mRFP, determined by pulses of acidic $(\mathrm{pH} 5.5)$ and high ammonium solution ( $\mathrm{n}=3$ and 5 experiments, respectively; \% stranded spH-TEV \pm SEM: control $33.2 \pm 0.9$; +synaptophysin-mRFP $10.1 \pm 0.8 ; P<0.0001)$

c. Relative (left) and peak-normalized (right) spH-TEV fluorescence time courses at control boutons and those co-overexpressing synaptophysin-mRFP upon stimulation with 200 APs at $20 \mathrm{~Hz}$ ( $\mathrm{n}=3$ and 5 experiments, respectively; $>50$ boutons each, error as SEM).

Taken together, these data suggest, that the stoichiometry of proteins inside vesicles is preserved irrespective of the relative expression levels, i.e. only a certain number of 'slots' can be occupied by each protein species per vesicle. The relative concentration of vesicular proteins stranded in the bouton membrane, however, determines the efficiency of retrieval for a given protein species, ensuring maintenance of protein stoichiometry in endocytosed 
vesicles and thereby, probably, their fusion competence. This also identifies vesicle formation at the plasma membrane as an important sorting step in synaptic vesicle recycling.

These experiments indicate that overexpression of only one synaptic vesicle protein species leads to artificially increased pools of plasma membrane stranded proteins $(\sim 30 \%$ for spH-TEV) that can be, at least partially, rescued by coexpressing an interacting partner protein $(\sim 10 \%$ for spH-TEV + synaptophysin-mRFP). However, the existence of a pool of about $10 \%$ of all vesicular components at the bouton membrane may still be of high functional importance.

One possibility to assess sizes of vesicular and putative plasma stranded pools in the absence of any overexpression is to perform an immunostaining against the endogenously expressed proteins. To selectively stain the plasma membrane stranded pool of the vesicle proteins, an antibody is required that recognizes an epitope on the extracellular site of synaptic vesicle protein residing in the plasma membrane. While there are no antibodies available against the short extracellular domain of synaptobrevin 2 there is a polyclonal antibody against the ecto- or luminal domain of synaptotagmin 1.

Incubation of living neurons (non-permeabilized) with this antibody was performed at 4 ${ }^{\circ} \mathrm{C}$ in saline with $1 \mu \mathrm{M}$ TTX and without calcium to prevent staining of cycling vesicles. This protocol indeed yielded specific staining of synaptic boutons (figure 3.19, top), albeit with weak fluorescence intensities when compared to the signals obtained with the same primary and secondary antibodies after fixation and permeabilization (figure 3.20, bottom). Although antibody uptake by spontaneous activity in non-permeabilized cells during the staining procedure cannot be fully ruled out, the fluorescence intensity profiles along axons with specific staining also at interconnecting axon segments (note that the feeding glial cell layer is not stained) suggest that under native condition a measurable fraction (about $10 \%$ ) of vesicular proteins are stranded at the plasma membrane. 

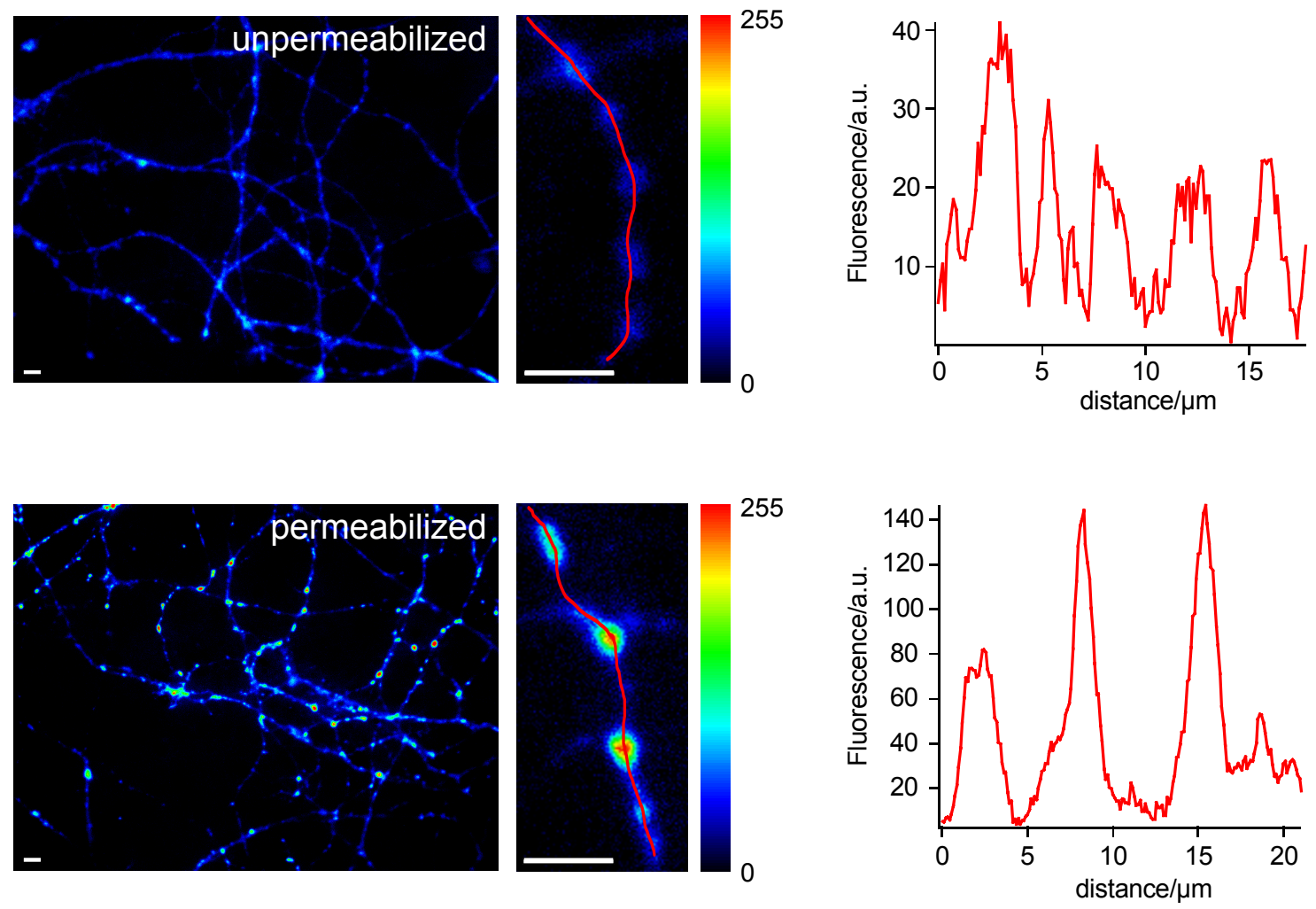

Figure 3.19 Stranded pool size comprises $\sim 10 \%$ under native conditions.

Images of axonal arborizations stained with antibodies against the ectodomain of synaptotagmin 1 without (left, top) and with (left, bottom) permeabilization (see Methods for details). Detail images for both conditions (middle) show punctate bouton staining. For non-permeabilized cells specific staining is also observed at the interconnecting axonal segments, better seen in the fluorescence intensity profiles (right) along the LOls shown as red solid lines in the detail images (middle). Fluorescence intensities at every position are integrated over a width (normal to the LOI) of three pixels. All scale bars are $5 \mu \mathrm{m}$.

\subsubsection{A 'readily retrievable pool' of vesicles?}

So far, the obtained data show that vesicular proteins are lost post fusion and diffuse away from sites of release. This raises the question whether vesicular proteins post fusion freely mix with the fraction of vesicular proteins stranded at the plasma membrane or whether one of the species, stranded or freshly exocytosed, is preferentially retrieved during compensatory endocytosis. The data indicate that in the latter case stranded vesicle 
proteins might constitute a 'readily retrievable pool' of partially pre-assembled structures that are preferentially and swiftly endocytosed upon exocytosis (figure 3.20).

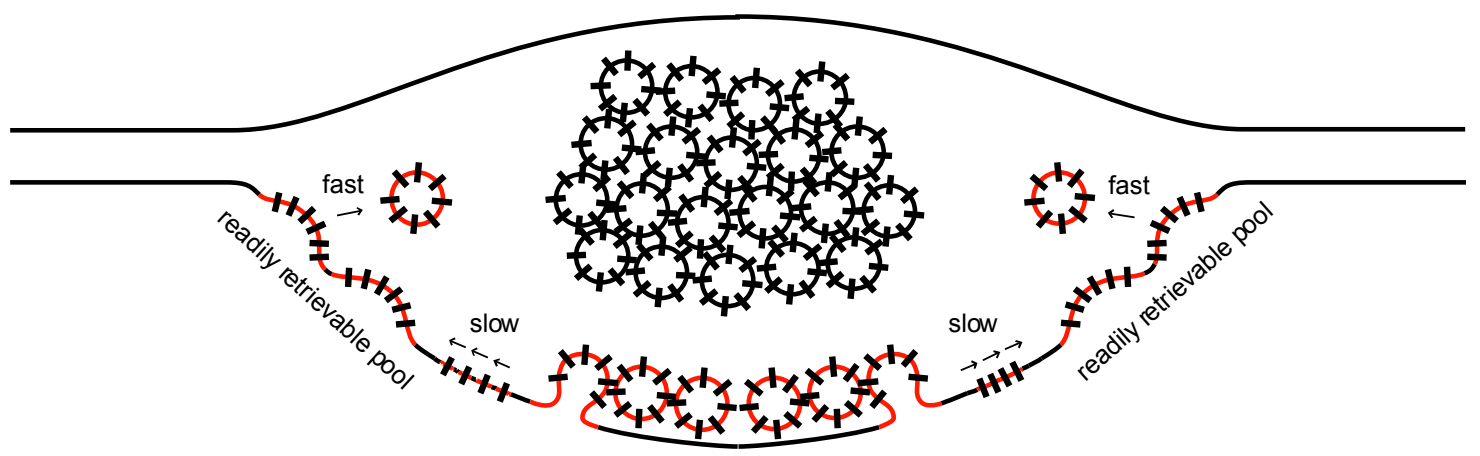

Figure 3.20 Schematic for spatial and temporal organization of exo- and endocytosis.

After exocytosis vesicle proteins have to be retrieved by compensatory endocytosis. Diffusion of exocytosed vesicle proteins as single entities (left) or as connected patches (right) to sites of endocytosis at the edge of the synapse and their recognition by adaptor proteins might be rate limiting. A readily retrievable pool of previously exocytosed vesicle components on the plasma membrane might be preferentially and quickly taken up.

To test this, boutons were stimulated with different numbers of APs after the protease treatment and the retrieval efficiencies of freshly exocytosed proteins were assessed by measuring relative recovery at a time point $58 \mathrm{~s}$ after stimulus end, when most endocytic activity has ceased, but errors due to focus or bouton drift or bleaching were still minimal (figure 3.22). Since for longer stimuli the fluorescence transients have not reached steady state level after this time interval, recoveries were plotted relative to the degree of recovery postmixing (800 APs at $20 \mathrm{~Hz}$ ). On the other hand the measured recovery postdigest, especially for weak stimuli (40APs), is critically depending on the size of the chosen region of interest (ROI) (figure 3.21). Fluorescence transients calculated based on small automatically selected ROIs around the center of an active synapse result in a rapid recovery directly after stimulus cessation, followed by a slow decay (figure 3.21a). The fast initial drop in fluorescence, however, disappears when the ROIs are dilated radially by one pixel $(204 \mathrm{~nm}$ ) (figure 3.21b), indicating that this fluorescence loss can be attributed to 
diffusion of released spH-TEV molecules out of the area of the initially small ROIs but not to quenching after very fast compensatory endocytosis and reacidification.

a

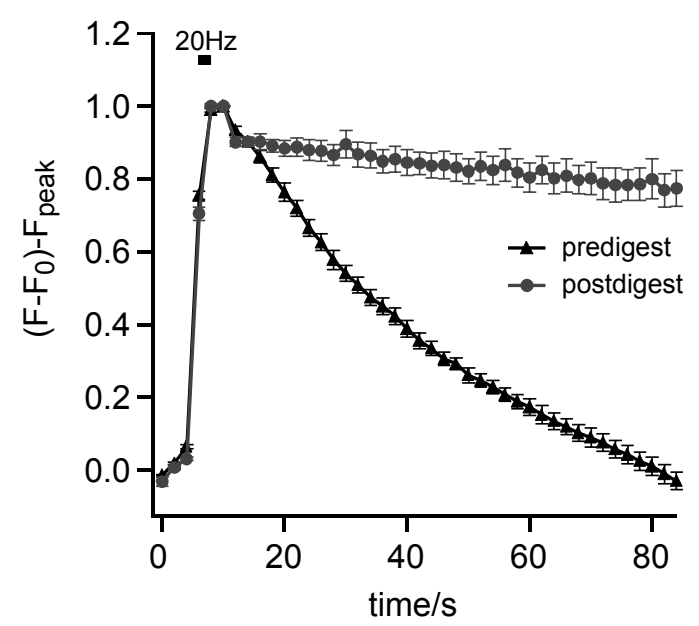

b

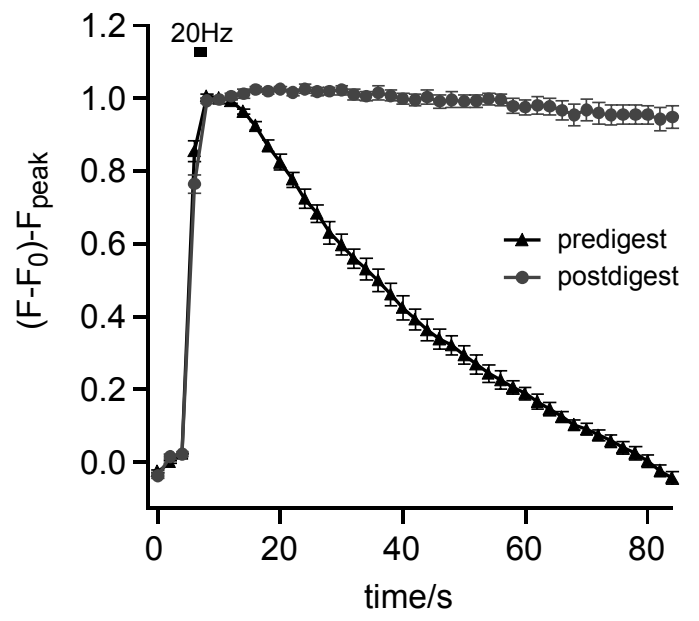

Figure 3.21 Small ROIs give rise to a recovery of the spH-TEV fluorescent signal that is due to diffusion but not to endocytosis.

a. Normalized sytpH-TEV fluorescence transients upon stimulation with $40 \mathrm{APs}$ at $20 \mathrm{~Hz}$ pre- and postdigest, analyzed with ROIs drawn close around active boutons.

b. Normalized sytpH-TEV fluorescence transients of boutons upon stimulation with 40 APs at $20 \mathrm{~Hz}$ preand postdigest with ROls used in (a) but radially dilated by one pixel $(204 \mathrm{~nm})$.

If stranded proteins were indeed preferentially retrieved, a plot of relative recovery versus the number of APs should intercept the abscissa at a number of APs different from zero. The number of vesicles exocytosed with the number of applied APs where such plot intercepts (no fluorescence recovery is observed after exocytosis) would be the size of the preferentially retrieved or readily retrievable pool. The measured relative recoveries favor the existence of a preferentially retrieved pool of stranded proteins. For 40 APs virtually no recovery postdigest was found (figure 3.21, inset in figure 3.22). The slight, slow downward trend of the signal is probably attributable to sources other than specific uptake by compensatory endocytosis, such as focus drift and bleaching. For a stimulus of 200 APs the measured relative recovery is the same, independent of the studied vesicle protein species (spH-TEV and syt-TEV-pH) and the method of fluorescent tag removal 
(bleaching and digest). The finding that relative recoveries plateau for high AP numbers (> 200 APs) shows that a maximum turnover of synaptic vesicles is reached and is in agreement with recent studies using synaptopHluorin (Fernandez-Alfonso and Ryan, 2004) or styryl dyes (Vanden Berghe and Klingauf, in press) to probe recycling.

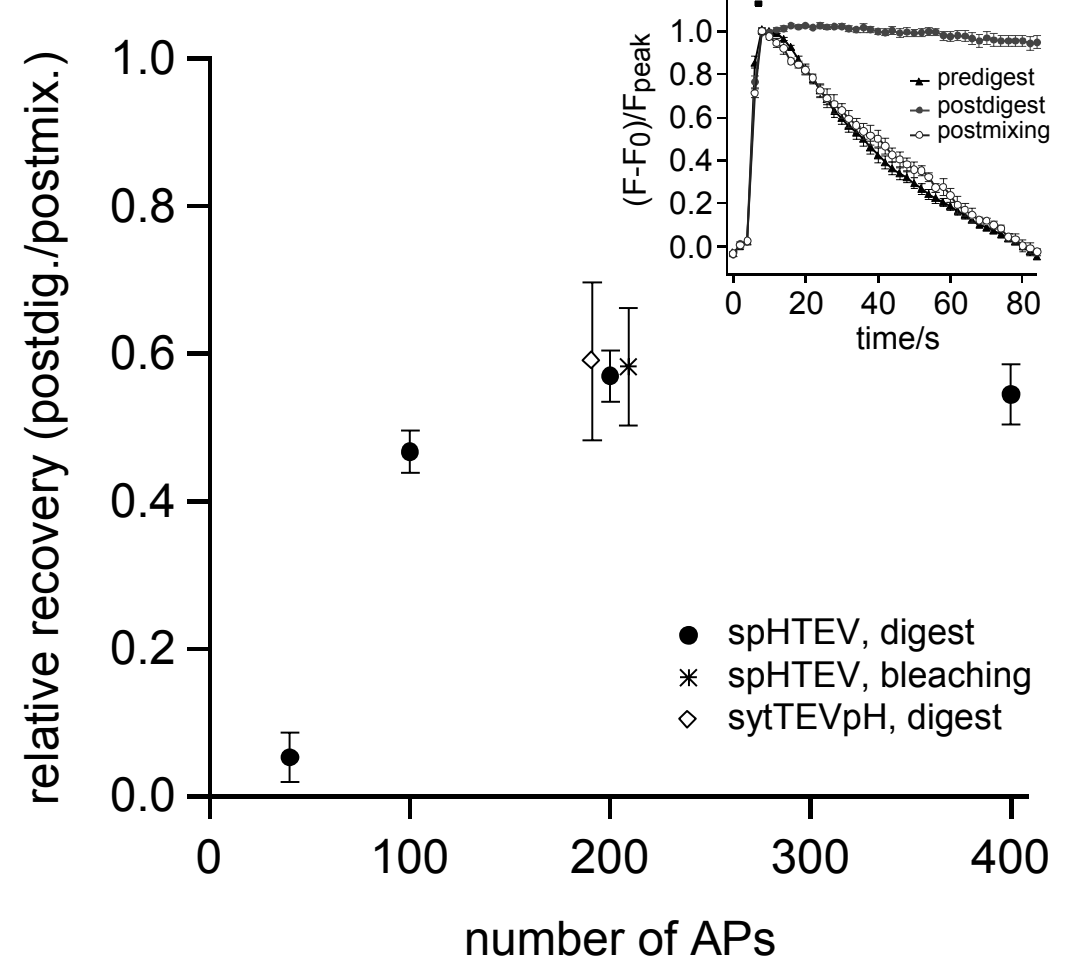

Figure 3.22 Stranded synaptic vesicle proteins are preferentially recycled.

Function of postdigest or postbleach relative recovery (i.e. relative to recovery postmixing at $t=58 \mathrm{~s}$ after stimulus end) of bouton fluorescence transients for spH-TEV and sytpH-TEV versus the number of APs applied. If stranded proteins were preferentially retrieved, this function should intercept the abscissa at a positive number of APs. The number of vesicles exocytosed with the number of APs where this function intercepts zero recovery yields the size of the preferentially retrieved or readily retrievable pool. The inset shows normalized responses to 40 APs at $20 \mathrm{~Hz}$ pre-, postdigest, and postmixing ( $\mathrm{n} \geq 3$ experiments for all conditions, errors as SEM). 


\subsection{Stonin 2 acts as an endocytic sorting adaptor which targets synaptotagmin to presynaptic recycling vesicles}

\subsubsection{Stonin 2 facilitates endocytosis of plasma membrane stranded syt 1 in synaptic boutons.}

In cultured primary hippocampal neurons synaptic vesicle proteins including synaptotagmin 1 undergo constitutive cycling between synaptic vesicles and the presynaptic plasma membrane. While many constitutively internalized cargo proteins are recognized directly by the clathrin adaptor complex AP-2, stimulation-dependent endocytosis of membrane proteins is often facilitated by specialized sorting adaptors. Although clathrin-mediated endocytosis appears to be a major pathway for presynaptic vesicle cycling, no sorting adaptor dedicated to endocytosis of synaptic vesicle membrane proteins has been indentified in mammals. The molecular mechanism of synaptotagmin 1 internalization thus remains obscure. In Drosophila, synaptotagmin 1 function is tightly linked to the expression of the stoned B gene product, a putative endocytic accessory protein expressed in the nervous system and enriched at presynaptic nerve terminals (Fergestad and Broadie, 2001; Stimson et al., 2001). Stonin 1 and 2 are the only mammalian orthologs of stoned B (Martina et al., 2001). Stonin 2 has been linked to clathrin-mediated endocytosis by its interactions with AP-2 (Walther et al., 2004), the endocytic accessory proteins eps15 and intersectin (Martina et al., 2001). Binding of stonin 2 to AP-2 is largely mediated by interactions between its WVxF motifs and the $\beta$-sandwich domain of the $\alpha$-adaptin appendage as well as indirect associations bridged by eps15 and perhaps other eps15-homology (EH) domain (Polo et al., 2003) containing molecules. However, the relationship between stonin 2 function in clathrin-dependent endocytosis and synaptotagmin internalization has not been explored. This is partly due to the problem that so far a tool to directly study synaptotagmin 1 recycling in living neurons was lacking. Therefore, in order to quantitatively assess the partitioning of synaptotagmin 1 between vesicular and plasmalemmal pools and to explore its possible modulation by stonin 2, the previously described chimeric reporter protein sytpHluorin (figure 3.15, figure 3.23a) was used. 

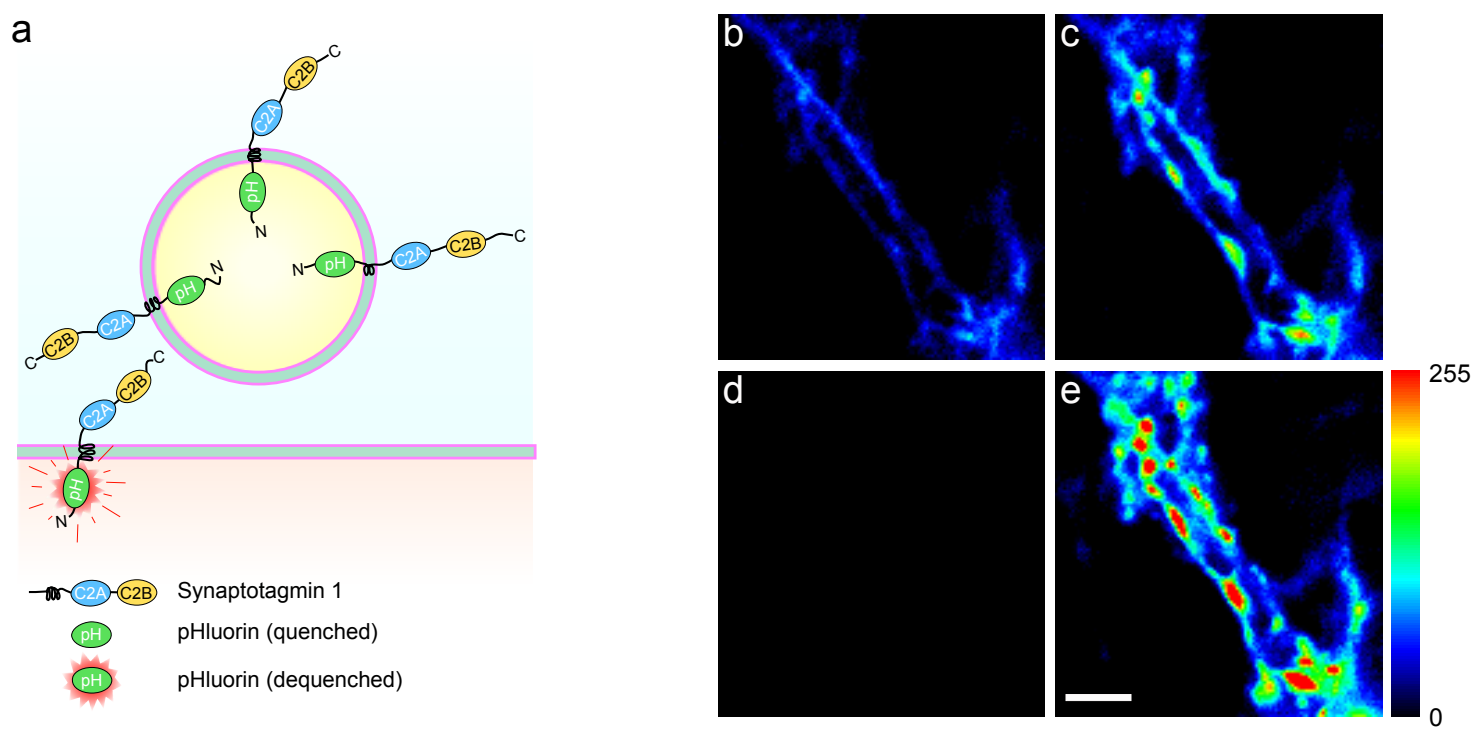

Figure 3.23 sytpHluorin serves as a faithful reporter of synaptotagmin 1 recycling at presynaptic nerve terminals.

a. Schematic illustrates how sytpHluorin can be used to probe synaptotagmin 1 localization: its fluorescence is quenched in the acidic vesicular lumen, but not when residing in the plasmalemma.

b.-e. SytpHluorin fluorescence before (b) and immediately after (c) stimulation with $200 \mathrm{APs}$ at $20 \mathrm{~Hz}$. Challenge with acidic solution results in fluorescence quenching (d) whereas alkalinization with $\mathrm{NH}_{4} \mathrm{Cl}$ produces maximum fluorescence (e). Scale bar $5 \mu \mathrm{m}$. Fluorescence values are color-coded according to the depicted scale.

The sytpHluorin chimera is properly targeted to presynaptic vesicles (figure 3.23, b and c) as electrical stimulation with 200 action potentials (APs) at $20 \mathrm{~Hz}$ gave rise to stimulationdependent sytpHluorin fluorescence increase at synaptic boutons with similar characteristics as described before for pHluorin-tagged synaptobrevin (Miesenbock et al., 1998; Sankaranarayanan and Ryan, 2000). The pH-dependence of the fluorescence makes it possible to monitor the effect of stonin 2 on sytpHluorin distribution within the presynaptic compartment (figure 3.23) of living neurons using a simple acid quenchingdequenching protocol, as introduced earlier (figure 3.17b). Acid quenching resulted in a nearly complete loss of fluorescence (figure 3.23d) whereas alkalinization of the vesicular lumen with $\mathrm{NH}_{4} \mathrm{Cl}$ produced a maximum intensity signal at synaptic boutons (figure 3.23e), indicating that the transient fluorescence increase following stimulation was due to 
exocytotic externalization of sytpHluorin. Together with the colocalization of sytpHluorin with other presynaptic vesicle proteins (see figure 3.16) and the kinetics of sytpHluorin exo-endocytosis (figure 3.24b and c), these data indicate that sytpHluorin can serve as a faithful reporter of synaptotagmin 1 recycling at presynaptic nerve terminals. Therefore the next step was to assess the effect of stonin 2 on synaptotagmin 1 recycling in living neurons both at steady state and under stimulating conditions.

Fluorescence analysis following acid quenching-dequenching revealed that under resting conditions co-expression of wild-type stonin 2 significantly decreased the relative steadystate plasmalemmal fraction of sytpHluorin at presynaptic boutons resulting in a nearly twofold increase of the vesicular-to-surface-stranded pool ratio (figure 3.24a). Conversely, a stonin 2 point mutant lacking the ability to bind to either AP-2 or eps15 and intersectin (Stonin $2^{\triangle \mathrm{WF} \triangle \mathrm{NPF}}$ ) exhibited a dominant-negative phenotype leading to increased surface levels of our reporter protein (figure 3.24a). This mutant had no effect on internalization of transferrin or AP-2 distribution when expressed in fibroblasts (Diril et al., 2006, in press). Stimulation of neurons with $200 \mathrm{APs}$ at $20 \mathrm{~Hz}$ produced a transient fluorescence increase followed by a decline reflecting sytpHluorin endocytosis (figure 3.24b). Due to a different contribution of the unquenched plasma membrane pool of sytpHluorin to $\mathrm{F}_{0}$ fluorescence intensity, depending on the presence of stonin 2 or the dominant-negative mutant, the amplitudes of these fluorescence changes significantly differed from each other. The largest increase was seen for wild-type stonin 2 , whereas stonin $2^{\Delta \mathrm{WF} \Delta \mathrm{NPF}}$ displayed a decrease in amplitude compared to controls (figure 3.24b). The different observed steady state levels might be a consequence of small differences in retrieval efficiency of exocytosed synaptotagmins (as seen at the end of the recordings), accumulated during several days (6-9 days post transfection) of ongoing synaptic activity. 

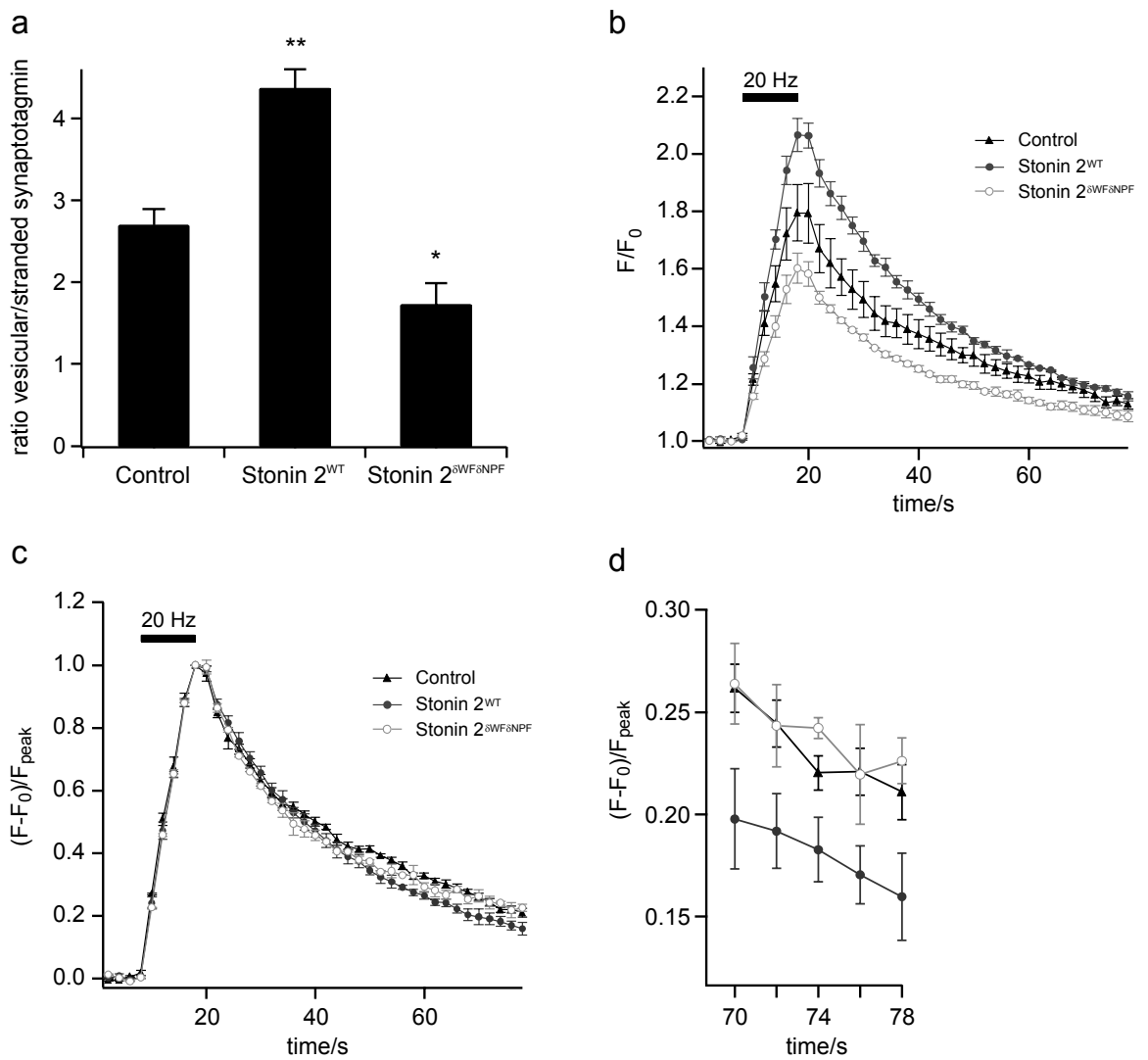

Figure 3.24 Stonin 2 targets synaptotagmin 1-pHluorin (sytpH) to recycling vesicles in primary hippocampal neurons.

a. Based on the relative fluorescence values measured before and after acid quenching-dequenching the vesicular-to-surface-stranded pool ratios of sytpH were calculated and plotted \pm SEM (Control: $2.69 \pm$ 0.20 ; Stonin $2^{\mathrm{WT}}: 4.37 \pm 0.23$; Stonin $2^{\triangle \mathrm{WF} \Delta \mathrm{NPF}}: 1.72 \pm 0.26 ;{ }^{*} p<0.01$; ${ }^{* *} p<0.05$ ). Expression of wildtype stonin 2 results in a significant increase whereas stonin $2^{\triangle \mathrm{WF} \triangle \mathrm{NPF}}$ produces a decrease in the vesicular-tosurface pool ratio.

b. Time course of sytpHluorin fluorescence ratios $\left(F / F_{0} \pm S E M\right)$ following stimulation with 200 APs at 20 $\mathrm{Hz}$. The bar indicates the stimulation period (10 s). Peak values \pm SEM are for control $1.80 \pm 0.10$; stonin $2^{\mathrm{WT}}: 2.07 \pm 0.06$ ( $p<0.03$ vs. control); stonin $2^{\mathrm{AWF} \Delta \mathrm{NPF}}: 1.60 \pm 0.05 ;\left(p<0.01\right.$ vs. stonin $\left.2^{\mathrm{WT}}\right)$.

c. Time course of sytpHluorin fluorescence ratios $\left(F / F_{0} \pm S E M\right)$ as in (b), but normalized with respect to peak amplitudes $\left(F_{\text {peak }}\right)$, reveals no differences in kinetics, however small differences in retrieval efficiency. Data are a subset of those in (b); only recordings with a signal-to-noise ratio $>50$ (measured as peak amplitude over the standard deviation of the baseline) have been included to better resolve the decay characteristics of the responses.

d. Detail of (c), documenting differences in the retrieval efficiencies at $t=78 \mathrm{~s}(\% \pm \mathrm{SEM})$ : for control 78.9 \pm 0.01 ; stonin $2^{\mathrm{WT}}: 84.0 \pm 0.02$ ( $p<0.06$ vs. control); stonin $2^{\text {סWFöNPF. }} 77.4 \pm 0.01\left(p<0.05\right.$ vs. stonin $\left.2^{W T}\right)$. Retrieval efficiency is defined as $\left(1-\left[\left(F-F_{0}\right) / F_{\text {peak }}\right]\right) \times 100$. 
In an attempt to resolve such expectedly small differences in retrieval after 200 APs the sytpHluorin responses were reanalyzed, restricting analysis to those boutons that gave signals with good signal-to-noise ratios $(>50$, measured as peak signals over standard deviation of the baseline). When normalizing these responses, indeed, small differences in retrieval efficiency can be observed. The degree of retrieval is slightly less for wildtype $(p<0.06)$ and the dominant-negative mutant $(p<0.05)$ (figure 3.24c and $d)$, and therefore might indeed be the cause of the differences in the resting vesicular-to-surface-stranded pool ratios of sytpHluorin shown in figure 3.24a.

The time course of individual endocytic events, however, remained remarkably unchanged (figure 3.24c), suggesting that sytpHluorin was retrieved by similar molecular mechanisms in all samples and that targeting of synaptotagmin 1 to clathrin-coated pits is not ratelimiting for the budding, scission, and reacidification reactions of individual vesicles.

These combined data suggest that stonin 2 acts as an endocytic sorting adaptor which targets synaptotagmin to presynaptic recycling vesicles in the brain.

Together with the data obtained by the laboratory of Prof. Haucke (Institut für Chemie und Biochemie, Freie-Universität-Berlin) we could identify stonin 2 as an AP-2-dependent endocytic sorting adaptor for synaptotagmin internalization and recycling and develop a possible model for the function of stonin 2 (Diril et al., 2006, in press) that is illustrated in figure 3.25: Stonin 2 may bind via its $\mu$-homology domain to plasma-membrane stranded synaptotagmin 1 oligomers (shown on top). The WVxF motif mediates interactions with the ear domain of AP- $2 \alpha$ and aids in recruitment of the synaptotagmin-stonin 2 complex to the membrane-bound AP-2 heterotetramers (shown in middle panel). The clathrin/AP2 mediated synaptotagmin internalization might then be driven either by a multimeric synaptotagmin-stonin2-AP-2 complex (shown on bottom, I) or via a sequential mode involving stonin 2 -mediated delivery of synaptotagmin to AP- $2 \mu$ (bottom, II). 

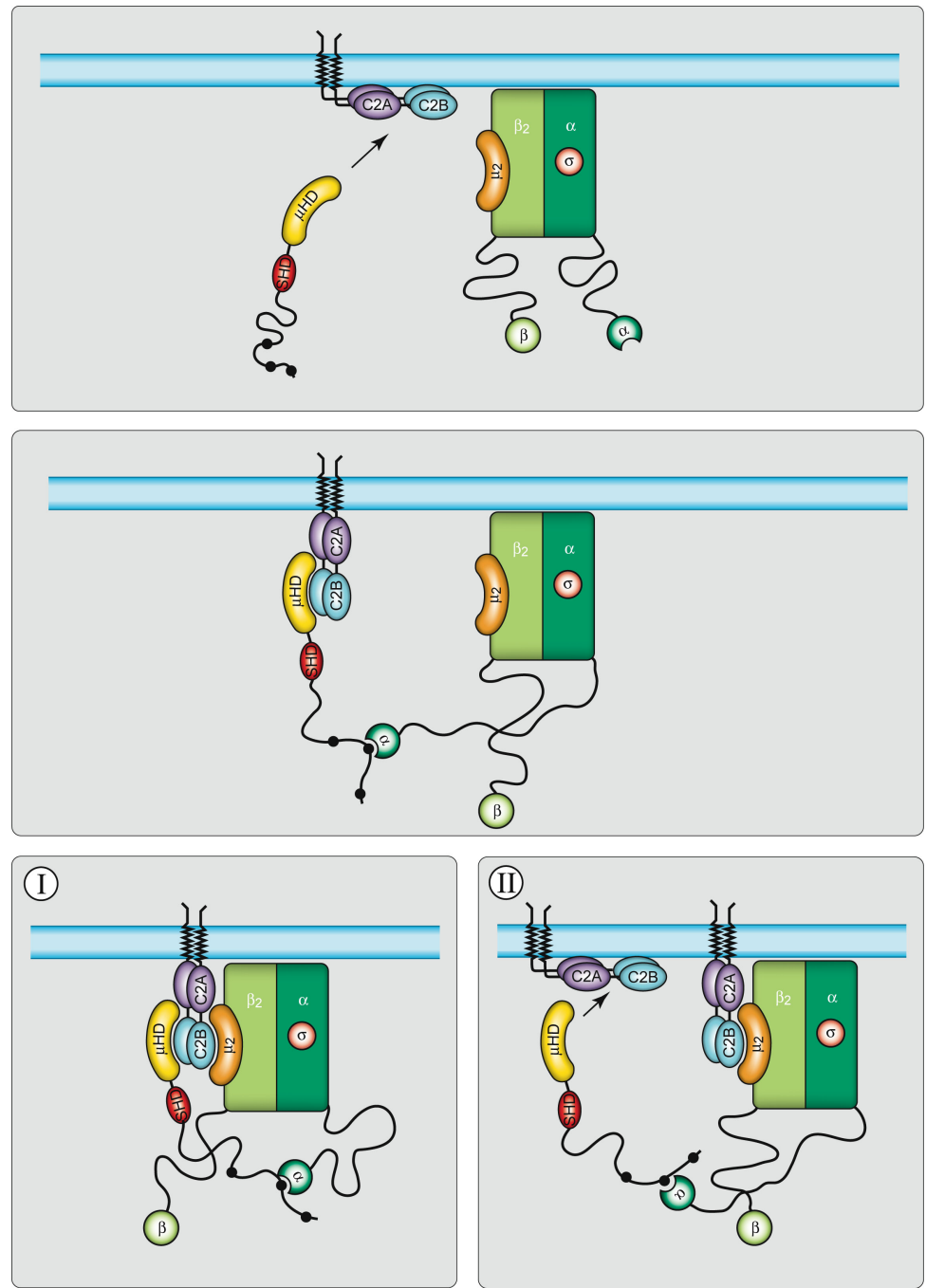

Figure 3.25 Hypothetical model for how stonin 2 and AP-2 may cooperate in synaptotagmin internalization. For details, see text.

\subsubsection{In stonin 2 knock-out mice the function of stonin 2 as specific adaptor for syt}

\section{1 is better seen}

The results of the previous chapter identify stonin 2 as endocytic sorting adaptor for synaptotagmin 1. While the conclusions drawn were based on experiments performed in neuronal cultures overexpressing stonin 2 or a dominant negative mutant, it would be interesting to see the effect of stonin 2 on synaptotagmin 1 recycling in a more physiological model system. To this end, a similar set of experiments was performed using 
sytpHluorin as a fluorescent reporter to compare its recycling in neurons from wild-type versus knock-out animals lacking the gene for stonin 2. The use of stonin 2 knock-out animals has three main advantages: First, one can study the effect of stonin 2 expressed at physiological levels by comparison with a stonin 2 null background. Second, a null background represents a better control than overexpressing a non-functional mutant in wild-type cultures because of the absence of endogenously expressed stonin 2 that might partially compensate or mask a recycling defect and the risk that the mutant protein interferes with other endocytic pathways is eliminated. Third, the specificity of the system can be tested by expressing stonin 2 on the null background of knock-out animals to examine its ability to rescue a possible alteration in synaptotagmin 1 recycling.

Stonin 2 knock-out mice were obtained from the lab of Prof. Volker Haucke (Institut für Chemie und Biochemie, Freie-Universität-Berlin) and their preliminary analysis of the animals showed that stonin 2 knock-out mice were viable and fertile. They showed no noticeable physical or behavioral abnormalities and the stonin 2 deficiency did not cause any major changes in the levels of other synaptic proteins. As suggested by the data of the previous chapter, one possible effect of stonin 2 deficiencies in the mice could be the presence of increased quantities of synaptotagmin 1 stranded on the presynaptic plasma membrane. However, in vitro analysis of distributions of synaptotagmin 1 together with other endocytic and presynaptic proteins in different membrane fractions obtained from the brains of wild-type and knock-out animals did not show any significant changes. Biochemical experiments may however not be sensitive enough to detect minor alterations in synaptotagmin 1 localization. Indeed, using the sytpHluorin construct as a probe, significant increase in the fraction of plasma membrane stranded synaptotagmin 1 could be detected. 
a

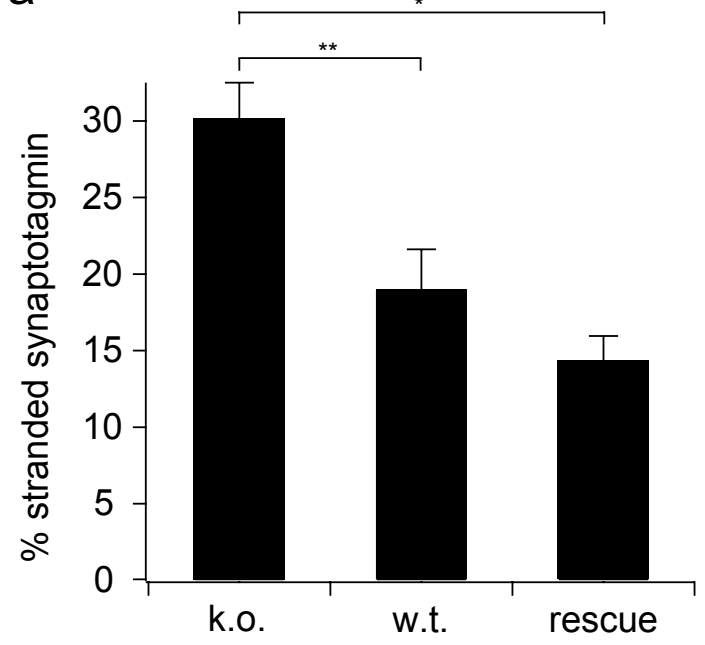

b

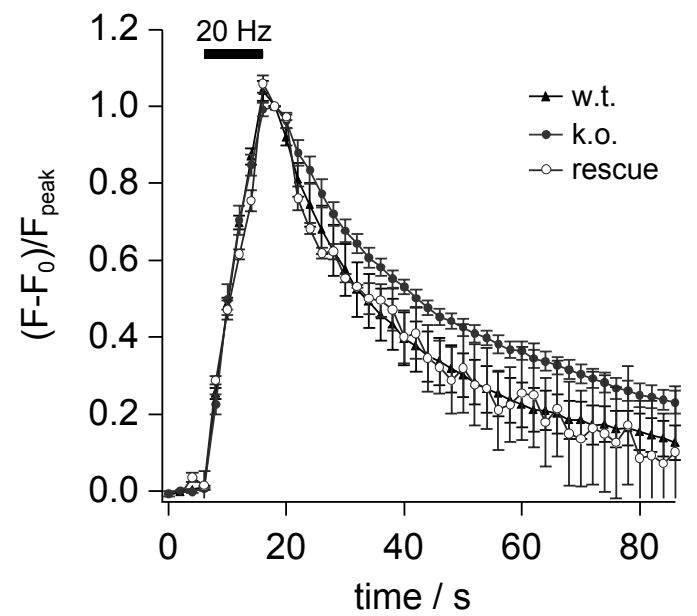

Figure 3.26 SytpHluorin surface levels and retrieval efficiencies in stonin 2 knock-out mice.

a. Based on the relative fluorescence values measured before and after acid quenching-dequenching the relative fractions of surface-stranded sytpHluorin were calculated and plotted as $\% \pm$ SEM (k.o.: $30.1 \pm$ 2.3; w.t: $18.9 \pm 2.6$; rescue: $14.3 \pm 1.6$; ${ }^{*} p<0.05$; ${ }^{* *} p<0.01$ ). Stonin 2 k.o. mice show a significant increase in the relative size of the stranded pool. The wild type phenotype can be restored by transfecting k.o. neurons with a stonin 2 w.t. construct.

b. Time course of normalized sytpHluorin fluorescence ratios \pm SEM following stimulation with $200 \mathrm{APs}$ at $20 \mathrm{~Hz}$. Retrieval efficiencies at $\mathrm{t}=86 \mathrm{~s}$ ( $\% \pm$ SEM): for w.t. $87.3 \pm 4.5$; k.0.: $77.0 \pm 2.9$ ( $p<0.06$ vs. w.t.); rescue: $89.9 \pm 16.9 ; n \geq 3$ experiments for all data. Small differences in the retrieval efficiencies could account for the effect shown in (a).

An acid quenching-dequenching protocol (see figure 3.17b) revealed that in mice lacking stonin 2 the plasmalemmal fraction of sytpHluorin is about one third higher than in wildtype littermates (figure 3.26a) under resting conditions. Furthermore, expression of wildtype stonin 2 in cultures from knock-out animals significantly decreased the relative steady-state plasmalemmal fraction of sytpHluorin at presynaptic boutons to a level that was statistically indistinguishable from wild-type animals.

In agreement with these findings, normalized sytpHluorin-responses after stimulation with $200 \mathrm{APs}$ at $20 \mathrm{~Hz}$ showed small differences in retrieval efficiency observed at the end of the transients in figure 3.26d. The degree of retrieval is slightly less for knock-out compared to wild-type littermates $(\mathrm{p}<0.06)$ and this difference can be rescued by 
expressing stonin 2 on the null background. These findings are in good qualitative and quantitative agreement with the data obtained by the overexpression studies presented in figure 3.24, and the small differences in retrieval efficiencies could be better detected with the null genetic background. This result confirms the previous interpretation that small differences in retrieval efficiencies can account for significant changes in steady state levels of plasma membrane stranded synaptotagmin by accumulation effect over time. 


\section{Discussion}

\subsection{Vesicular proteins exocytosed and subsequently retrieved by compensatory endocytosis are non-identical}

In the first part of this thesis, it was tested whether synaptic vesicles loose their identity with respect to their protein composition during stimulus-evoked exo-endocysis using a fusion construct of the vSNARE synaptobrevin with pHluorin, a $\mathrm{pH}$-sensitve GFP variant (synaptopHluorin). A TEV-protease cleavage site was introduced between both moieties accessible only if spH-TEV is in the plasma membrane. It was found that mostly digested molecules are recycled during compensatory endocytosis, i.e. $\mathrm{spH}$ deposited on the plasma membrane prior to digestion. The same results were obtained when using a pHluorintagged version of synaptotagmin 1. This indicates that for one round of stimulation a different set of vesicle proteins is retrieved than exocytosed and suggests that recycling synaptic vesicles loose their protein complement in between exo- and endocytosis. In addition, this finding implies that a sorting step either during and/or after endocyosis (i.e. by an endosome) is essential to equip a recycling vesicle with the necessary proteins (figures 3.5 - 3.10). While overexpression of or cotransfection with synaptophysin-mRFP affects spH-TEV targeting to the plasma membrane (figure 3.18), under native conditions there also appears to be a functional pool of stranded synaptic vesicle components (figure 3.19) from which new vesicles are retrieved preferentially (figure 3.22). Since the large pHluorin moiety does not affect vSNARE recycling or rates of endocytosis, this preferential endocytosis of stranded vesicle proteins cannot be attributed to sterical hindrance (figure 3.14).

\subsubsection{Plasma membrane stranded synaptic vesicle proteins}

Exo-endocytic cycling implies that vesicle proteins are incorporated into the presynaptic plasma membrane for a more or less extended time. This study shows that even at rest a significant fraction of two GFP-labeled synaptic vesicle proteins, synaptobrevin 2/ VAMP 2 and synaptotagmin 1 , is found on the plasma membrane when expressed in cultured hippocampal neurons (figure 3.3; figure 3.17). Furthermore, it could be demonstrated that 
the plasma membrane pool of these proteins actively participates in vesicle recycling during stimulation and vesicle proteins from it are even preferentially retrieved (figure $3.22)$.

The origin of this surface population is still unclear but its existence is in agreement with previous studies expressing synaptobrevin 2 / VAMP 2 in hippocampal neurons and was interpreted as either a result of small inefficiencies during retrieval ( $\mathrm{Li}$ and Murthy, 2001; Sankaranarayanan and Ryan, 2000) or ectopic recycling during synaptogenesis (Ahmari et al., 2000; Sampo et al., 2003). The idea that the delivery of synaptic vesicle proteins to the plasma membrane is important during development has also been proposed for synaptotagmin 1 (Matteoli et al., 1992). It might be that this constitutive exo-endocytic cycling of vesicle proteins is also required for functional maintenance of mature synapses, and this could explain the observed diffuse distribution of synaptobrevin 2 / VAMP 2 and synaptotagmin 1 along the axonal membrane.

Another reason for an increased pool of plasma membrane stranded vesicle proteins could be a changed stoichiometry after overexpression of only one component. Synaptobrevin/VAMP 2 forms a complex with synaptophysin 1 on the synaptic vesicle membrane (Calakos and Scheller, 1994) and it has been suggested that the presence of both proteins in similar amounts is necessary for efficient targeting of VAMP 2 / synaptobrevin 2 to synaptic vesicles (Pennuto et al., 2003). Comparable results were obtained in this thesis by finding that co-overexpressing synaptophysin 1 reduces the presynaptic plasma membrane stranded pool of spH threefold (figure 3.18). However, this study could show that coexpression of synaptophysin 1 had neither a significant effect on the total expression level of $\mathrm{spH}$ nor on the number of $\mathrm{spH}$ molecules per vesicle as revealed by the unaltered total fluorescence contents and the unaltered absolute $\mathrm{spH}$ amplitudes of $\mathrm{spH}$ following stimulation. Also, the time course of endocytosis is unchanged for both conditions and only a slight reduction in retrieval efficiency could be detected when $\mathrm{spH}$ is overexpressed alone (figure 3.18c). Taken together, these data reveal that the physiological functionality of synaptic vesicle recycling is not affected by the existence of an artificially increased plasma membrane pool of a vesicle protein. The finding that small differences in retrieval efficiencies can lead to significant changes in the steady state levels of the vesicular/membrane distribution ratio is in good agreement with 
the results regarding stonin 2 function in synaptotagmin 1 endocytosis (cf. figures18, 24 and 26).

Interestingly, in contrast to the ubiquitous distribution of VAMP 2 / synaptobrevin 2 and synaptotagmin 1 a GFP-tagged version of synaptophysin 1 expressed in hippocampal cultures shows a staining that is rather restricted to synaptic specializations (own observations and (Sampo et al., 2003)). An explanation for this could be that synaptophysin 1 has a synaptic vesicle targeting signal that is more efficient than that of synaptobrevin 2 / VAMP 2 (Grote and Kelly, 1996). In addition, synaptophysin 1 is known to bind cholesterol. This might mediate the formation of membrane domains enriched in synaptic vesicle constituents (Thiele et al., 2000), and hence be important for the retrieval process of synaptobrevin 2 / VAMP 2. Such interaction could be the molecular explanation for the finding that adjusting the expression levels of synaptophysin 1 to those of $\mathrm{spH}$ leads to a reduction of the number of plasma membrane-stranded $\mathrm{spH}$ molecules (figure 3.18).

The existence of a plasma membrane pool of synaptic vesicle proteins under physiological, i.e. not overexpressed, conditions is still a matter of debate and answers may vary depending on the studied protein species and the respective model system. The findings of this study estimate the fraction of plasma membrane stranded synaptotagmin 1 to be less than $10 \%$ in hippocampal cultures under native conditions (figure 3.19). It should be mentioned, however, that the confidence of this estimate is limited by antibody specificity and possibly different epitope affinities in non-permeabilizing compared to permeabilizing conditions. Selective immunolabeling of plasma membrane stranded VAMP 2 / synaptobrevin 2 on living cells is not possible since no antibody against the short lumenal C-terminus exists. To overcome this problem one could immunolabel the total pool of VAMP 2 / synaptobrevin 2 with an antibody directed against the cytoplasmic domain under permeabilizing conditions and then study its subcellular distribution by electronmicroscopy. Such immunogold labelings have been performed on nerve endings of the Torpedo electric organ and it has been estimated that VAMP / synaptobrevin is present in the synaptic membrane at a density that is only three times lower then in synaptic vesicles under resting conditions (Taubenblatt et al., 1999). In contrast, no immunolabeling of 
synaptophysin 1 in the presynaptic membrane of frog neuromuscular junctions could be detected under resting conditions, neither on a light- (Valtorta et al., 1988) nor on an electronmicroscopic (Torri-Tarelli et al., 1990) level.

Conversely, the plasma membrane-located target-SNARE proteins syntaxin-1 and SNAP25 were found in purified synaptic vesicles and have been estimated to compromise about $3 \%$ of the total vesicular protein content (Walch-Solimena et al., 1995). This also suggests that the molecular identity of the two membranes is not maintained during synaptic activity. However, it is not clear whether the target-SNAREs located in vesicles actively participate in exo-endocytic recycling (Mitchell and Ryan, 2004).

\subsubsection{A readily-retrievable pool of vesicles?}

The stranded pool of preferentially retrieved vSNARES was depleted by stimuli of more than $40 \mathrm{APs}$ (figure 3.22). Interestingly, a stimulus of $40 \mathrm{APs}$ at $20 \mathrm{~Hz}$ has been shown to also deplete the readily releasable pool of docked vesicles, comprising about 5-10 vesicles (Murthy and Stevens, 1999; Schikorski and Stevens, 1997). Thus, the readily releasable pool of vesicles may be counterbalanced by a 'readily retrievable pool' of preassembled endocytic structures (figure 3.20). Results from synaptophysin co-overexpression experiments, however, argue that the size of the stranded pool of vSNARES is highly overestimated in our measurements relying on overexpression of spH-TEV or sytpHTEV. On the other hand, the 'stranded' pool size measured with acidic and ammonium solution pulses (figure 3.18) may not be identical to the 'functional' retrievable pool size measured by determining the stimulus yielding zero recovery (figure 3.22). In fact, with about 200 vesicles per bouton (Schikorski and Stevens, 1997) a stranded pool of $30 \%$ should correspond to 60 vesicles, while a functional retrievable pool of 5-10 vesicles would correspond to 2-5\% fluorescence on the bouton membrane only, in good agreement with the synaptophysin coexpression and synaptotagmin immunocytochemistry data (figures 3.18 and 3.19). Thus, overexpression of one vesicle protein species may merely result in an oversupply of stranded or orphan proteins without changing the functional retrievable pool size. This is supported by the finding that coexpression of synaptophysin decreases dramatically the steady-state stranded pool of spH-TEV (figure 
3.18b), but did not affect the number of spH-TEV molecules per vesicle, nor the number of vesicles released during stimulation (note that no change in absolute $\Delta \mathrm{F}$ was observed), and altered only slightly retrieval kinetics and recovery efficiency (figure 3.18c). Likewise, in presynaptic boutons of the temperature-sensitive Drosophila dynamin mutant shibire, which was kept at non-permissive temperature to block synaptic vesicle endocytosis, dispersion of excess synaptic vesicle molecules in the plasma membrane by lateral diffusion did not alter the spatial organization of the endocytic machinery (Estes et al., 1996; Roos and Kelly, 1999). Thus the endocytic machinery at sites of retrieval may define the size of the functional stranded pool opposed to the total stranded pool, which also may comprise excess or orphan cargo molecules in bouton and axonal membranes.

The finding that complete diffusional loss of vesicle proteins post fusion occurs for a stimulus of 40 APs makes the existence of a small pool of readily retrievable vesicle patches near the active zones of small CNS synapses under native conditions a very attractive hypothesis. It has been shown that for this stimulus the rate of endocytosis is fastest (Sankaranarayanan and Ryan, 2000). A readily retrievable pool could nicely explain a first fast and depletable endocytic component at synapses without having to postulate a clathrin-independent mechanism like kiss-and-run. Such a pool of pre-sorted or preassembled endocytic structures could also explain the first peak of endocytic pits $($ at $t=1 \mathrm{~s}$ s) in the electron microscopic reconstruction of the endocytic time course at frog NMJ by Miller and Heuser (Miller and Heuser, 1984). It has been suggested that for 40 APs kissand-run or kiss-and-stay are the dominant mechanisms of vesicle retrieval (Pyle et al., 2000). Since molecular identity is the major hallmark of kiss-and-run recycling, the data of this thesis argue for full collapse of all fusing synaptic vesicles during 40-AP stimulation. If, however, reacidification was much faster than the 2-s stimulation period kiss-and-run events might add only to the noise in the rising phase of our averaged fluorescence signals (figure 3.22, inset) and thus go mostly undetected. But even then one would expect to observe a sharp decrease in the averaged fluorescence after the last AP of the stimulus, reflecting the kiss-and-run events triggered by the last few APs. Such initial fluorescence drop in the bouton could indeed be detected, if the region of interest for analysis was restricted to the bouton. However, dilating the region of interest by just one pixel showed 
that this fast component was solely caused by fast diffusional spread of exocytosed proteins to the bouton periphery and adjacent axonal segments (figure 3.21).

In non-neuronal cells, numerous quite stationary clathrin structures are often observed (Gaidarov et al., 1999; Kirchhausen, 2000) and cargo molecules like activated G-proteincoupled receptor- $\beta$-arrestin complexes are endocytosed from such pre-existing clathrincoated lattices (Santini et al., 2002; Scott et al., 2002). In presynaptic boutons, however, such clathrin structures have thus far not been detected, but spatial segregation of exocytic and endocytic sites in presynaptic boutons has been observed (Gundelfinger et al., 2003). In Drosophila NMJ (Estes et al., 1996; Gonzalez-Gaitan and Jäckle, 1997; Roos and Kelly, 1999), for example, components of the endocytic machinery, like dynamin and $\alpha$-adaptin, are highly enriched at 'hot spots', indicating that the molecular players of the endocytic machinery are anchored by specialized scaffolding proteins and the cytoskeleton in close proximity to exocytic sites, thereby acting as spatial organizers of endocytosis.

\subsubsection{Diffusion of synaptic vesicle proteins}

Spillover of GFP-tagged VAMP 2 / synaptobrevin 2 into axonal membranes during synaptic activity could be shown previously (Li and Murthy, 2001; Sankaranarayanan and Ryan, 2000) suggesting that vesicle membrane proteins diffuse laterally freely on the plasma membrane. This implies that no impermeant barrier to lateral diffusion exists once a vesicle has fused with the plasma membrane and is consistent with the observations that fluorescent lipids (FM1-43) (Zenisek et al., 2002) as well as vesicle proteins (Allersma et al., 2004) mix rapidly with the plasma membrane and diffuse freely once a fusion pore of the vesicle is formed.

The approach to selectively remove the fluorophores from plasma membrane-stranded $\mathrm{spH}$ molecules by enzymatic digest presented in this study permits the selective study of the diffusional movement of synaptic vesicle proteins newly added upon exocytosis, since the background fluorescence arising from the stranded $\mathrm{spH}$-pool is eliminated (figures 3.5 and 3.6). The obtained observations are best explained by a model (figure 3.20) where synaptic vesicles fully collapse post fusion, vesicle proteins disperse in the bouton membrane and are rather slowly resorted at specialized sites of endocytosis at the

periphery of the membrane (figure 3.20, left). Alternatively, vesicles post collapse may 
form raft-like patches (Martin, 2000; Thiele et al., 2000) that diffuse in toto to sites of retrieval (figure 3.20, right; see also figure 4.1). Interestingly, data by Kenworthy et al (2004) indicate that raft association is not the major determinant of plasma membrane protein diffusional mobility.
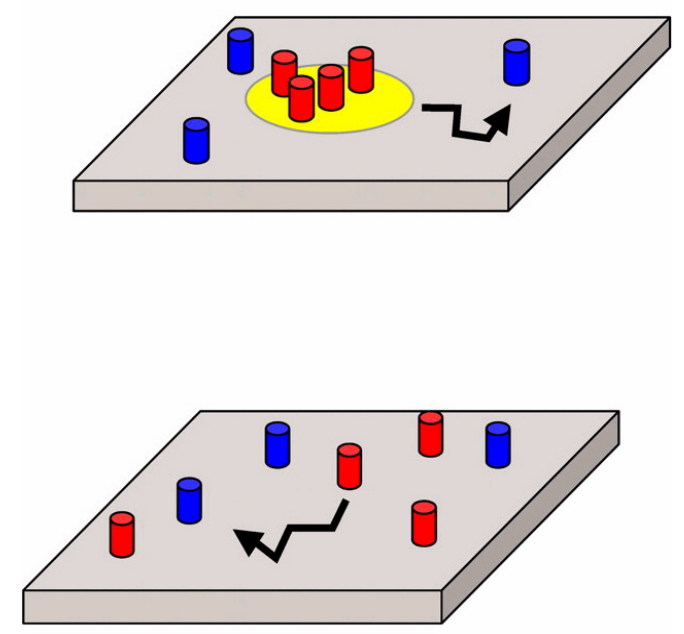

Figure 4.1 After fusion, synaptic vesicle proteins (red) could either diffuse in form of mobile rafts (top) or as single molecules (bottom). Schematics taken from Kenworthy et al., 2004.

In fact, the latter model is supported by the findings of Gandhi et al. (2003). They have used selective photobleaching of membrane-stranded $\mathrm{spH}$ molecules to increase the signal-to-noise ratio and resolve the fluorescence responses to single APs postbleaching. They report three modes of vesicle retrieval: a fast (400-860 ms) 'kiss-and-run' mode; a slow (8-21 s) 'compensatory' mode; and a 'stranded' mode of recycling, in which the vesicle's spH are left on the cell surface until retrieved by a later AP. The latter 'stranded' events are in agreement with the existence of a readily retrievable pool, as suggested in this thesis. However, both the compensatory and the stranded modes are, in their hands, characterized by fluorescence decreases marking endocytosis of the same size as the fluorescence increases triggered by single APs. This implies that in both cases the exocytosed $\mathrm{spH}$ molecules of a single vesicle stay together for ten's of seconds, while 
moving to the sites of retrieval, despite a large pool of bleached $\mathrm{spH}$ molecules being present on the plasma membrane. All three modes ('kiss-and-run', 'compensatory', and 'stranded) Gandhi et al (2003) reported should thus not lead to any diffusional dispersal of spH into axonal segments. Therefore, my findings of fast diffusion and preferential uptake of bleached/cleaved spH for stimuli with less than 40 APs fully contradicts these earlier findings, and I have no explanation to offer.

In contrast, I think that the observation of fast diffusion after fusion in all directions favors dispersion and mixing of vesicular and bouton membrane components. During stimulus-evoked exo-endocytic activity initially only presorted membrane patches at these specialized sites of endocytosis are retrieved swiftly by compensatory endocytosis, leading to the observed non-identity of exocytic and endocytic vesicles as long as the presorted pool is not depleted, i.e. for stimuli of less than 40 APs. For prolonged stimulation a mixture of fast retrieval of presorted structures and slow retrieval of newly inserted vesicle components will be observed resulting in progressively slower endocytic kinetics with stronger or longer stimuli (Fernandez-Alfonso and Ryan, 2004; Sankaranarayanan and Ryan, 2000). Based on my finding of fast diffusion of $\mathrm{spH}$ molecules I would expect to find on the single vesicle level either transient fluorescence events like the 'kiss-and-run' events reported by Gandhi et al. (2003) or fully stranded ones, depending on the particular size of the region of interest chosen relative to bouton size and geometry: for $40 \mathrm{AP}$ both effects are observed, when contracting or dilating the regions of interest by only one pixel (cf. figure 3.21).

Compared to the plasma membrane composition, synaptic vesicle membranes are enriched in cholesterol (Breckenridge et al., 1973). This implies that after fusion new synaptic vesicles are generated by endocytosis of a cholesterol-rich plasma membrane domain. The interaction of synaptophysin 1 with both cholesterol and synaptobrevin 2 / VAMP 2 might be helpful to reassemble synaptic vesicle components in the plasma membrane and prime them for endocytosis, even when the membrane integrity of the vesicle is initially lost after fusion. Thus, when considering the fate of an individual vesicle, its identity might neither be fully lost nor fully preserved during exo-endocytosis: on its way to the periactive zone lipid and protein components are slowly reassembled, partially by self-assembly, but also aided by specific adaptor proteins (see figure 4.2). 


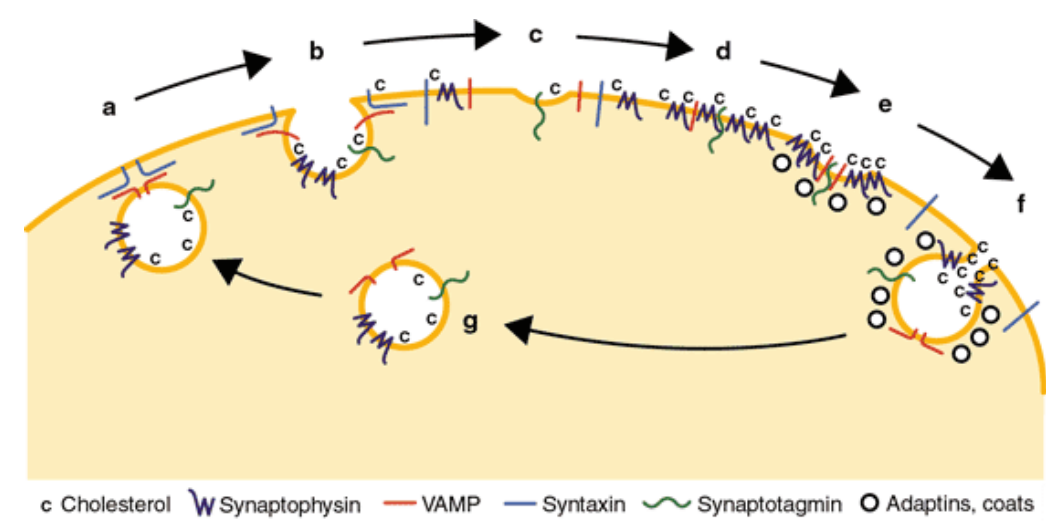

Figure 4.2 Possible model for exo- and endocytosis of synaptic vesicles (from Martin, 2000).

One such specific adaptor protein aiding in this process seems to be stonin 2, whose role in modulating the stranded pool size of synaptotagmin 1 could be uncovered by fusing the GFP variant pHluorin to its ectodomain. These results will be discussed in the next section.

\subsection{Role of stonin 2 in synaptotagmin 1 retrieval}

Our data described here suggest that stonin 2, a brain-enriched endocytic protein, serves as an AP-2-dependent sorting adaptor which targets synaptotagmin for clathrin/ AP-2mediated internalization. This proposal is based on the following lines of evidence: stonin 2-mediated synaptotagmin 1 internalization facilitates sorting of synaptotagmin 1 to synaptic like microvesicles (SLMVs) (data by Prof. Volker Haucke, not shown) and to a recycling vesicle pool in primary hippocampal neurons in culture. The latter observation strongly suggests that stonin 2-mediated endocytic recycling of synaptotagmin is a physiologically relevant pathway.

While it is conceivable that stonin 2 and AP-2 perform related and partially overlapping functions in synaptotagmin 1 endocytosis and vesicle recycling, it is also possible that stonin 2 executes a more specific role in regulating the amount of synaptotagmin 1 targeted to the recycling vesicle pool. The obtained kinetic data in transfected 
hippocampal neurons expressing wild-type or dominant-negative stonin 2 mutant proteins (figure 3.24) or in neurons lacking the stonin 2 gene (figure 3.26) argue in favor of this latter possibility. Although stonin 2 appears to affect the ratio of synaptotagmin 1 present at the presynaptic plasma membrane or within synaptic vesicles, it was not possible to detect any differences in the kinetics of individual endocytic events. How could targeting of synaptotagmin 1 to sites of endocytosis be not rate-limiting for endocytosis of synaptic vesicles, i.e. not alter the kinetics of synaptotagmin 1 retrieval? As proposed earlier, one attractive hypothesis is that cargo molecules stranded at the plasma membrane are targeted to and concentrated at sites of endocytosis at rest, i.e. prior to stimulation, thereby constituting a partially preassembled pool of 'early retrievable vesicles' (Mueller et al., 2004), that is endocytosed first. These observations thus suggest that the decreased ratio of vesicular-to-surface-stranded pools of synaptotagmin seen in stonin $2^{\Delta \mathrm{WF} \Delta \mathrm{NPF}}$-expressing or stonin 2 knock-out cells may arise by progressive accumulation of synaptotagmin 1 molecules at the plasma membrane. Conversely, overexpression of wild-type stonin 2 is sufficient to rescue synaptotagmin 1 stranded at the plasmalemma and for targeting synaptotagmin 1 to the recycling vesicle pool. Together with the findings of the lab of Prof. Volker Haucke we thus propose that stonin 2 acts at an early cargo selection step of clathrin/ AP-2-mediated SV endocytosis. This is also in line with the observation that synaptotagmin 1 overexpression targets stonin 2 to plasmalemmal AP-2-coated pits and that stonin 2 is enriched in synaptotagmin-containing clathrin/ AP-2-coated vesicles isolated from presynaptic nerve terminals (Walther et al., 2001). Such a model is consistent with observations made in stoned mutant animals in Drosophila where loss of stoned B/ stonin function is correlated with synaptotagmin mislocalization and degradation (Fergestad et al., 1999). 


\section{SUMMARY}

Upon exocytosis synaptic vesicle proteins are released into the plasma membrane and must be retrieved by compensatory endocytosis. When overexpressing GFP-labeled versions of the vesicle proteins synaptobrevin 2 / VAMP 2 and synaptotagmin 1 in neurons, up to $30 \%$ are found on external axonal membranes under resting conditions. To test whether and to which extent these plasma membrane stranded proteins participate in exo- endocytic cycling, a novel proteolytic approach was used to visually separate their fate from those proteins that are newly added upon fusion. The data obtained indicate that both pools are rapidly mixing by diffusion and that endocytosed vesicles are largely composed of previously stranded molecules. The degree of non-identity of vesicular proteins exo- and endocytosed depends on the stimulus duration. By coexpressing synaptophysin 1 and by using an antibody against the external luminal domain of synaptotagmin 1 , we estimate that under physiological conditions about $10 \%$ of vesicular proteins are located near the active zone from which they are preferentially recycled upon stimulation. These findings suggest that the readily releasable pool of vesicles may be counterbalanced on the endocytic limb of the cycle by a 'readily retrievable pool' of partially preassembled pits, from which new vesicles can be quickly reformed ensuring the maintenance of the recycling vesicle pool under normal stimulation conditions.

Secondly, in collaboration with the lab of Prof. Volker Haucke (Institut für Chemie und Biochemie, Freie-Universität-Berlin) the relationship between stonin 2 function in clathrin-dependent endocytosis and synaptotagmin 1 internalization was explored. Although clathrin-mediated endocytosis appears to be a major pathway for presynaptic vesicle cycling no sorting adaptor dedicated to synaptic vesicle membrane protein endocytosis has been identified in mammals. Together we could show that stonin 2 is an AP-2-dependent sorting adaptor for endocytic internalization and recycling of synaptotagmin 1 in neurons. 



\section{REFERENCES}

Ahmari, S. E., Buchanan, J., and Smith, S. J. (2000). Assembly of presynaptic active zones from cytoplasmic transport packets. Nat Neurosci 3, 445-451.

Allersma, M. W., Wang, L., Axelrod, D., and Holz, R. W. (2004). Visualization of regulated exocytosis with a granule-membrane probe using total internal reflection microscopy. Mol Biol Cell 15, 4658-4668.

Aravanis, A. M., Pyle, J. L., and Tsien, R. W. (2003). Single synaptic vesicles fusing transiently and successively without loss of identity. Nature 423, 643-647.

Benfenati, F., Greengard, P., Brunner, J., and Bahler, M. (1989). Electrostatic and hydrophobic interactions of synapsin I and synapsin I fragments with phospholipid bilayers. J Cell Biol 108, 1851-1862.

Betz, W. J., Mao, F., and Smith, C. B. (1996). Imaging exocytosis and endocytosis. Curr Opin Neurobiol 6, 365-371.

Breckenridge, W. C., Morgan, I. G., Zanetta, J. P., and Vincendon, G. (1973). Adult rat brain synaptic vesicles. II. Lipid composition. Biochim Biophys Acta 320, 681-686.

Brodin, L., Low, P., and Shupliakov, O. (2000). Sequential steps in clathrin-mediated synaptic vesicle endocytosis. Curr Opin Neurobiol 10, 312-320.

Brodsky, F. M., Chen, C. Y., Knuehl, C., Towler, M. C., and Wakeham, D. E. (2001). Biological basket weaving: formation and function of clathrin-coated vesicles. Annu Rev Cell Dev Biol 17, 517-568.

Calakos, N., and Scheller, R. H. (1994). Vesicle-associated membrane protein and synaptophysin are associated on the synaptic vesicle. J Biol Chem 269, 24534-24537.

Campbell, R. E., Tour, O., Palmer, A. E., Steinbach, P. A., Baird, G. S., Zacharias, D. A., and Tsien, R. Y. (2002). A monomeric red fluorescent protein. Proc Natl Acad Sci U S A 99, 7877-7882.

Ceccarelli, B., Hurlbut, W. P., and Mauro, A. (1973). Turnover of transmitter and synaptic vesicles at the frog neuromuscular junction. J Cell Biol 57, 499-524.

Chalfie, M., Tu, Y., Euskirchen, G., Ward, W. W., and Prasher, D. C. (1994). Green fluorescent protein as a marker for gene expression. Science 263, 802-805.

Cochilla, A. J., Angleson, J. K., and Betz, W. J. (1999). Monitoring secretory membrane with FM1-43 fluorescence. Annu Rev Neurosci 22, 1-10.

Cremona, O., and De Camilli, P. (1997). Synaptic vesicle endocytosis. Curr Opin Neurobiol 7, 323-330.

Damer, C. K., and O'Halloran, T. J. (2000). Spatially regulated recruitment of clathrin to the plasma membrane during capping and cell translocation. Mol Biol Cell 11, 21512159. 
de Lange, R. P., de Roos, A. D., and Borst, J. G. (2003). Two modes of vesicle recycling in the rat calyx of Held. J Neurosci 23, 10164-10173.

Donovan, F. M., Pike, C. J., Cotman, C. W., and Cunningham, D. D. (1997). Thrombin induces apoptosis in cultured neurons and astrocytes via a pathway requiring tyrosine kinase and RhoA activities. J Neurosci 17, 5316-5326.

Estes, P. S., Roos, J., van der Bliek, A., Kelly, R. B., Krishnan, K. S., and Ramaswami, M. (1996). Traffic of dynamin within individual Drosophila synaptic boutons relative to compartment-specific markers. J Neurosci 16, 5443-5456.

Fergestad, T., and Broadie, K. (2001). Interaction of stoned and synaptotagmin in synaptic vesicle endocytosis. J Neurosci 21, 1218-1227.

Fergestad, T., Davis, W. S., and Broadie, K. (1999). The stoned proteins regulate synaptic vesicle recycling in the presynaptic terminal. J Neurosci 19, 5847-5860.

Fernandez-Alfonso, T., and Ryan, T. A. (2004). The kinetics of synaptic vesicle pool depletion at CNS synaptic terminals. Neuron 41, 943-953.

Fesce, R., Grohovaz, F., Valtorta, F., and Meldolesi, J. (1994). Neurotransmitter release: fusion or 'kiss-and-run'? Trends Cell Biol 4, 1-4.

Gad, H., Low, P., Zotova, E., Brodin, L., and Shupliakov, O. (1998). Dissociation between $\mathrm{Ca} 2+$-triggered synaptic vesicle exocytosis and clathrin-mediated endocytosis at a central synapse. Neuron 21, 607-616.

Gaidarov, I., Santini, F., Warren, R. A., and Keen, J. H. (1999). Spatial control of coated-pit dynamics in living cells. Nat Cell Biol 1, 1-7.

Gandhi, S. P., and Stevens, C. F. (2003). Three modes of synaptic vesicular recycling revealed by single-vesicle imaging. Nature 423, 607-613.

Geppert, M., Goda, Y., Hammer, R. E., Li, C., Rosahl, T. W., Stevens, C. F., and Sudhof, T. C. (1994). Synaptotagmin I: a major Ca2+ sensor for transmitter release at a central synapse. Cell 79, 717-727.

Gonzalez-Gaitan, M., and Jackle, H. (1997). Role of Drosophila alpha-adaptin in presynaptic vesicle recycling. Cell 88, 767-776.

Grass, I., Thiel, S., Honing, S., and Haucke, V. (2004). Recognition of a basic AP-2 binding motif within the $\mathrm{C} 2 \mathrm{~B}$ domain of synaptotagmin is dependent on multimerization. J Biol Chem 279, 54872-54880.

Greenbaum, L., Rothmann, C., Lavie, R., and Malik, Z. (2000). Green fluorescent protein photobleaching: a model for protein damage by endogenous and exogenous singlet oxygen. Biological Chemistry 381, 1251-1258.

Grote, E., and Kelly, R. B. (1996). Endocytosis of VAMP is facilitated by a synaptic vesicle targeting signal. J Cell Biol 132, 537-547.

Gundelfinger, E. D., Kessels, M. M., and Qualmann, B. (2003). Temporal and spatial coordination of exocytosis and endocytosis. Nat Rev Mol Cell Biol 4, 127-139. 
Haucke, V., Wenk, M. R., Chapman, E. R., Farsad, K., and De Camilli, P. (2000). Dual interaction of synaptotagmin with mu2- and alpha-adaptin facilitates clathrin-coated pit nucleation. Embo J 19, 6011-6019.

Heuser, J. E., and Reese, T. S. (1973). Evidence for recycling of synaptic vesicle membrane during transmitter release at the frog neuromuscular junction. J Cell Biol 57, 315-344.

Holt, M., Cooke, A., Wu, M. M., and Lagnado, L. (2003). Bulk membrane retrieval in the synaptic terminal of retinal bipolar cells. J Neurosci 23, 1329-1339.

Jahn, R., and Sudhof, T. C. (1993). Synaptic vesicle traffic: rush hour in the nerve terminal. J Neurochem 61, 12-21.

Jarousse, N., and Kelly, R. B. (2001). Endocytotic mechanisms in synapses. Curr Opin Cell Biol 13, 461-469.

Jorgensen, E. M., Hartwieg, E., Schuske, K., Nonet, M. L., Jin, Y., and Horvitz, H. R. (1995). Defective recycling of synaptic vesicles in synaptotagmin mutants of Caenorhabditis elegans. Nature 378, 196-199.

Kaether, C., Skehel, P., and Dotti, C. G. (2000). Axonal membrane proteins are transported in distinct carriers: a two-color video microscopy study in cultured hippocampal neurons. Mol Biol Cell 11, 1213-1224.

Katz, B., and Miledi, R. (1967). The timing of calcium action during neuromuscular transmission. J Physiol 189, 535-544.

Kenworthy, A. K., Nichols, B. J., Remmert, C. L., Hendrix, G. M., Kumar, M., Zimmerberg, J., and Lippincott-Schwartz, J. (2004). Dynamics of putative raftassociated proteins at the cell surface. J Cell Biol 165, 735-746.

Kirchhausen, T. (2000). Three ways to make a vesicle. Nat Rev Mol Cell Biol 1, 187198.

Kiseleva, E. V., Storozhevykh, T. P., Pinelis, V. G., Gluza, E., and Strukova, S. M. (2004). Role of thrombin in activation of neurons in rat hippocampus. Bull Exp Biol Med 137, 453-456.

Klingauf, J., Kavalali, E. T., and Tsien, R. W. (1998a). Kinetics and regulation of fast endocytosis at hippocampal synapses. Nature 394, 581-585.

Klingauf, J., Kavalali, E. T., and Tsien, R. W. (1998b). Kinetics and regulation of fast endocytosis at hippocampal synapses. Nature 394, 581-585.

Koenig, J. H., and Ikeda, K. (1989). Disappearance and reformation of synaptic vesicle membrane upon transmitter release observed under reversible blockage of membrane retrieval. J Neurosci 9, 3844-3860.

Koenig, J. H., Yamaoka, K., and Ikeda, K. (1998). Omega images at the active zone may be endocytotic rather than exocytotic: implications for the vesicle hypothesis of transmitter release. Proc Natl Acad Sci U S A 95, 12677-12682. 
Kohl, T., Heinze, K. G., Kuhlemann, R., Koltermann, A., and Schwille, P. (2002). A protease assay for two-photon crosscorrelation and FRET analysis based solely on fluorescent proteins. Proc Natl Acad Sci U S A 99, 12161-12166.

Kugler, S., Meyn, L., Holzmuller, H., Gerhardt, E., Isenmann, S., Schulz, J. B., and Bahr, M. (2001). Neuron-specific expression of therapeutic proteins: evaluation of different cellular promoters in recombinant adenoviral vectors. Mol Cell Neurosci 17, 78-96.

Li, Z., and Murthy, V. N. (2001). Visualizing postendocytic traffic of synaptic vesicles at hippocampal synapses. Neuron 31, 593-605.

Lichtman, J. W., Wilkinson, R. S., and Rich, M. M. (1985). Multiple innervation of tonic endplates revealed by activity-dependent uptake of fluorescent probes. Nature 314, 357-359.

Littleton, J. T., Bai, J., Vyas, B., Desai, R., Baltus, A. E., Garment, M. B., Carlson, S. D., Ganetzky, B., and Chapman, E. R. (2001). synaptotagmin mutants reveal essential functions for the $\mathrm{C} 2 \mathrm{~B}$ domain in $\mathrm{Ca} 2+$-triggered fusion and recycling of synaptic vesicles in vivo. J Neurosci 21, 1421-1433.

Liu, G., and Tsien, R. W. (1995). Properties of synaptic transmission at single hippocampal synaptic boutons. Nature 375, 404-408.

Llinas, R. R., Sugimori, M., Moran, K. A., Moreira, J. E., and Fukuda, M. (2004). Vesicular reuptake inhibition by a synaptotagmin I C2B domain antibody at the squid giant synapse. Proc Natl Acad Sci U S A 101, 17855-17860.

Loerke, D., Wienisch, M., Kochubey, O., and Klingauf, J. (2005). Differential control of clathrin subunit dynamics measured with EW-FRAP microscopy. Traffic 6, 918929.

Malgaroli, A., and Tsien, R. W. (1992). Glutamate-induced long-term potentiation of the frequency of miniature synaptic currents in cultured hippocampal neurons. Nature 357, 134-139.

Martin, T. F. (2000). Racing lipid rafts for synaptic-vesicle formation. Nat Cell Biol 2, E9-11.

Martina, J. A., Bonangelino, C. J., Aguilar, R. C., and Bonifacino, J. S. (2001). Stonin 2: an adaptor-like protein that interacts with components of the endocytic machinery. $\mathrm{J}$ Cell Biol 153, 1111-1120.

Matteoli, M., Takei, K., Perin, M. S., Sudhof, T. C., and De Camilli, P. (1992). Exoendocytotic recycling of synaptic vesicles in developing processes of cultured hippocampal neurons. J Cell Biol 117, 849-861.

Merrifield, C. J., Feldman, M. E., Wan, L., and Almers, W. (2002). Imaging actin and dynamin recruitment during invagination of single clathrin-coated pits. Nat Cell Biol 4, 691-698.

Miesenbock, G., De Angelis, D. A., and Rothman, J. E. (1998). Visualizing secretion and synaptic transmission with pH-sensitive green fluorescent proteins. Nature 394, 192-195. 
Miller, T. M., and Heuser, J. E. (1984). Endocytosis of synaptic vesicle membrane at the frog neuromuscular junction. J Cell Biol 98, 685-698.

Mitchell, S. J., and Ryan, T. A. (2004). Syntaxin-1A is excluded from recycling synaptic vesicles at nerve terminals. J Neurosci 24, 4884-4888.

Mueller, V. J., Wienisch, M., Nehring, R. B., and Klingauf, J. (2004). Monitoring clathrin-mediated endocytosis during synaptic activity. J Neurosci 24, 2004-2012.

Murthy, V. N., and De Camilli, P. (2003). Cell biology of the presynaptic terminal. Annu Rev Neurosci 26, 701-728.

Murthy, V. N., and Stevens, C. F. (1999). Reversal of synaptic vesicle docking at central synapses. Nat Neurosci 2, 503-507.

Neher, E., and Marty, A. (1982). Discrete changes of cell membrane capacitance observed under conditions of enhanced secretion in bovine adrenal chromaffin cells. Proc Natl Acad Sci U S A 79, 6712-6716.

Nelson, N. (1992). Structure and function of V-ATPases in endocytic and secretory organelles. J Exp Biol 172, 149-153.

Nicholson-Tomishima, K., and Ryan, T. A. (2004). Kinetic efficiency of endocytosis at mammalian CNS synapses requires synaptotagmin I. Proc Natl Acad Sci U S A 101, 16648-16652.

Olivo-Marin, J. C. (2002). Extraction of spots in biological images using multiscale products. Pattern Recognition 35, 1989-1996.

Paillart, C., Li, J., Matthews, G., and Sterling, P. (2003). Endocytosis and vesicle recycling at a ribbon synapse. J Neurosci 23, 4092-4099.

Parks, T. D., Howard, E. D., Wolpert, T. J., Arp, D. J., and Dougherty, W. G. (1995). Expression and purification of a recombinant tobacco etch virus NIa proteinase: biochemical analyses of the full-length and a naturally occurring truncated proteinase form. Virology 210, 194-201.

Passafaro, M., Piech, V., and Sheng, M. (2001). Subunit-specific temporal and spatial patterns of AMPA receptor exocytosis in hippocampal neurons. Nat Neurosci 4, 917926.

Pearse, B. M. (1976). Clathrin: a unique protein associated with intracellular transfer of membrane by coated vesicles. Proc Natl Acad Sci U S A 73, 1255-1259.

Pennuto, M., Bonanomi, D., Benfenati, F., and Valtorta, F. (2003). Synaptophysin I controls the targeting of VAMP2/synaptobrevin II to synaptic vesicles. Mol Biol Cell 14, 4909-4919.

Phan, J., Zdanov, A., Evdokimov, A. G., Tropea, J. E., Peters, H. K., 3rd, Kapust, R. B., Li, M., Wlodawer, A., and Waugh, D. S. (2002). Structural basis for the substrate specificity of tobacco etch virus protease. J Biol Chem 277, 50564-50572.

Polo, S., Confalonieri, S., Salcini, A. E., and Di Fiore, P. P. (2003). EH and UIM: endocytosis and more. Sci STKE 2003, re17. 
Poskanzer, K. E., Marek, K. W., Sweeney, S. T., and Davis, G. W. (2003). Synaptotagmin I is necessary for compensatory synaptic vesicle endocytosis in vivo. Nature 426, 559-563.

Pyle, J. L., Kavalali, E. T., Piedras-Renteria, E. S., and Tsien, R. W. (2000). Rapid reuse of readily releasable pool vesicles at hippocampal synapses. Neuron 28, 221-231.

Richards, D. A., Guatimosim, C., and Betz, W. J. (2000). Two endocytic recycling routes selectively fill two vesicle pools in frog motor nerve terminals. Neuron 27, 551559.

Rizzoli, S. O., and Betz, W. J. (2005). Synaptic vesicle pools. Nat Rev Neurosci 6, 5769.

Roos, J., and Kelly, R. B. (1999). The endocytic machinery in nerve terminals surrounds sites of exocytosis. Curr Biol 9, 1411-1414.

Rosenboom, H., and Lindau, M. (1994). Exo-endocytosis and closing of the fission pore during endocytosis in single pituitary nerve terminals internally perfused with high calcium concentrations. Proc Natl Acad Sci U S A 91, 5267-5271.

Ryan, T. A., Reuter, H., Wendland, B., Schweizer, F. E., Tsien, R. W., and Smith, S. J. (1993). The kinetics of synaptic vesicle recycling measured at single presynaptic boutons. Neuron 11, 713-724.

Ryan, T. A., Smith, S. J., and Reuter, H. (1996). The timing of synaptic vesicle endocytosis. Proc Natl Acad Sci U S A 93, 5567-5571.

Sampo, B., Kaech, S., Kunz, S., and Banker, G. (2003). Two distinct mechanisms target membrane proteins to the axonal surface. Neuron 37, 611-624.

Sankaranarayanan, S., De Angelis, D., Rothman, J. E., and Ryan, T. A. (2000). The use of pHluorins for optical measurements of presynaptic activity. Biophys J 79, 21992208.

Sankaranarayanan, S., and Ryan, T. A. (2000). Real-time measurements of vesicleSNARE recycling in synapses of the central nervous system. Nat Cell Biol 2, 197-204.

Santini, F., Gaidarov, I., and Keen, J. H. (2002). G protein-coupled receptor/arrestin3 modulation of the endocytic machinery. J Cell Biol 156, 665-676.

Schikorski, T., and Stevens, C. F. (1997). Quantitative ultrastructural analysis of hippocampal excitatory synapses. J Neurosci 17, 5858-5867.

Scott, M. G., Benmerah, A., Muntaner, O., and Marullo, S. (2002). Recruitment of activated $\mathrm{G}$ protein-coupled receptors to pre-existing clathrin-coated pits in living cells. J Biol Chem 277, 3552-3559.

Shupliakov, O., Low, P., Grabs, D., Gad, H., Chen, H., David, C., Takei, K., De Camilli, P., and Brodin, L. (1997). Synaptic vesicle endocytosis impaired by disruption of dynamin-SH3 domain interactions. Science 276, 259-263.

Slepnev, V. I., and De Camilli, P. (2000). Accessory factors in clathrin-dependent synaptic vesicle endocytosis. Nat Rev Neurosci 1, 161-172. 
Smith-Swintosky, V. L., Cheo-Isaacs, C. T., D'Andrea, M. R., Santulli, R. J., Darrow, A. L., and Andrade-Gordon, P. (1997). Protease-activated receptor-2 (PAR-2) is present in the rat hippocampus and is associated with neurodegeneration. $\mathrm{J}$ Neurochem 69, 1890-1896.

Stevens, C. F., and Williams, J. H. (2000). "Kiss and run" exocytosis at hippocampal synapses. Proc Natl Acad Sci U S A 97, 12828-12833.

Stimson, D. T., Estes, P. S., Rao, S., Krishnan, K. S., Kelly, L. E., and Ramaswami, M. (2001). Drosophila stoned proteins regulate the rate and fidelity of synaptic vesicle internalization. J Neurosci 21, 3034-3044.

Sudhof, T. C. (2000). The synaptic vesicle cycle revisited. Neuron 28, 317-320.

Sudhof, T. C. (2004). The synaptic vesicle cycle. Annu Rev Neurosci 27, 509-547.

Takei, K., Mundigl, O., Daniell, L., and De Camilli, P. (1996). The synaptic vesicle cycle: a single vesicle budding step involving clathrin and dynamin. J Cell Biol 133, 1237-1250.

Taubenblatt, P., Dedieu, J. C., Gulik-Krzywicki, T., and Morel, N. (1999). VAMP (synaptobrevin) is present in the plasma membrane of nerve terminals. J Cell Sci 112 ( Pt 20), 3559-3567.

Teng, H., and Wilkinson, R. S. (2000). Clathrin-mediated endocytosis near active zones in snake motor boutons. J Neurosci 20, 7986-7993.

Thiele, C., Hannah, M. J., Fahrenholz, F., and Huttner, W. B. (2000). Cholesterol binds to synaptophysin and is required for biogenesis of synaptic vesicles. Nat Cell Biol 2, 42-49.

Thomas, P., Lee, A. K., Wong, J. G., and Almers, W. (1994). A triggered mechanism retrieves membrane in seconds after $\mathrm{Ca}(2+)$-stimulated exocytosis in single pituitary cells. J Cell Biol 124, 667-675.

Threadgill, R., Bobb, K., and Ghosh, A. (1997). Regulation of dendritic growth and remodeling by Rho, Rac, and Cdc42. Neuron 19, 625-634.

Torri-Tarelli, F., Villa, A., Valtorta, F., De Camilli, P., Greengard, P., and Ceccarelli, B. (1990). Redistribution of synaptophysin and synapsin I during alpha-latrotoxininduced release of neurotransmitter at the neuromuscular junction. J Cell Biol 110, 449-459.

Tucker, W. C., and Chapman, E. R. (2002). Role of synaptotagmin in Ca2+-triggered exocytosis. Biochem J 366, 1-13.

Valtorta, F., Jahn, R., Fesce, R., Greengard, P., and Ceccarelli, B. (1988). Synaptophysin (p38) at the frog neuromuscular junction: its incorporation into the axolemma and recycling after intense quantal secretion. J Cell Biol 107, 2717-2727.

Walch-Solimena, C., Blasi, J., Edelmann, L., Chapman, E. R., von Mollard, G. F., and Jahn, R. (1995). The t-SNAREs syntaxin 1 and SNAP-25 are present on organelles that participate in synaptic vesicle recycling. J Cell Biol 128, 637-645. 
Walther, K., Diril, M. K., Jung, N., and Haucke, V. (2004). Functional dissection of the interactions of stonin 2 with the adaptor complex AP-2 and synaptotagmin. Proc Natl Acad Sci U S A 101, 964-969.

Walther, K., Krauss, M., Diril, M. K., Lemke, S., Ricotta, D., Honing, S., Kaiser, S., and Haucke, V. (2001). Human stoned B interacts with AP-2 and synaptotagmin and facilitates clathrin-coated vesicle uncoating. EMBO Rep 2, 634-640.

Wu, L. G., and Betz, W. J. (1996). Nerve activity but not intracellular calcium determines the time course of endocytosis at the frog neuromuscular junction. Neuron 17, 769-779.

Xia, Z., Dudek, H., Miranti, C. K., and Greenberg, M. E. (1996). Calcium influx via the NMDA receptor induces immediate early gene transcription by a MAP kinase/ERKdependent mechanism. J Neurosci 16, 5425-5436.

Zenisek, D., Steyer, J. A., Feldman, M. E., and Almers, W. (2002). A membrane marker leaves synaptic vesicles in milliseconds after exocytosis in retinal bipolar cells. Neuron 35, 1085-1097.

Zhang, J. Z., Davletov, B. A., Sudhof, T. C., and Anderson, R. G. (1994). Synaptotagmin I is a high affinity receptor for clathrin AP-2: implications for membrane recycling. Cell 78, 751-760. 


\section{CURRICUlum VitAE}

\section{Personal detalls:}

Name:

Nationality:

Date and Place of Birth:

Marital Status:

Work Address:

\section{EDUCATION:}

University Entrance Qualification:

Jun 1995

University Studies:

Oct 1996 - Nov 1999:

Nov 1999 - Aug 2000:

Sep 2000 - present:

$2000-2001:$

Oct 2001 - Apr 2002:

Aug - Sept 2004

Apr 2002 - Feb 2005:

Apr 2002 - present:
Martin Wienisch

German

7.5.1976 in Oberhausen, Germany

Single

Max-Planck Institute for Biophysical Chemistry

Department Membrane Biophysics

Am Fassberg 11

37077 Gőttingen

Germany

Email: mwienis1@gwdg.de
Abtei-Gymnasium
Duisburg-Hamborn
Germany

Biochemistry, University of Bochum, Germany Neurosciences, University of Magdeburg, Germany

International MSc/PhD Program in

Neurosciences, Gőttingen, Germany

Stipend International Max-Planck Research

School

Master's Thesis“A Slow Endocytosis Pathway

in Hippocampal Synapses"

MPI for Biophysical Chemistry, Gőttingen,

Germany

Summer course in neurobiology, MBL, Woods Hole, U.S.A.

$\mathrm{PhD}$ scholarship of the Boehringer Ingelheim Fonds

PhD student, MPI for Biophysical Chemistry, Gőttingen, Germany 



\title{
Publication list
}

\author{
Wienisch M, Klingauf J.
}

Vesicular proteins exocytosed and subsequently retrieved by compensatory endocytosis are non-identical.

(submitted)

Diril KM, Wienisch M, Jung N, Klingauf J, Haucke V.

Stonin 2 is an AP-2-dependent endocytic sorting adaptor for synaptotagmin internalization and recycling.

Developmental Cell. (in press)

Loerke D, Wienisch M, Kochubey O, Klingauf J.

Differential control of clathrin subunit dynamics measured with EW-FRAP microscopy.

Traffic. 2005 Oct;6(10):918-29.

Mueller VJ, Wienisch M, Nehring RB, Klingauf J.

Monitoring clathrin-mediated endocytosis during synaptic activity.

J Neurosci. 2004 Feb 25;24(8):2004-12. 



\section{ACKNOWLEDGEMENTS}

I want to thank my research advisor Dr. Jürgen Klingauf for being a great teacher and for all imaginable kinds of help. The conversation on the way to Edinborough started it all.

I am grateful to Prof. Dr. Erwin Neher and Prof. Dr. Dr. Detlev Schild for their assistance and for their support as my thesis committee members.

I owe many thanks to Dr. Kasim Diril, Prof. Dr. Volker Haucke and Nadja Jung for giving me the opportunity to participate in this fruitful collaboration.

Special thanks to all the members of the department, especially to Dr. Ralf Nehring for teaching me molecular biology, to my MOST lab mates Anna "Nono" Botvinnik, Dr. Natalya Glyvuk, Alexey “O.” Kochubey, Dr. Maria Krikounova, Dr. Edward "Punkt!" Lemke, Dr. Dinah "Xena" Loerke, Dr. Amitabha "Express" Majumdar, Dr. Veronika "S" Müller, Michael "Pilz" Pilot, Dr. Yaroslav Tsytsyura and Dr. Pieter "Côte d'Or" Vanden Berghe and all the regular visitors of room 334.

For reading and commenting this manuscript I want to thank Dr. Aimee K. Boegle and once again Alexey Kochubey - you are the true macrophage.

I would like to acknowledge Dr. Steffen Burkhardt, Dr. Simone Cardoso de Oliviera, Sandra Drube, Prof. Dr. Michael Hörner and Dr. Dorothee Wegener and all the people involved in the coordination and realization of the neuroscience program in Göttingen.

I would also like to express my gratitude to the Graduiertenkolleg Neuronal Signaling and Cellular Biophysics and the Boehringer Ingelheim Fonds for their support. Here, I particularly want to thank Monika Beutelspacher, Dr. Hermann Fröhlich and Dr. Claudia Walther.

I also want to express my gratitude to all my friends here in Göttingen - you know who you are!

For an unforgettable summer I want to thank the MBL and all the people who made and make it what it is.

I would also like to thank Dartmouth College Class of ' $66 \ldots$

Finally the greatest thanks appertain to my parents and to Sabine Wienisch on whose I can trust at every time. 